\title{
Impacts of Anionic and Cationic Nanoparticles on the Rheological, Hydraulics and Filtration Properties of the Water- Based Drilling Fluid
}

Ali Hashim Salih

Follow this and additional works at: https://researchrepository.wvu.edu/etd

\section{Recommended Citation}

Salih, Ali Hashim, "Impacts of Anionic and Cationic Nanoparticles on the Rheological, Hydraulics and Filtration Properties of the Water-Based Drilling Fluid" (2017). Graduate Theses, Dissertations, and Problem Reports. 6558.

https://researchrepository.wvu.edu/etd/6558

This Thesis is protected by copyright and/or related rights. It has been brought to you by the The Research Repository @WVU with permission from the rights-holder(s). You are free to use this Thesis in any way that is permitted by the copyright and related rights legislation that applies to your use. For other uses you must obtain permission from the rights-holder(s) directly, unless additional rights are indicated by a Creative Commons license in the record and/ or on the work itself. This Thesis has been accepted for inclusion in WVU Graduate Theses, Dissertations, and Problem Reports collection by an authorized administrator of The Research Repository @ WVU. For more information, please contact researchrepository@mail.wvu.edu. 
Impacts of Anionic and Cationic Nanoparticles on the Rheological, Hydraulics and Filtration Properties of the Water-Based Drilling Fluid

\section{Ali Hashim Salih}

Thesis Submitted to the College of Engineering and Mineral Resources at West Virginia University

in Partial Fulfillment of the Requirements for the Degree of

Master of Science in Petroleum and Natural Gas Engineering

Ilkin Bilgesu, Ph.D., Chair

Samuel Ameri, M.S.

Brijes Mishra, Ph.D.

Department of Petroleum and Natural Gas Engineering

Morgantown, West Virginia 2017

Keywords: Drilling Fluid, Cationic Nanoparticles, Anionic Nanoparticles, Rheological Properties, Filtration, Hydraulics, API Tests, Drillbench,

Nanosilica, Nanotitanium, Nanoaluminum.

Copyright 2017 Ali Hashim Salih 


\title{
Abstract \\ Impacts of Anionic and Cationic Nanoparticles on the Rheological, Hydraulics and Filtration Properties of the Water-Based Drilling Fluid
}

\begin{abstract}
Ali Hashim Salih
Nanoparticles are the new chemical additives for drilling fluids that can improve their properties and eliminate problems due to increased downtime and well costs. This study investigates the relative impacts of previously untested nanoparticles on the rheology, hydraulics and filtration of water-based drilling muds. The objectives of the experimental study were to select the optimum types and concentrations of commercially available nanoparticles that enhance the rheological and filtration properties and optimize the hydraulics of the water-based drilling fluids.
\end{abstract}

In this study, the samples were prepared as water-based muds with and without three different types and various concentrations of anionic nanosilica, nanotitanium, and nanoaluminum nanoparticles. In addition, cationic nanoaluminum was tested. Series of laboratory tests were carried out for all samples using standard API Low Pressure Low Temperature (LPLT) filtration and rheological devices. Two mud systems at different $\mathrm{pH}$ conditions were used to evaluate the impact of the nanoparticles on the mud's properties. A commercially available software was used to evaluate the impact of the nanoparticles on the equivalent circulation density (ECD) and the circulation pressure loss in a directional well.

Results show enhancements in the rheological, hydraulics and filtration properties for waterbased muds treated by some of the nanoparticles with concentrations below $0.7 \%$ by weight. The enhancement levels varied based on their type and concentration used in the mixtures. Further, the results show the ability of these nanoparticles to make the filter cake consistent, compacted, fragile, and thin and to prevent the spurt water loss. However, the results reflect the negative impact of all nanoparticles with concentrations above $0.7 \%$ by weight on mud's properties. Among all nanoparticles, the optimum concentrations and type resulting in the best properties are observed as $0.1 \%-0.3 \%$ by weight of the nanosilica. Furthermore, the concentration of $0.1 \%$ by weight reflected the more significant reduction in the ECD and the pump circulating pressure. 
Nanoparticles used in this research can play a vital role in reducing drilling problems, such as stuck pipe, formation damage, and shale swelling if they are properly formulated. Thus, multilateral wells, slim holes and deep horizontal wells can be drilled using water-based muds with the addition of proper nanoparticles and eliminating the need for oil-based muds that are expensive and environmentally unacceptable. However, it is critical to select the proper nanoparticle size, type, and concentration in order to eliminate its negative impact on the drilling fluid properties. 


\section{Dedication}

I Dedicate This Thesis to

My Mother and Father

for

Supporting and Making Me Be Who I am 


\section{Acknowledgement}

Foremost, I would like to thank God, for his direction and blessing. Definitely, I would not be able to complete this research without his help. Also, I would like to express my honest and deepest gratitude to my advisor Dr. Ilkin Bilgesu for the continuous technical support, for his patience, motivation, and for his help to publish this work. His guidance and interest in using nanoparticles with drilling fluids helped me in constructing this thesis.

Besides my advisor, I would like to thank the rest of my thesis committee: Prof. Samuel Ameri and Dr. Brijes Mishra for agreeing to be members of my committee. A special thank goes to Professor Samuel Ameri for his financial support throughout my period of study.

In addition, I would like to extend huge thanks and appreciations to my sponsor, The Higher Committee for Education Development in Iraq, for giving me this chance to pursue my master and for financial support. More so, my appreciations also go to Dr. Victor A. Lifton of Evonik Corporation and Michael Donaty of Sonics \& Materials, Inc. for material support for this work.

Last but not the least, I would like to express unlimited gratitude to my mother Karima Latif, my brother Khalid Al-Khafaji, and my wife Lamaan Rabeea for the emotional support throughout my life and for the motivation throughout my study. I owe a lot to them. 


\section{Table of Contents}

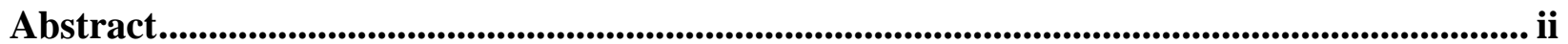

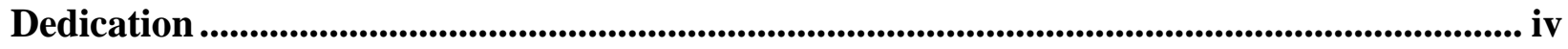

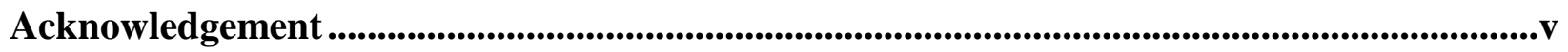

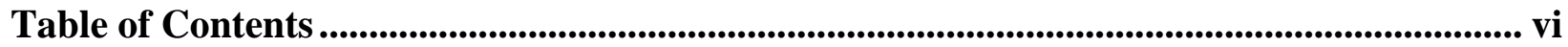

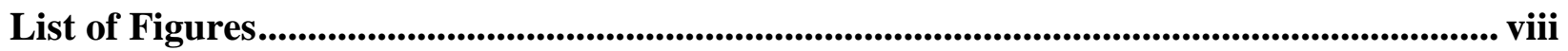

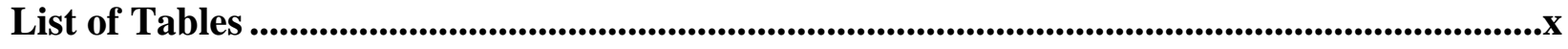

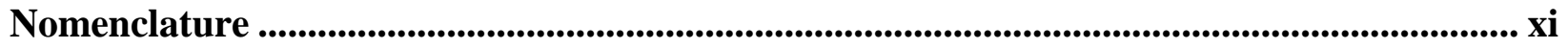

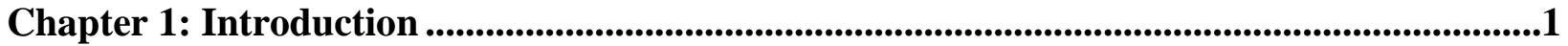

1.1. General Overview .........................................................................................................

1.2. The Drilling Mud Related Problems .............................................................................2

1.3. Nanoparticles Definition and Performance in Drilling Muds .............................................9

1.4. Challenges Associated with Water-Based Nanomuds ......................................................11

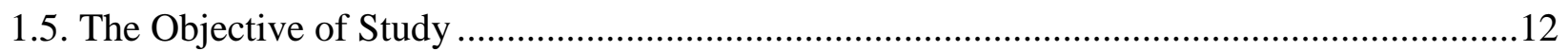

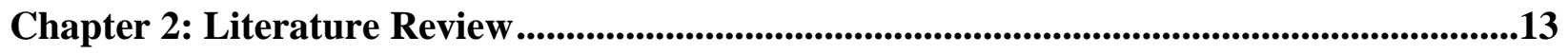

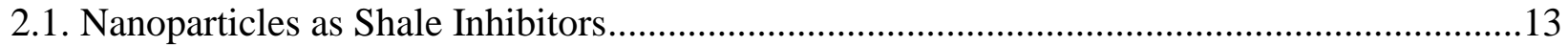

2.2. Nanoparticles as Rheological and Filtration Properties Modifiers .....................................15

2.3. Theoretical Researches Related to Nanoparticles ........................................................20

2.4. Summary of the Literature Review ...............................................................................21

Chapter 3: Overview of Water-Based Muds ..................................................................................23

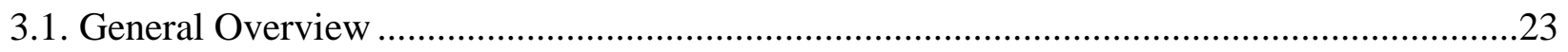

3.2. Rheological and Physical Properties of Water-Based Mud .............................................25

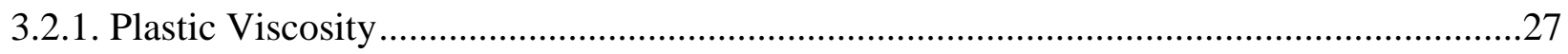

3.2.2. Yield Points-Bingham and Actual Yield Points .........................................................28

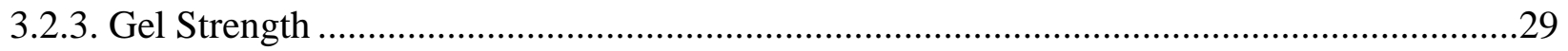

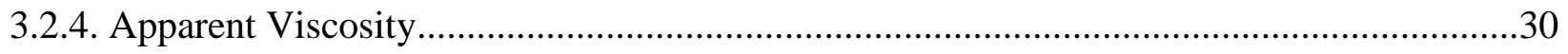

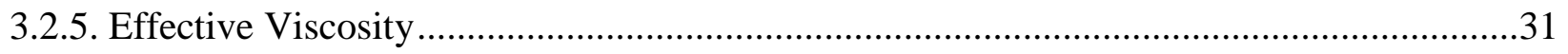

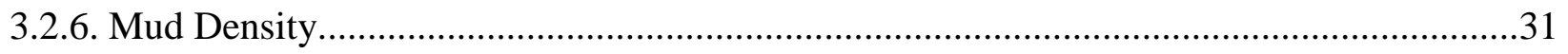

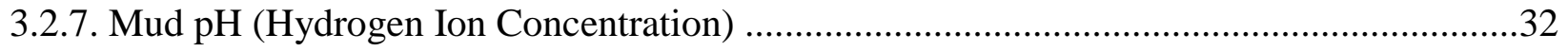

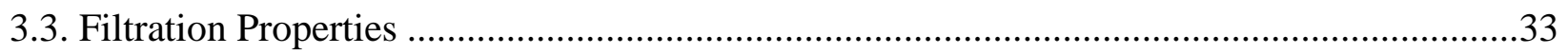

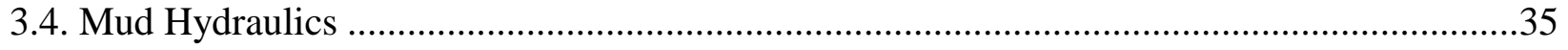

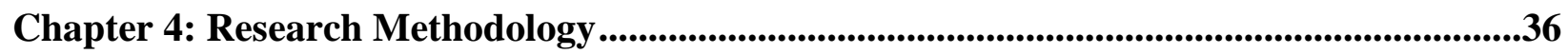

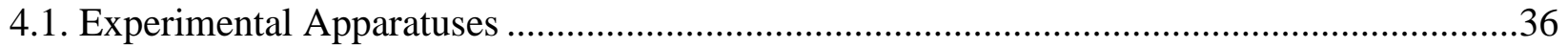

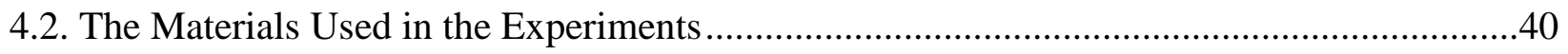

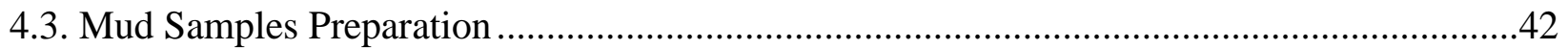

4.3.1. Basic Water-based Mud Samples Preparation .............................................................42

4.3.2. Preparation of Water-based Nanomud Samples ........................................................43

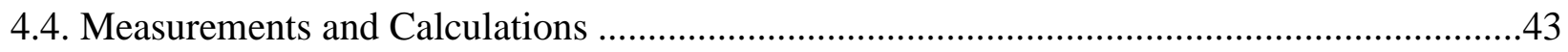

4.4.1. Rheological Measurements and Calculations .........................................................43

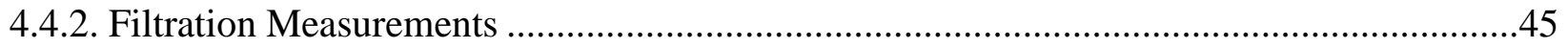




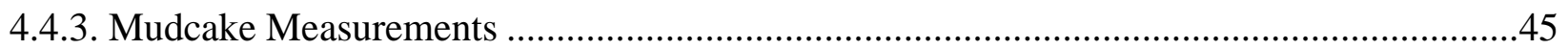

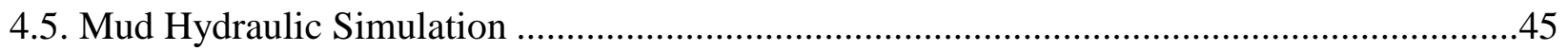

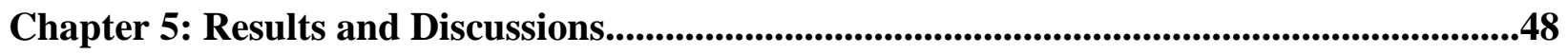

5.1. Results and Discussions of Using Nanosilica with Water-Based Muds ..............................48

5.1.1. API Rheological Properties of Water-Based Nanosilica Muds .........................................48

5.1.2. API Filtration Properties of Water-Based Nanosilica Muds..............................................54

5.1.3. Impact of Nanosilica on Drilling Mud Hydraulics-ECD \& Circulating Pressure ...............59

5.2. Results and Discussions of Using Nanotitanium with Water-Based Muds ..........................64

5.2.1. API Rheological Properties of Water-Based Nanotitanium Muds ....................................64

5.2.2. API Filtration Properties of Water-Based Nanotitanium Muds......................................70

5.2.3. Drilling Mud Hydraulics-ECD \& Circulating Pressure based on Nanotitanium muds .......75

5.3. Results and Discussions of Using Nanoaluminum with Water-Based Muds ........................80

5.3.1. API Rheological Properties of Water-Based Nanoaluminum Muds ...............................80

5.3.2. API Filtration Properties of Water-Based Nanoaluminum Muds.....................................86

5.3.3. Drilling Mud Hydraulics-ECD \& Circulating Pressure based on Nanoaluminum muds ....90

5.4. The Impact of Cationic Nanoparticles on the Mud Properties ..........................................95

5.5. Impact of the Current Nanoparticles on the Mud density .................................................100

Chapter 6: The Final Comparison of the Main Results ............................................................101

6.1. Impact of Different Nanoparticles on the Low pH Mud Properties ....................................102

6.2. Impact of Different Nanoparticles on the High pH Mud Properties..................................105

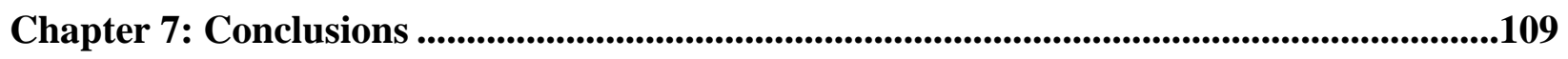

Chapter 8: Recommendations for Future Works Using Nanoparticles...............................113

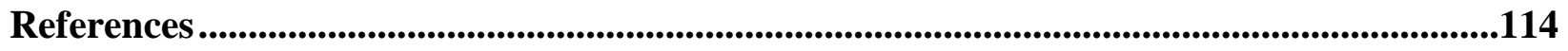

Appendix A: Mud Viscometer Dial Readings ...........................................................................116 


\section{List of Figures}

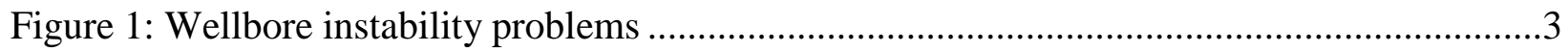

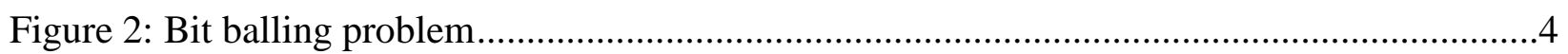

Figure 3: Cuttings settling and associated stuck pipe problems ...............................................5

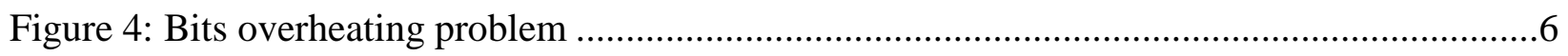

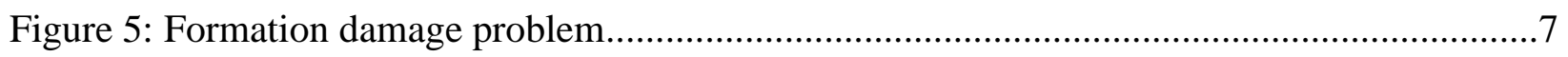

Figure 6: Formation fractures and its associated mud circulation loss problems .........................8

Figure 7: Nanoparticles increasing surface area to volume ratio...............................................9

Figure 8: Solids content of nanomuds versus bentonite muds..............................................17

Figure 9: Bentonite hydration after 24 hours .....................................................................25

Figure 10: The rheological models (profiles) for Newtonian and non-Newtonian fluids ............26

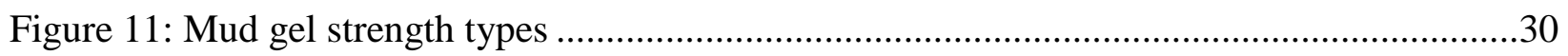

Figure 12: The impact of mud pH on the viscosity of the mud ...............................................33

Figure 13: The Sonic VCX130PB Ultrasonic Processor, Digital Weighing Scale, and

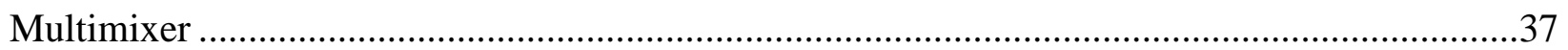

Figure 14: The Digital Pocket pH Meter and the Mud Balance ................................................38

Figure 15: The RheoVADR ${ }^{\circ}$ Variable Automated Digital Rheometer.......................................38

Figure 16: Baroid multiple unit filter presses, dial caliper gauge, and filter paper .....................39

Figure 17: Samples of the nanoparticles used in study ..........................................................41

Figure 18: The trajectory of the directional well ...................................................................46

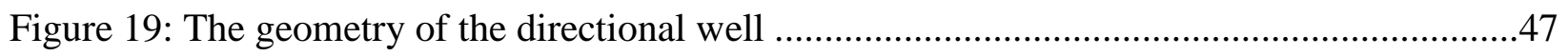

Figure 20: The rheological profiles for muds with and without nanosilica...............................49

Figure 21: The impact of nanosilica on the rheological properties .........................................51

Figure 22: The impact of nanosilica on the effective viscosity ............................................52

Figure 23: The impact of nanosilica on the gel strength.......................................................53

Figure 24: The filtration profiles for muds with and without nanosilica.....................................55

Figure 25: The impact of nanosilica on the filtration ...........................................................56

Figure 26: The impact of nanosilica on the mudcake thickness …..........................................57

Figure 27: The impact of nanosilica on the equivalent circulating density-high pH mud system.66

Figure 28: The impact of nanosilica on the equivalent circulating density-low pH mud system..61

Figure 29: The impact of nanosilica on the drillpipe pressure-high $\mathrm{pH}$ mud system ...................62

Figure 30: The impact of the nanosilica on the drillpipe pressure-low $\mathrm{pH}$ mud system ..............63

Figure 31: The rheological profiles for muds with and without nanotitanium ..........................65

Figure 32: The impact of nanotitanium on the rheological properties....................................67

Figure 33: The impact of nanotitanium on the effective viscosity .........................................68

Figure 34: The impact of nanotitanium on the gel strength...............................................69

Figure 35: The filtration profiles for muds with and without nanotitanium ................................71

Figure 36: The impact of nanotitanium on the filtration volume................................................72

Figure 37: The impact of nanotitanium on the mudcake thickness .........................................73 
Figure 38: The impact of nanotitanium on the equivalent circulating density-high $\mathrm{pH}$ mud system

Figure 39: The impact of nanotitanium on the equivalent circulating density-low $\mathrm{pH}$ mud

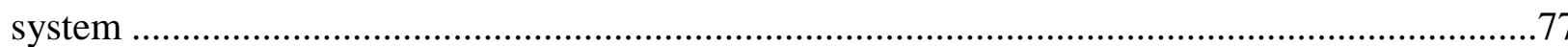

Figure 40: The impact of nanotitanium on the drillpipe pressure-high $\mathrm{pH}$ mud system ...............78

Figure 41: The impact of the nanotitanium on the drillpipe pressure-low pH mud system ...........79

Figure 42: The rheological profiles for muds with and without nanoaluminum ...........................8

Figure 43: The impact of nanoaluminum on the rheological properties......................................83

Figure 44: The impact of the nanoaluminum on effective viscosity ........................................8

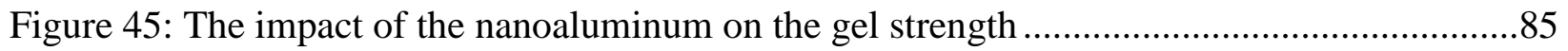

Figure 46: The filtration profiles for muds with and without nanoaluminum ..............................87

Figure 47: The impact of the nanoaluminum on the filtration volume .......................................8

Figure 48: The impact of the nanoaluminum on the mudcake thickness ...................................89

Figure 49: The impact of nanoaluminum on the equivalent circulating density-high $\mathrm{pH}$ mud system

Figure 50: The impact of nanoaluminum on the equivalent circulating density-low $\mathrm{pH}$ mud system

Figure 51: The impact of nanoaluminum on the drillpipe pressure-high $\mathrm{pH}$ mud system ............94

Figure 52: The impact of the nanoaluminum on the drillpipe pressure-low pH mud system .......95 Figure 53: The impact of cationic \& anionic nanoaluminum on the rheological properties-low $\mathrm{pH}$ mud system

Figure 54: The impact of cationic \& anionic nanoaluminum on the gel strength-low pH mud system

Figure 55: The impact of cationic \& anionic nanoaluminum on the filtration and mudcake thickness-low pH mud system

Figure 56: The cationic nanoaluminum muds before and after increasing the $\mathrm{pH}$ 100

Figure 57: The impact of different nanoparticles on the rheological properties-low $\mathrm{pH}$ mud system

Figure 58: The impact of different nanoparticles on the gel strengths-low pH mud system.......103

Figure 59: The impact of different nanoparticles on the filtration-low $\mathrm{pH}$ mud system ..............104

Figure 60: The impact of different nanoparticles on mudcake thickness-low $\mathrm{pH}$ mud system...104 Figure 61: The impact of different nanoparticles on the rheological properties-high $\mathrm{pH}$ mud system 105

Figure 62: The impact of different nanoparticles on the gel strengths-high $\mathrm{pH}$ mud system......106 Figure 63: The impact of different nanoparticles on the filtration-high $\mathrm{pH}$ mud system .............108 Figure 64: The impact of different nanoparticles on mudcake thickness-high pH mud system..108 


\section{List of Tables}

Table 1: The raw materials used to prepare basic water-based muds-low and high $\mathrm{pH}$ mud system .40

Table 2: Nanoparticles' physical and chemical properties

Table 3: The initial composition of the basic water-based muds.........................................42

Table 4: The rheological properties for the basic high and low $\mathrm{pH}$ mud systems.......................44

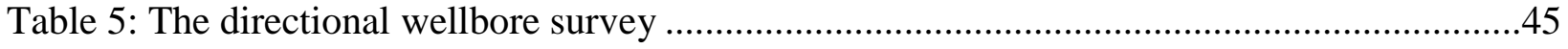

Table 6: The hydraulics operational parameters .....................................................................4 47

Table 7: Mudcake development for muds with and without nanosilica ....................................58

Table 8: Mudcakes development for muds with and without nanotitanium................................74

Table 9: Mudcake development for muds with and without nanoaluminum ............................90

Table A-1: Viscometer readings for WBM with nanosilica-low $\mathrm{pH}$......................................116

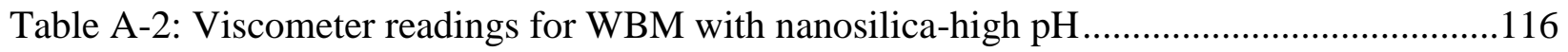

Table A-3: Viscometer readings for WBM with nanotitanium-low $\mathrm{pH}$.................................116

Table A-4: Viscometer readings for WBM with nanotitanium-high $\mathrm{pH}$.................................117

Table A-5: Viscometer readings for WBM with nanoaluminum-low $\mathrm{pH}$...............................117

Table A-6: Viscometer readings for WBM with nanoaluminum-low $\mathrm{pH}$...............................117 


\section{Nomenclature}

\begin{tabular}{|c|c|}
\hline A & Angstrom \\
\hline API & American Petroleum Institute \\
\hline AV & Apparent Viscosity, cp \\
\hline $\mathrm{cc}$ & Cubic Centimeters \\
\hline $\mathrm{cp}$ & Centipoise \\
\hline ECD & Equivalent Circulation Density \\
\hline $\mathrm{F}$ & Fahrenheit \\
\hline & Foot \\
\hline gm & Grams \\
\hline gal & Gallons \\
\hline $\mathrm{hr}$ & Hours \\
\hline HPHT & High Pressure High Temperature \\
\hline & Consistency Index \\
\hline LPLT & Low Pressure Low Temperature \\
\hline LCM & Lost Circulating Materials \\
\hline $\min$ & Minutes \\
\hline MWCNTs & Multi-Walled Carbon Nanotubes \\
\hline & Micrometer \\
\hline & Flow Behavior Index \\
\hline $\mathrm{nm}$ & Nanometer \\
\hline ND & Nano Darcy \\
\hline $\mathrm{NaOH}$ & Sodium Hydroxide \\
\hline NPT & Non Productive Time \\
\hline OBM & Oil-Based Mud \\
\hline PV & Plastic Viscosity, cp \\
\hline PDC & Polycrystalline Diamond Compact \\
\hline PPA & Particles Plugging Appartus \\
\hline ROP & Rate of Penetration \\
\hline RPM & Rotation per Minutes \\
\hline TEM & Transmission Electron Microscopy \\
\hline WBM & Water-Based Muds \\
\hline Yp & Yield Point, $1 \mathrm{~b} / 100 \mathrm{ft}^{2}$ \\
\hline$\gamma$ & Shear Rate, $1 / \mathrm{sec}$ \\
\hline$\theta_{600}$ & Dial Reading at $600 \mathrm{rpm}$ \\
\hline$\theta_{300}$ & Dial Reading at $300 \mathrm{rpm}$ \\
\hline$\theta_{200}$ & Dial Reading at $200 \mathrm{rpm}$ \\
\hline$\theta_{100}$ & Dial Reading at $100 \mathrm{rpm}$ \\
\hline$\theta_{600}$ & Dial Reading at $6 \mathrm{rpm}$ \\
\hline$\theta_{300}$ & Dial Reading at $3 \mathrm{rpm}$ \\
\hline & Shear Stress, lb/100 ft ${ }^{2}$ \\
\hline & Effective Viscosity lb/100 $\mathrm{ft}^{2}$ \\
\hline
\end{tabular}




\section{Chapter 1: Introduction}

\subsection{General Overview}

Drilling fluid, or "drilling mud" in the common usage by specialists, is a major component used to perform vital roles in the downhole circulation system of the well drilling operations. As a part of the circulation system, the mud has to perform a number of functions. These functions must be enhanced to minimize borehole problems and their associated costs. It has to remove the drilled cuttings from the wellbore, suspend these cuttings and other solid materials when its circulation stops, maintain the wellbore stability, cool and lubricate drill bit and bottom hole assembly, control formation pressure, protect exposed formations, transmit maximum allowable hydraulic energy to downhole tools and drill bit, and minimize the environmental impact.

These functions are impacted differently by changing the rheological and filtration properties of the mud. Therefore, mud engineers cannot design a magic fluid with superior properties that overcomes all problems simultaneously. This means other functions are impacted when engineers design a mud for a specific task. For example, increasing the mud density to overcome a blowout results in a severe formation damage and a slow rate of penetration. Therefore, the priority based on the function type, its importance, and the influence of the mud properties on other functions are the keys for the mud design. Mud density, plastic viscosity, yield point, gel strength, apparent viscosity, effective viscosity, low shear rate viscosity, hydraulics, and filtration are the targeted drilling mud's properties, which are the concerns of this research.

Poor drilling fluid designs cause many directly related problems facing drilling operations since it is an essential part of these operations. Therefore, they must be carefully formulated to fulfill their functions. In other words, their physical, mechanical, and chemical properties must be optimized and balanced so that these functions can be fulfilled. Currently, the mud specialists and companies use and test many chemical additives throughout a series of lab and field experiments to optimize these properties. Similarly, this research tries to minimize the drilling fluids related problems by enhancing these properties based on testing different nanoparticles as new chemical additives to the water-based muds. Hence, this thesis is based more on experimental tests and real world applicability than hypothetical models and theories. 


\subsection{The Drilling Mud Related Problems}

The failure to optimize the drilling fluid properties due to poor designs leads to many drilling problems. Therefore, drilling mud is one of the major aspects that either increases or decreases the well cost and later the production capacity. Based on that, it has to be efficient enough to overcome the problems, thereby reducing the drilling costs. For example, it has to overcome shale swelling, prevent stuck pipes, reduce bit balling, minimize generated torque and drag, prevent formation caving and sloughing, prevent drilled cuttings sagging while mud pumps are off and on, minimize downhole tool damage, reduce reservoir damage, prevent mud circulation loss, enhance the insufficient mud hydraulic system, and other problems.

All these problems are directly related to the rheological, filtration and hydraulics properties of the drilling muds. It has been proven that the conventional or unmodified water-based muds are unable to minimize these problems. Their rheological behavior and filtration property are not stable under complicated drilling conditions. According to the nature of problems, oil-based mud is the more suitable solution. However, unlike the water-based muds, it is expensive and environmentally unfavorable.

Wellbore instability such as formation swelling, caving, fracturing and sloughing are very serious and costly problems, especially in the shale and unconsolidated formations. As shown in Figure 1, wellbore instability does not maintain its gauge size and shape and/or its structural integrity. Figure 1 shows (A) caving and sloughing in an unconsolidated formation such as shale and sand, (B) formation fracturing in a faulted formation, and (C) wellbore swelling and narrowing in a reactive formation such as shale. 


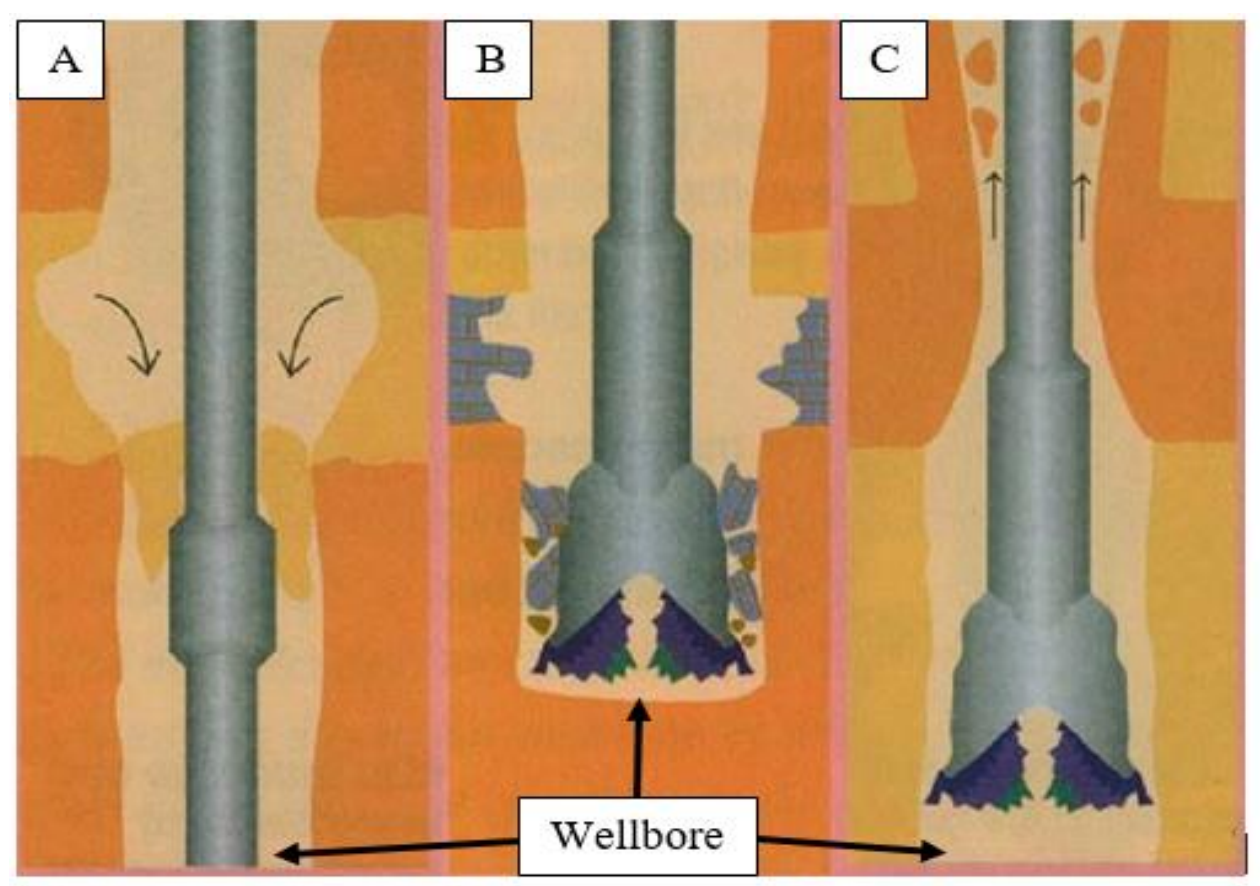

Figure 1: Wellbore instability problems (Justin 2015)

The chemical interaction between the minerals in the shale, such as Smectite, and the mud's filtrated water and its associated chemicals is one of the proven reasons behind these problems. Preventing these problems is not a realistic solution since shale consists of various components and exhibits a wide range of sensitivity. Therefore, no single additive is good enough to inhibit its interaction (Swaco 2001). Hence, mitigating the filtration loss is the closest solution. The filtration loss clarifies the direct relation between the mud and these problems.

Subsequently, there are many problems associated with wellbore instability. For instance, an increase in torque and drag, stuck pipes, difficulty of casings landing, low quality cementing, an increase in hydraulic requirements due to caves, and an increase in logging operations are the common associated problems. Therefore, strengthening and lubricating the wellbore wall and preventing the filtrated water invasion into the formations are the proper solutions that have to be fulfilled by the drilling mud. This function is obtained by constructing a compacted, thin, plaster like and low permeability mudcake around the wellbore's wall. More so, using drilling mud with high lubricity significantly helps in reducing the torque, drag, stuck pipes, and difficulty of running other equipment to the wellbore. 
Based on the nature of the above-mentioned problems, smart chemicals have to be used to enhance the behavior and filtration properties of the drilling fluid. Nanoparticles in this research are the chemicals that are intended to enhance the filtration, rheological, and mudcake properties and then overcome these problems.

For the poor rate of penetration, bit balling as shown in Figure 2, directly contributes to this problem. Bit balling is a proven result of shale swelling, hydration. It occurs mostly when the plastic shale is drilled. The shale cuttings slough and adhere to the face of the drill bit preventing the teeth from penetrating the formation. This occurs when the water-based mud with poor inhibition ability and insufficient filtration and lubricity properties is used. Therefore, enhancing the mud properties by using the nanoparticles is a promising solution.

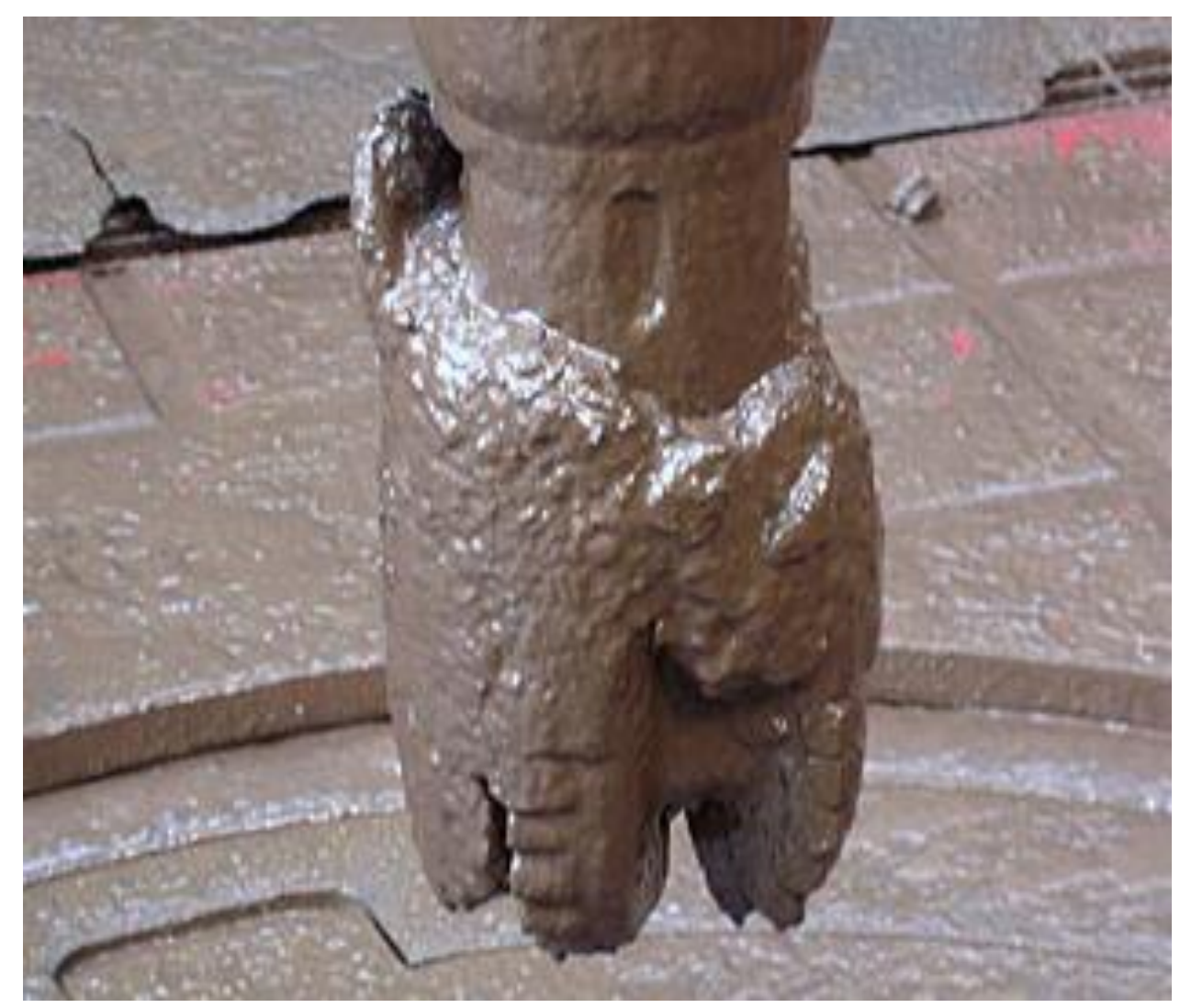

Figure 2: Bit balling problem (Drilling Formulas.Com)

More so, poor drilled cuttings suspension and carrying capacity are directly related to the mud performance in the wellbore, since they are the primary function of the mud. During the mud circulation — down the drill string, through the bit, and up the annulus to the surface - the mud 
caries the cuttings and gets rid of them at the surface, where the shale shakers are located. If the cuttings are not carried by the mud to the surface and if they are settled at the bottom of the wellbore, especially during the circulation stop periods, the drilling performance will decrease, a stuck pipe will occur, down hole equipment will fail, and the costs will increase.

Figure 3 depicts the impact of the poor carrying and suspension capacity on the drilling operation. Mechanical stuck pipe occurs due to the perpendicular accumulation of the cutting on the drill string in the horizontal portion of the wellbore. Effective viscosity, shear thinning, gel strength, and yield point are the major properties that control this issue. Hence, these properties have to be optimized by using nanoparticles as a new technique to overcome these problems especially in the directional wells.

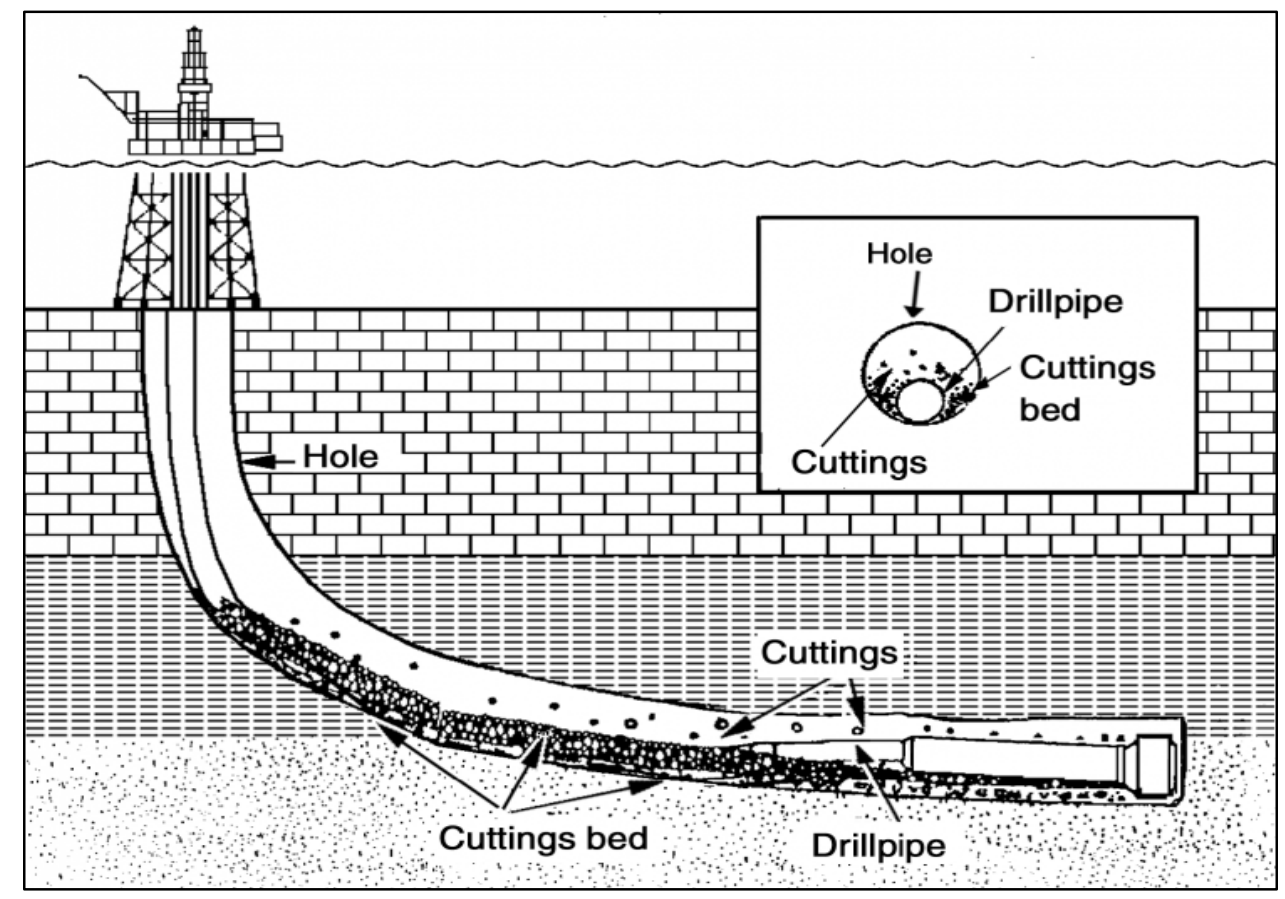

Figure 3: Cuttings settling and associated stuck pipe problems (Azar 2006)

Downhole equipment failure is one of the costly problems that must be minimized by optimizing drilling fluid performance. Considerable underground and frictional heat generation by rotation of the bit and bottom hole assembly (BHA) is the main reason behind this failure, especially in the directional and deeper wells. The drilling fluid with its circulation action must act as a conductor to transfer this heat from the downhole equipment to the surface and as a lubricant to minimize the friction. Particularly, it must lubricate the cutter's surfaces of the bit thereby 
extending its useful life. Figure 4 shows the negative impact of the excessive heat on a bit's cutters. Nanoparticles as well heat conductors have to transfer the heat from the equipment to the surface (El-Diasty and Ragab 2013).

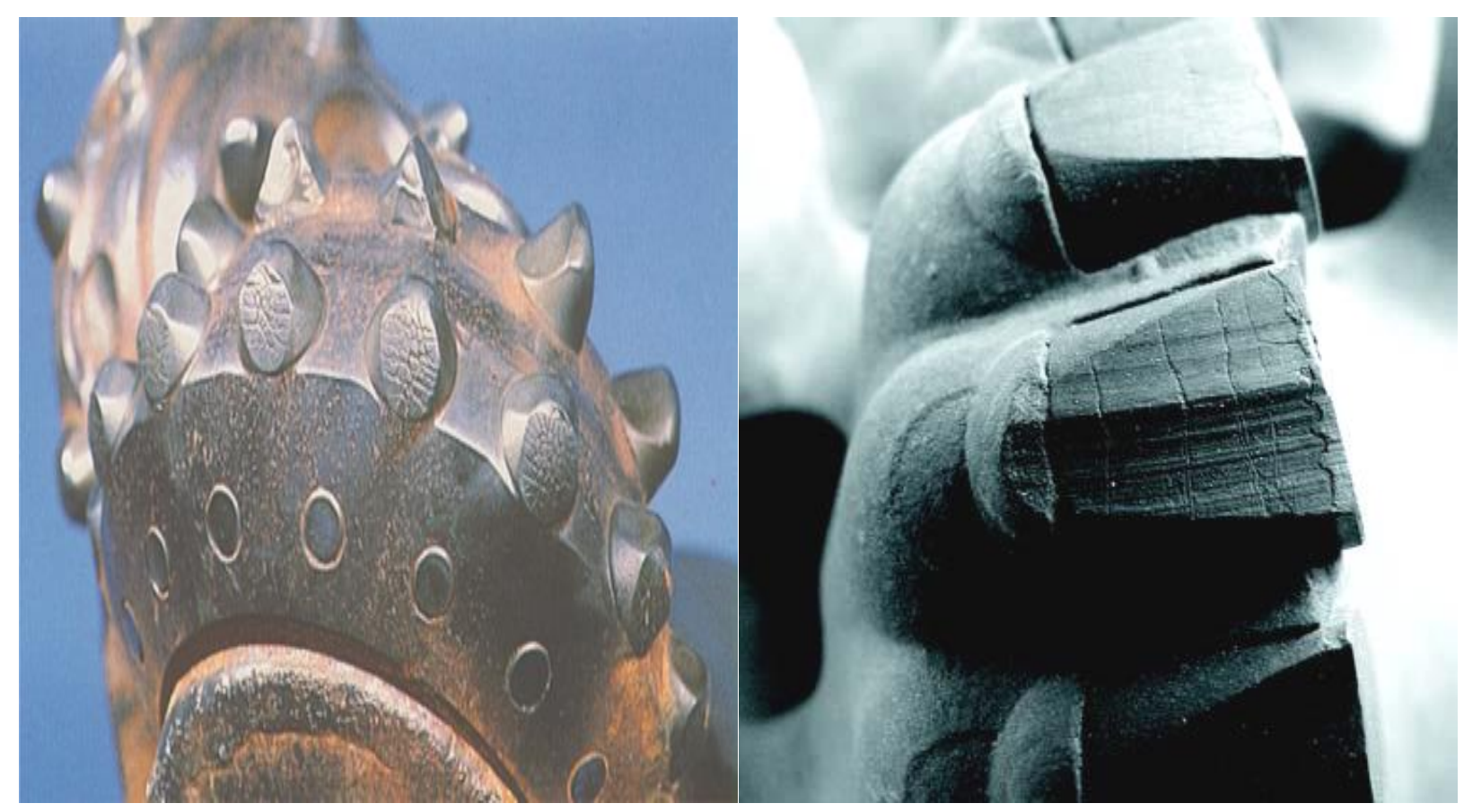

Figure 4: Bits overheating problem (www.smithbits.com)

The mudcake developed by the drilling mud on the wellbore wall should provide perfect lubricity to the BHA. The more lubricity in the drilling mud, less the generated heat. Mudcake developed by oil-based mud is the perfect solution for this problem because it has natural lubricity. Nevertheless, this mud is economically and environmentally undesirable. Therefore, water-based mud treated by chemicals such as nanoparticles to enhance its lubricity may replace the oil-based mud. Hence, nanoparticles work as lubricant and heating transfer agent.

Regarding to the formation damage and reservoir protection, drilling mud must not impair the production due to formation damage that results in low permeability and porosity. Formations with high permeability such as hydrocarbon reservoirs are damaged when the solids and small particles from different resources such as drilled and mud solids block their pore throats. Figure 5 shows how the solids plug the formation and lower the permeability. Formation damage can occur due to the chemical interaction between the water filtrated from the mud and the rocks or 
their occupied fluids. Therefore, formation damage is more related to water-based muds than oilbased mud, as the water may interact with salt bearing and clay formations.

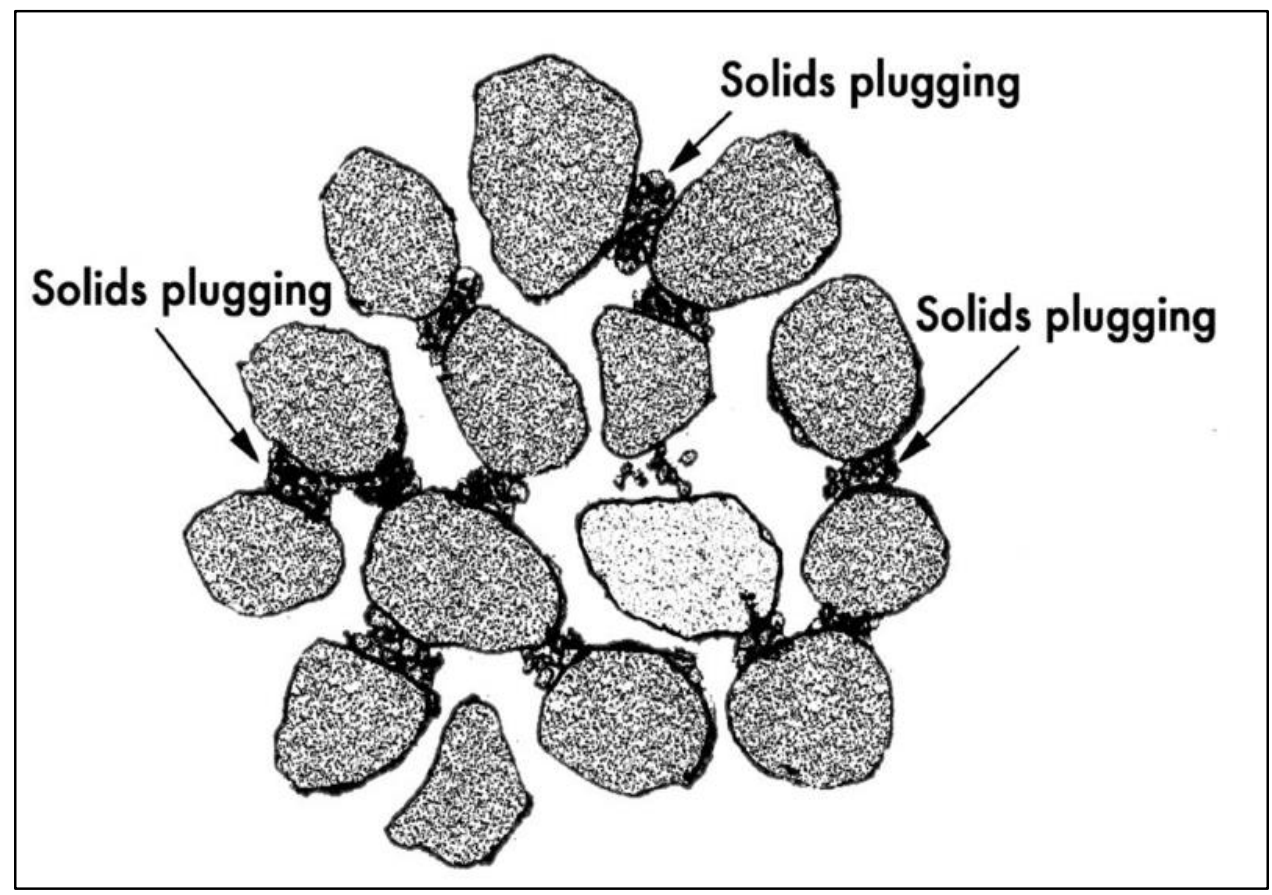

Figure 5: Formation damage problem (Azar 2006)

The high quality mudcake that developed around the wellbore is the best solution to minimize water and solids invasion into the permeable formation and then prevent formation damage. In addition, the chemical features of the filtrate must be controlled to reduce formation damage. Thus, the well-designed nano water-based mud should provide less formation damage potential than traditional water-based mud. Many researchers have reported that nanoparticles, as new chemicals, develop a low permeability mudcake, thereby preventing the solids and water invasion into the formation. Hence, water-based nano fluids work as a Drill-in fluid that can be used to drill through particularly productive reservoirs.

Similarly important, the mud hydraulics must be in the optimum levels in order to achieve maximum hole cleaning and avoid many other related problems such as underground fracturing, cuttings sagging, low rate of penetration, etc. The severity of these problems increases when the equivalent circulation density (ECD) is close to the formation fracture gradient. Indeed, there are many constraints impact the hydraulics optimization such as wellbore geometry, design of the bottom hole assembly, rig's equipment conditions, and mud density. These parameters usually 
limit the maximum allowable circulation pressure and its associated flow rate. Therefore, mud rheological properties are the only parameters that play a significant role in the optimization of the hydraulics process since rheology and hydraulics are interrelated aspects of fluid behavior.

Finally, mud circulation loss into a fractured formation is regarded as one of the drilling problems that is directly related to the mud performance and cause Non-Productive Time (NPT). Figure 6 illustrates the mud circulation loss and the formation fractures problems.

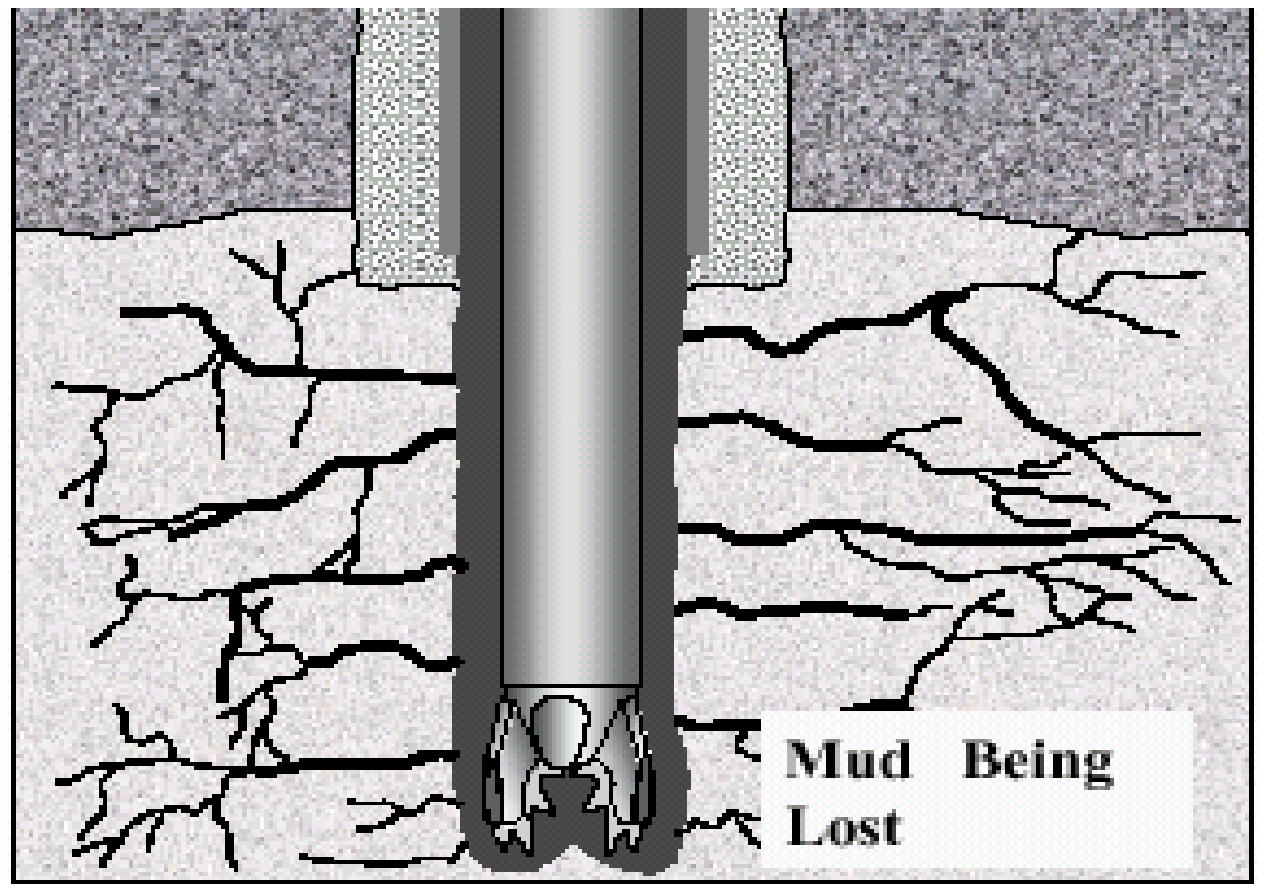

Figure 6: Formation fractures and its associated mud circulation loss problems (Rabia 2002)

Occasionally, fracturing occurs when the annular pressure based on the ECD exceeds an exposed formation-fracture pressure. The associated problem is a possible kick occurrence due to insufficient mud hydrostatic pressure resulting after the mud loss. Minimizing the ECD is one of the solutions to prevent this problem. ECD is directly related to the mud rheological properties. Particularly, controlling viscosity and gel strength is the best option to optimize the ECD. High viscosity and gel strength will cause high ECD, thereby increasing the possibility to fracture the formation. Therefore, a well-designed mud with low viscosity and fragile gel strength significantly helps to overcome this problem. Nanoparticles should aid in mitigating this problem by enhancing the rheological properties. Based on the above facts, in recent years, researchers started improving the water-based mud by making it a nano-mud as a better solution. 


\subsection{Nanoparticles Definition and Performance in Drilling Muds}

Nano-mud can be defined as any drilling mud that contains at least one chemical additive with particles sized in nanoscale, $1 \mathrm{~m}=10^{6} \mu=10^{9} \mathrm{~nm}$. They perform multi-functions in the drilling mud due to their unique features. In other words, nano water-based mud has the advantages of the oil-based mud, but it is cheaper and environmentally acceptable (Srivatsa \& Ziaja 2011). The nanoparticles are characterized by high surface area to volume ratio, by providing surplus charges to the mud, by tiny sizes, by high sensitivity, and by perfect particle distribution (Amanulah et al. 2011). Figure 7 illustrates the new particles after crashing a parent particle. As chemicals, they are strongly charged particles. In addition, they are classified into cationic and anionic particles according to the ion types on their surfaces.

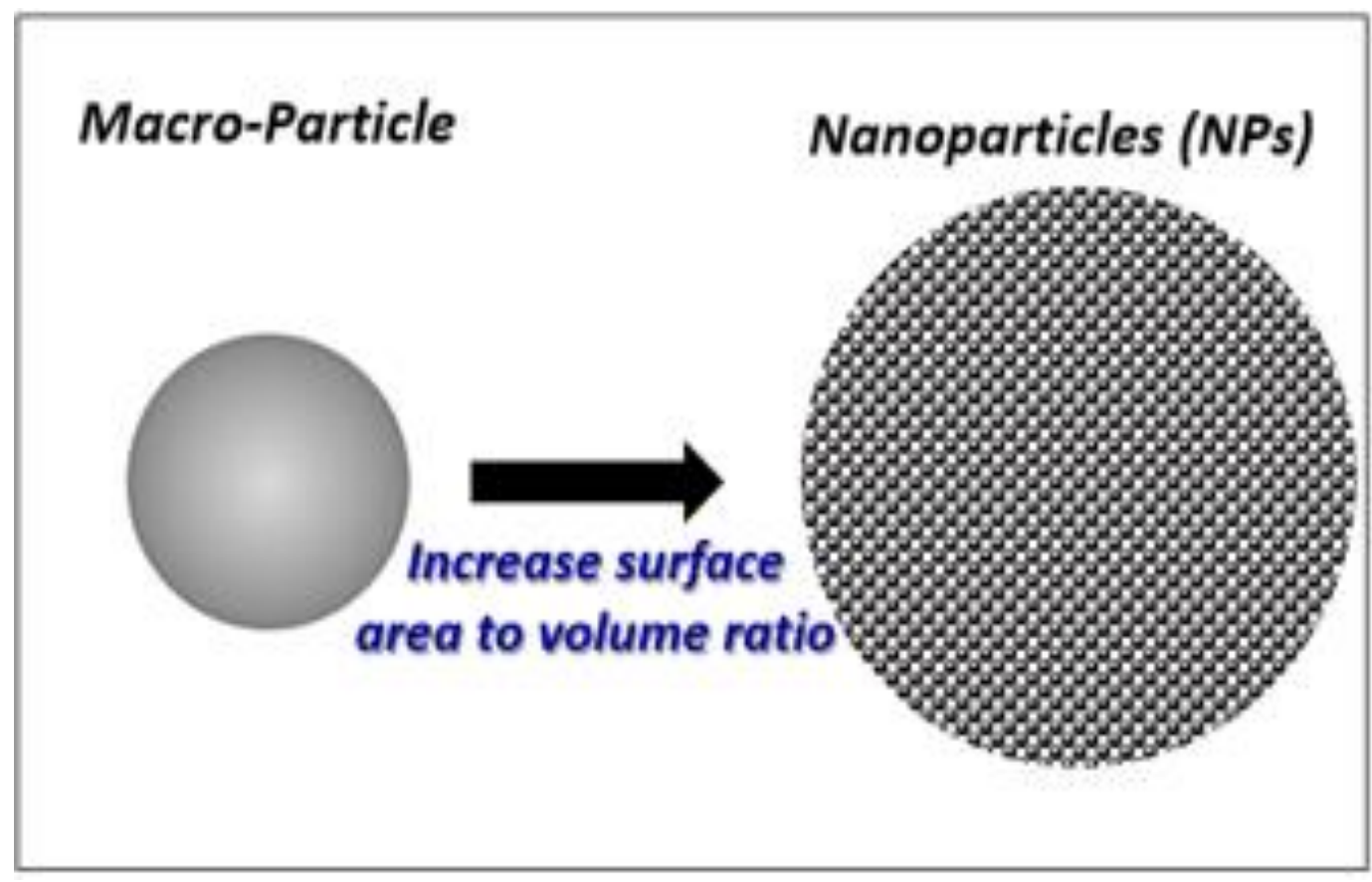

Figure 7: Nanoparticles increasing surface area to volume ratio (Salih et al. 2016)

These features play significant roles in efficient chemical interaction between them and other mud components. Few amounts of them change the linking process and the distribution of the clay particles, Bentonite platelets. The result is a wide range of drilling fluid behaviors and filtration properties that is based on their concentrations and charging types. 
Furthermore, nanoparticles work as a perfect bridging agent due their tiny sizes. They physically plug the nanometer-sized pores and shut off water loss-for example, in shale formations, thereby preventing shale swelling and its related problems ((Sharma et al. 2012), (Sensoy et al. 2009), (Cai et al. 2011), (Li et al. 2012), and (Riley et al. 2012)). Hence, properly formulated nanoparticles with water-based mud can replace the oil-based mud used as a shale swelling inhibitor.

Due to the high surface area to volume ratio and very low concentration requirements of the nanoparticles, the treated water-based mud with hydrophilic film forming capability on the bit surface is expected to eliminate the bit balling entirely (El-Diasty and Ragab 2013). This occurs especially in sticky formations such as marl and shale rocks. As a result of minimizing the bit balling, the rate of penetration will increase. For the same reason, nanoparticles play a significant role in reducing the torque and drag forces throughout drilling operations. They work as lubricants, reducing the friction between drilling pipes and the well wall interface. Furthermore, this feature helps in stuck pipes, equivalent circulation density (ECD), and mud pump pressure reduction. By reducing the ECD, the circulation loss problems can be minimized.

The nanoparticles have less kinetic energy impact, thereby increasing the life of the downhole tools (Amanulah et al. 2011). It is well known that wear and tear decrease the life of the tools. They are caused by the forces created due to the extreme kinematic energy associated with the large particles continuously added to the mud either naturally such as cuttings or by rig crew for specific purposes during drilling operations. These forces can be minimized by replacing the large quantities of micro particle additives with a small amount of nanoparticles for the same purposes. By replacing the big particles with tiny particles, the plastic viscosity will decrease which is desirable. In addition, the mud hydraulic system can be optimized when the rheological properties and the ECD are optimized.

According to the aforementioned ideas and studies, the oil-based mud can be replaced by waterbased mud with nanoparticles additives. However, the researchers need to attain the optimum filtration and rheological properties for the latest mud by finding the proper types, concentrations, and sizes of the nanoparticles. 


\subsection{Challenges Associated with Water-Based Nanomuds}

Currently, only few papers have shown the effect of the nanoparticles on the rheological and filtration properties of water-based muds. The selection of the right nanoparticle types and the proper concentrations always challenges the researchers. That justifies the common use of the macro materials to enhance the mud properties such as loss circulation materials (LCMs), lignosulphonate, lignite, filtration inhibitors, etc. However, these materials do not work efficiently in horizontal drilling, directional drilling, extremely deep wells, and shale drilling operations. Indeed, the selection of the right concentration is very sensitive because of the unique feature of the nanoparticles, which has a high surface area to volume ratio that makes them extraordinary chemicals (Amanulah et al. 2011). In other words, use of nanoparticles should be in limited quantities since excessive amounts lead to reverse results, which lead to more cost.

Moreover, some nanoparticles efficiently work or completely soluble in a base environment only. On the other hand, others efficiently work in an acidic environment only. These features may cause solids agglomeration while blending them with water-based mud, which is usually base. The nanoparticles' agglomeration makes them a non-effective agent.

The nanoparticle size should be small enough to fit and seal the spaces between the mudcake components and Bentonite particles (Contreras et al. 2014). Otherwise, the continuous phase can easily be lost from the mud, causing a filtration increase and a thicker mudcake, which are undesirable. For the purpose of shale inhibition, the nanoparticle sizes should be less than the pore throats of the shale, which are usually in the range of 5-10 $\mathrm{nm}$. The conventional lost circulation materials, LCM, are too large to fit and seal those pores. Therefore, the nanoparticles can influence the fluid loss in a positive way with the right sizes.

Finally, the cost of the nanoparticles should be taken into account as a challenge. The concentration should be as low as possible to achieve the goal with the lowest cost. This is also related to the quality of the other chemicals and materials interacting with the nanoparticles in the mud. It has been proven that high quality mud's components lead to needing less amount of nanoparticles to perform a specific function. 


\subsection{The Objective of Study}

The main objective of this research is to explore the applicable potential of different nanoparticles in the water-based muds and to provide indications about their performance trends in order to design efficient muds. This was handled by formulating and testing commercially affordable and environmentally acceptable water-based nanomuds that retain the high performance and stability of oil-based mud. Three nanoparticle types were used to study the rheological and filtration properties of the water-based muds with different concentrations. The impact of these materials on the mud hydraulics was investigated based on the obtained rheological data, utilizing Drillbench hydraulics software. Furthermore, the impact of the mud's $\mathrm{pH}$ on the nanoparticles' performance was targeted. Finally, the difference in the performance for the same nanoparticle type, but with different specifications (particle surface charging), was investigated.

The second main goal of this study is to pick up the right types and concentrations of the nanoparticles that enhance or diminish the rheological and filtration properties. Therefore, the API rheological and filtration tests were carried out to find the best types and concentrations that reflect a low viscosity at high shear rates and high viscosity at low shear rates, reduce the filtrate volume by making consistent and compacted mudcake, reduce the initial spurt loss, enhance the gel strength, etc. The best types and concentrations were selected based on various comparisons that were made between the basic water-based mud test results and the treated water-based mud test results. 


\section{Chapter 2: Literature Review}

Recently, nanotechnology has played a significant role in improving the oil and gas industry in the world. Different nanoparticles are produced that protect the petroleum reservoirs and develop the drilling and production operations. Particularly, the materials with nano-scale particles have a wide range of attractive applications in the drilling fluid related challenges, such as lost circulation control, borehole stability, hole lubricity and cleaning, shale problems, downhole equipment failure, etc. Therefore, researchers have studied the impact of nanoparticles on the drilling fluid properties that control the previously mentioned challenges, but in a limited capacity. The following literature review shows previous works related to testing various types of nanoparticles as drilling fluid additives based on different methodologies.

\subsection{Nanoparticles as Shale Inhibitors}

Shale instability is one of the major problems that challenge the drilling operations. Preventing water invasion to shale formation is one of the best solutions to inhibit its swelling. As mentioned, nanoparticles are used as shale inhibitors. Hence, Sensoy et al. (2009) showed the positive effect of using $20 \mathrm{~nm}$ particles of nanosilica as additives to water-based drilling fluids in reducing shales' permeability by physically plugging pore throats and building an internal mudcake, thereby reducing shales' instability. They conducted laboratory experiments with four field muds, brine, hard shale, and soft shale, which were from Atoka and the Gulf of Mexico fields. They placed the four fluids in contact with the shales under elevated pressure conditions in order to investigate the penetration of fluids through the shales with and without using nanoparticles.

Pressure transmission technique was used to measure the permeability of the shale sample to various fluids. After using various concentrations of nanoparticles (40\%, 29\%, 10\%, and 5\% wt.), they concluded that the nanoparticles with higher concentrations helped to reduce the fluid penetration of Atoka shale and Gulf of Mexico shale by 16-72\% and 17-27\%, respectively. Furthermore, they concluded that better shale sealing performance for the Atoka shale is obtained with $20 \mathrm{~nm}$ size nanoparticles compared to $5 \mathrm{~nm}$ size nanoparticles. In addition, the nanoparticles reduced water penetration by up to $98 \%$ compared to seawater, brine. 
In a similar study, Cai et al. (2011) studied the positive effects of (5-22) nm particles of untreated nanosilica on the Atoka shale stability and on the water-based drilling fluid properties as well. They reported laboratory results showing these effects on the amount of the water penetration into the Atoka shale. Their experiment included a pressure penetration test to measure the permeability of the shale, mud filtration test, and mud rheological test. They did these tests when they put three types of fluids in contact with the shale. These fluids are brine, water-based mud, and water-based mud with $10 \%$ wt. of nanoparticles. Two types of water-based mud were used, a Bentonite mud and low solids mud. In addition, they used six different brands of commercial nanosilica particles for the comparison purpose.

As a result, Cai and his coworkers found that the best effect on reducing the Atoka shale permeability is obtained by using nanoparticles with the water-based muds. Hence, the permeability decrease was about $45.67 \%-87.63 \%$ for the low solid muds and $57.7 \%-99.33 \%$ for the Bentonite mud with nanoparticles. However, they discovered that using nanoparticles negatively affected the rheological properties of the water-based mud. For example, the plastic viscosity (PV) increased and the yield point (YP) decreased after treating the muds with nanosilica with the aforementioned specifications of concentration and size.

Sharma et al. (2012) showed the physical effect of nanosilica particles sized in $20 \mathrm{~nm}$ on the Mancos and Gas shales when water-based mud with nanoparticles is used to drill these formations. The main principle of this effect is how these nanoparticles will prevent the water transportation from the mud to the shale pores by plugging the pores and/or making impermeable mudcake. Throughout their experiment, Sharma and his coworkers did a flow-throw test to measure the permeability, a rheological test to measure the enhancement in the mud rheological properties, a mud stability test to measure the mud's ability to stay in a good condition, and a HPHT filtration test to simulate the filtration of the mud under the downhole conditions.

They exposed the shale samples to three types of fluid with different concentrations of nanosilica, but they did not mention the amounts of nanosilica used. The tested fluids were $4 \%$ brine, to be a reference, water-based mud without nanoparticles, and water-based mud with nanoparticles. As a result, they concluded that by using the nanomaterials with the water-based mud, the water invasion to the shale formation can be reduced by 10 to 100 times or completely 
stopped. Therefore, it helps to stabilize the shale. However, the nanoparticles with the aforementioned size could not plug the cracks in the shales.

Riley et al. (2012) also exposed Texas gas shale to different fluids with and without nanosilica. They used a Shale Membrane Tester to investigate the physical plugging characteristics of the nanosilica with $20 \mathrm{~nm}$ size and different concentrations (3\%, 5\%, 10\%, and $29 \%$ by volume). They exposed the shale samples to $4 \%$ brine, water-based mud without nanosilica, and with water-based mud with the previously mentioned concentrations. As the volume concentration of nanosilica was increased from $3 \%$ to $29 \%$, an increase in plugging properties was observed. However, only $3 \%$ by volume was selected as a reasonable amount based on the cost and field considerations. As a result, the permeability was decreased by $77 \%$ based on the water-based mud without nanosilica and $97 \%$ based on the $3 \%$ volume. of the nanosilica. However, $3 \%$ volume is greater than the concentrations used in the current study.

Finally, Jung et al. (2013) reported experimental results for shale permeability and pressure penetration tests, using different fluids: brine, water-based mud without nanoparticles, and waterbased mud with nanoparticles (10\% and $30 \%$ by weight) They used samples from Texas gas shale formation in their experiments. Jung and his coworkers focused on how to prevent the interaction between the clay in the shale and the filtered water. This interaction leads to the loss of pore pressure support, and thereby leads to shale instability.

They observed that the nanoparticles need to be less than $30 \mathrm{~nm}$ to plug shale pores. Finally, they concluded that with the use of nanoparticles as additives to drilling fluids, the shale permeability was reduced $100 \%$ based on the comparison with the base drilling mud and the brine performance. For this reason, they recommended drilling the Texas gas shale with nano-based fluids instead of oil-based mud (OBM), which is good as a shale swelling inhibitor, but it is expensive.

\subsection{Nanoparticles as Rheological and Filtration Properties Modifiers}

Researchers studied the impact of different types and concentrations of nanoparticles on the rheological and filtration properties of water-based and oil-based drilling fluids based on different methodologies. Particles' size, shape, surface charging, $\mathrm{pH}$, solubility type, and 
concentration has the significant impact on their performance, thereby affecting the properties of the drilling fluids. Therefore, the results show enhancements and/or declines in the rheological and filtration properties for the drilling fluids treated by the nanoparticles.

In 2011, Amanullah et al. investigated the impact of three types of commercial nanoparticles on the water-based muds' rheological and filtration properties based on the API LPLT filtration and rheological tests. They used $14 \%$ and less than $1 \%$ by weight concentrations of these nanoparticles to formulate the nanofluids. They did not mention the names and sizes of the nanoparticles in their research. In addition, they prepared and used the water-based mud without nanoparticles as a baseline for the comparison purpose.

Results showed enhancements in the rheological properties such as stability and gel strength of the nanomuds based on the comparison with the water-based muds without nanoparticles, but there is no impact on the filtration property. However, the results showed developing thin mudcake and zero spurt loss after treating the mud with nanoparticles, which is desirable in reducing formation damage. Amanullah and his coworkers wrote that the use of nanoparticles in the drilling fluid can help to recover more than $70 \%$ of the oil and gas in the shale reservoirs due to reduced formation damage. Furthermore, the scope of the deposition of a thin mudcake by nanofluids may lead to a dramatic decrease in differential pipe sticking in highly permeable formations.

Furthermore, results showed enhancement in the thermal conductivity of the drilling muds with nanoparticles, due to extremely high surface area to volume ratio. The enhanced thermal conductivity of drilling mud will provide efficient cooling of drill bits and other downhole equipment leading to extended life of downhole drilling equipment. Thus, the nanoparticles can prevent the downhole equipment failure due to extreme heat. Finally, the extremely low solids content was noticed in the treated muds, which plays an important role in enhancing the rate of penetration in competent hard rock formation. Figure 8 compares the solid content of nanofluids with basic muds. 


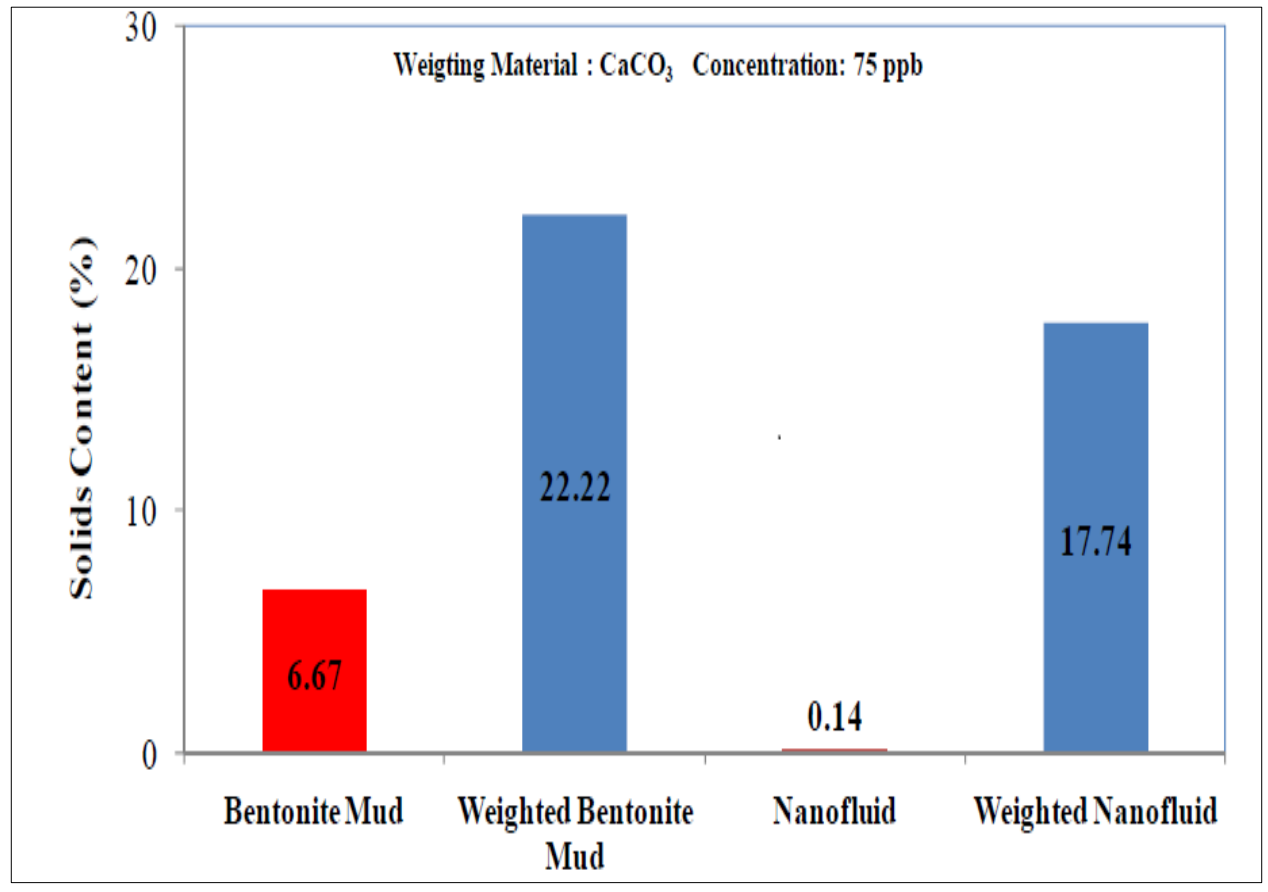

Figure 8: Solids content of nanomuds versus bentonite muds (Amanullah et al. 2011)

In a similar area of study, Zakaria et al. (2012) investigated the impact of in-house prepared nanoparticles with $30 \mathrm{~nm}$ in size, conventional loss circulation materials (LCM), and commercial nanoparticles with $20-30 \mathrm{~nm}$ in size on the filtration properties of the oil-based mud samples. Under low pressure low temperature (LPLT) API tests, the results showed $70 \%$ reduction in the filtration after adding nanoparticles, 9\% reduction after adding LCM, and 6.67\% reduction after adding the commercial nanoparticles. In addition, it was noticed that the mudcake that developed during the presence of nanoparticles was thin and compacted. However, it was observed that there was no positive impact of the nanoparticles on the fluid rheological properties.

Contreras et al. (2014) also studied the effect of in-house prepared nanoparticles on oil-based drilling fluids filtration property. They prepared the nanoparticles from iron and calcium. Three concentrations of each type were used $(0.5 \%, 1 \%$, and $2.5 \% \mathrm{wt}$.), but they did not report the size of these nanoparticles. In addition, graphite as conventional lost circulation material (LCM) with two concentrations ( $2 \%$ and $0.5 \%$ wt.) was added to the blends as a conventional lost circulation material in order to study the combined effect of both nanoparticles and LCM on the filtration. API low pressure low temperature (LPLT) and high pressure high temperature tests were carried out to analyze the blends in the presence of graphite at low and high concentrations. For the 
HPHT test, 500 psi and $250^{\circ} \mathrm{F}$ were applied on a ceramic disc, which has 775 md permeability to get results similar to the underground conditions.

Contreras et al. observed that after intervals of 30 minutes of LPLT filtration tests, $100 \%$ reduction was achieved based on using $1 \% \mathrm{wt}$. of iron-based nanoparticles and $2 \% \mathrm{wt}$. of graphite, and less filtration reduction percentage was achieved based on using calcium-based nanoparticles. For the HPHT tests, $76 \%$ reduction was achieved based on using $0.5 \%$ wt. of ironbased nanoparticles and $2 \%$ wt. of graphite, and less filtration reduction percentage was achieved based on using calcium-based nanoparticles. Contreras and his coworkers also tested the friction of the drilling fluid with and without using the nanoparticles. They got a reduction of $38 \%$ with the calcium-based nanoparticles and 59\% reduction with the iron-based nanoparticles. This friction reduction is due to the reduction in the solids concentration in the fluids. As a result, stuck pipe and torque throughout drilling operations will be at their minimum values when these nanofluids will be used.

In a similar study, Srivatsa \& Ziaja (2011) studied the effectiveness and the advantages of a system that included xanthan gum-based polymer, visco elastic surfactant, conventional fluid loss additive (polymer-based additive), and silica nanoparticles in reducing the filtrate loss to the formation by forming a thin, non-erodible filter cake and in enhancing the rheological properties. They mixed and tested various concentrations of the polymer, the surfactant and three concentrations of the nanosilica to find the optimum performance of the fluid. The three high nanosilica concentrations were $(10 \%, 20 \%$ and $30 \%$ wt.). Economically, these concentrations may not be desirable. The mud balance, the standard viscometer, the API filter press, and the particle plugging apparatus (PPA) were used to test the mud weight, the rheological properties, standard API filtration, and HPHT filtration for these samples. The HPHT test was conducted at $200{ }^{\circ} \mathrm{F}$ and $1000 \mathrm{psi}$. In addition, they compared the performance of the nanosilica as a fluid loss agent with the performance of the conventional fluid loss additive. They concluded that the nanoparticles with the higher concentration played a more significant role in reducing the fluid loss than the conventional loss additive. However, the blends without nanosilica reflected better rheological properties than the blends with nanosilica. The nanosilica and the polymer without the surfactant helped in fluid stability at the high temperature system. However, the high concentrations of the nanosilica are not desirable in terms of the economic considerations. 
Ismail et al. (2014) studied the impact of different concentrations of multi-walled carbon nanotubes (MWCNTs) on the rheological and filtration properties of the water-based and esterbased drilling fluids at various temperatures. Three concentrations of the $30 \mathrm{~nm}$ of MWCNTs were used in this experimental research $(0.001,0.01$, and $0.1 \mathrm{ppb})$. LPLT and HPHT filtration and rheological tests were conducted to measure the rheological and filtration properties of the fluids. In addition, $80{ }^{\circ} \mathrm{F}, 200{ }^{\circ} \mathrm{F}$, and $250{ }^{\circ} \mathrm{F}$ were considered to investigate the impact on different temperatures on the properties. For the water-based muds, results showed no impact of the MWCNTs with all concentrations on the rheological properties based on the comparison with the basic mud's properties. However, $0.01 \mathrm{ppb}$ of the MWCNT resulted in the lowest filtration loss for both tests. In addition, as the temperature increased, the plastic viscosity, yield point, and gel strength decreased. For the ester-based muds, results showed an increase in the rheological properties of the muds, such as plastic viscosity, gel strength, and yield point as the MWCNT concentration increased. However, the used concentrations did not affect the filtration volume. In addition, the rheological properties increased as the temperature increased.

Nasser et al. (2013) developed a drilling fluid recipe by adding 3\% wt. of $40 \mathrm{~nm}$ nanographite and nanosilicon wires to the water-based mud. They studied the impact of the previously mentioned nanoparticles on the rheological and filtration properties at different temperatures by using the basic apparatus commonly used in the mud labs. Results showed a detrimental effect of the temperature on the rheological properties of the water-based drilling mud without nanoparticles. On the other hand, the behavior of the fluids with nanoparticles retained all the desired rheological properties at elevated temperatures.

Jung et al. (2011) investigated the impact of iron oxide nanoparticles with $3 \mathrm{~nm}$ and 30nm in size on the rheological and filtration properties of Bentonite-based drilling fluids at HTHP conditions. Two concentrations of the nanoparticles were used: $0.5 \%$ wt. and $5 \%$ wt. As a result, yield point, plastic viscosity, and gel strength increased more after adding the smaller size of the nanoparticles than the bigger size. Jung and his coworkers reported that oxide nanoparticles embedded in the randomly dispersed pore structure on the surface of the clay particle confer links between Bentonite particles, which might promote gelation of the Bentonite particles. However, the results showed negative impact of the nanoparticles with the above-mentioned specifications on the filtration properties of the treated muds. 
Javeri et al. (2011) used 40-130 nm of silicon nanoparticles in water-based drilling mud and investigated its impact on the mudcake thickness and rheological properties. API rheological and filtration tests were conducted for this purpose. As a result, they reported that silicon nanoparticles with concentration about $3 \%$ by volume did not have much effect on the drilling fluid viscosity and other properties. On the other hand, the cake thickness was reduced by $34 \%$.

\subsection{Theoretical Researches Related to Nanoparticles}

Li et al. (2012) presented a literature review including various benefits of nanoparticles in the development of the petroleum industry as long as they reduce the operations cost and enhance the oil and gas production. They summarized that nano-drilling fluids play a significant role in intensifying mudcake quality, enhancing the rheological properties, reducing friction, eliminating differential pipe sticking, maintaining borehole stability, protecting reservoirs, and enhancing oil and gas recovery. Li and his coworkers focused on the positive effect of the nanoparticles on the shale stability, whereas the water-based mud without nanoparticles cannot maintain borehole stability since the conventional drilling fluid particles are too large to seal the nano-sized pore throats of shale. Li and his coworkers found that these nanoparticles reduced the water invasion to shale significantly because they are small enough to penetrate and seal the pore throats in the shale and build an internal mudcake.

In a similar study, El-Diasty and Ragab (2013) wrote an article about the various applications of nanoparticles in the oil and gas industry. They mentioned that nanoparticles are one of the most important ways to produce more oil and gas with minimum possible costs because they help in overcoming the drilling related problems. For instance, they have positive impacts on fluid loss and wellbore stability in the shale formations with Nano Darcy (ND) permeability because they fill the pores and seal them, so they prevent the invasion of filtered water from the mud to the shales. Preventing water invasion to the shale is the best solution for shale swelling problems. In addition, they are able to prevent bits, tool joints, and stabilizers balling, which are common problems in the drilling operations. This is due to the capability of the nanofluids to form hydrophilic and tiny film on the downhole equipment, which is expected to prevent sticking of the rocks or cutting on the equipment. 
Furthermore, the researchers clearly reported the role of nanoparticles in increasing the rate of penetration and thereby decreasing drilling costs because of their high surface area to volume ratio and then the low concentration requirement compared to the conventional drilling mud additives. This will decrease the solids content, thereby decreasing the plastic viscosity and increasing the rate of penetration. Nanoparticles are also helpful in the torque and drag mitigation during drilling operations. In other words, nanofluids can provide a significant reduction of frictional resistance between the pipe and the borehole wall due to formation of continuous and thin lubricating film in the wall-pipe interface. As a result, El-Diasty and Ragab (2013) recommended using water-based mud with nanoparticles instead of OBM to drill shale formation in the future because of the high cost and bad effect on the environment of using oilbased mud as drilling fluid.

\subsection{Summary of the Literature Review}

According to the above-mentioned studies and researches, it is obvious that the nano-based drilling fluids are regarded as a new generation of drilling fluids that has been recently discovered. That implies the possibility of a wide range of further studies and improvements using nanoparticles with drilling fluids. In addition, it is clear that the nanoparticles have a vital role and ability in reducing the operations cost and increasing the oil and gas production when they minimize the well instability and enhance the drilling fluid properties. Therefore, they are interesting for the researchers.

The above studies and experiments are noteworthy because of their significant role in enhancing and improving water-based drilling fluid properties, thereby replacing this fluid by oil-based fluid is the right choice. However, the above studies did not take into account the economic issue. The researchers used high concentrations of the nanoparticles, which is not preferable. In addition, some of them tested the impact of the nanoparticles with the oil-based mud. There is no point behind increasing the cost of the oil-based muds by adding nanoparticles as long as the oilbased muds without nanoparticles are enough to overcome the drilling fluid related problems. Furthermore, most of the studies were poorly reported and they are characterized by limited capacity. For example, the nanoparticles' name and size were not disclosed. 
Therefore, the idea of this study is to investigate and test the impact of previously untested nanoparticles with lower concentrations on the water-based mud's properties. This experimental study tries to expose the impact of less than $0.7 \%$ wt. of different sizes and types of nanoparticles on the water-based mud's rheological and filtration properties. The selected concentrations were $0.1 \%, 0.3 \%, 0.5 \%$, and $0.7 \%$ wt. Based on these low concentrations, the economic limits are taken into account making the study a novel one.

According to Srivatsa \& Ziaja (2011) and Napierska et al. (2010), nanoparticles are very sensitive to the $\mathrm{pH}$ changes. Therefore, the impact of the mud's $\mathrm{pH}$ on the selected nanoparticles' performance is also studied considering low and high $\mathrm{pH}$ mud systems. Then, the influence of the nanoparticles on the drilling mud hydraulics for these systems is studied. Based on the above considerations, the best type and concentrations that enhance the drilling fluids properties will be recommended. 


\section{Chapter 3: Overview of Water-Based Muds}

\subsection{General Overview}

This chapter discusses water-based muds and their related properties. Generally, a drilling mud consists of three major phases plus chemicals. These are continuous, dispersed or reactive solids, and inert solids phases. The continuous phase consists of liquids such as oil and/or water. The reactive phase consists of clays. They dissolve and react in the continuous phase to develop the rheological and filtration properties. The inert phase consists of weighting materials. They are used to control the density of the mud. The chemical additives are the necessary materials used to control the drilling fluids' properties as needed by the mud engineers. Based on whether the continuous phase used to prepare the mud is oil or water, water-based and oil-based muds are the most common fluid types in the drilling industry. This study focuses on the water-based muds.

Water-based mud is prepared by mixing one of different clays with water, such as Kaolinite, Attapulgite, or Montmorillonite. They may be mixed with fresh water or saltwater. Only the Montmorillonite serves as a viscosifier and filtration control agent, simultaneously. It helps in depositing solids that develop a mudcake on the wellbore wall or on the lab filter paper, thereby preventing the filtration. Weighting agents, such as Barite (BaSO4), are added to the mixture as suspensions to increase the density. More so, various chemicals, such as caustic soda $(\mathrm{NaOH})$, lignosulphonate, etc. are added to maintain and condition the water-based mud.

As a common type of clay, Montmorillonite or commercially named Bentonite was used in this research. Bentonite is a collection of electrochemically charged particles. Each particle has 2000 $\mathrm{nm}$ length and width and $1 \mathrm{~nm}$ thickness, so it looks like a plate. Neutrally, the Bentonite particle consists of three thin and flexible layers, combined as packages. They are an alumina layer with a silica layer above and below it. These layers have a very large total surface area. For example, one gram of the Bentonite has a surface area around $750 \mathrm{~m}^{2}$.

Some of the aluminum ions $\left(\mathrm{Al}^{+3}\right)$, cations, can be replaced by other cations when the Bentonite is exposed to chemical environments containing high concentrations of different cations, positive atomic-valence ions such as Calcium $\left(\mathrm{Ca}^{+2}\right)$, Sodium $\left(\mathrm{Na}^{+1}\right)$, or Magnesium $\left(\mathrm{Mg}^{+2}\right)$. This is the cation exchange phenomenon in the Bentonite-based muds (Swaco 2001). If a significant amount 
of these cations is sodium, the clay is called Sodium Bentonite and so on. This causes extra net negative charges on the wide surface and positive charges on the thin edge of the Bentonite particles. This also determines the Bentonite particle associating and later fluid's behavior. Therefore, Bentonite particles can be aggregated (face to face connecting), dispersed (no connecting), flocculated (face to edge or edge to edge connecting), or deflocculated (disconnection of flocculated particles). Thus, the cation exchange process, cation type, and related particle connections are the base for Bentonite interaction with nanoparticles and the differences in the rheological properties.

The negative charged ions can be balanced by attracting various positive ions, such as hydrogen ions, based on covalent or ionic bonding. Mud hydration is a good example of this process. Hydration is developed based on covalent bonds, weak attractions, between the positive hydrogen ions of the water and the negative clay particle's surfaces. As a result, Bentonite's layers adsorb and trap amounts of water, thereby time-dependently swelling to the level where the forces holding these layers together become weak. Hence, the layers can be disconnected from the packages. This increase in number of particles, with the resulting increase in surface area, causes bentonite hydration (Swaco 2001). The hydration phenomena create the viscosity in the mud when there is few free water available. Figure 9 illustrates the hydration for $10 \mathrm{gm}$ of Sodium Bentonite. It is clear that the volume and surface area of the Bentonite increase after 24 hours.

Water salinity, atomic bonding type (covalent or ionic), cation types (divalent or monovalent), and sensitive chemicals such as nanoparticles affect the hydration degree. Salt water decreases the hydration. Monovalent cations cause more hydration than divalent cations because they cause less attraction between the Bentonite particles. Less particle attraction means more water capacity. 


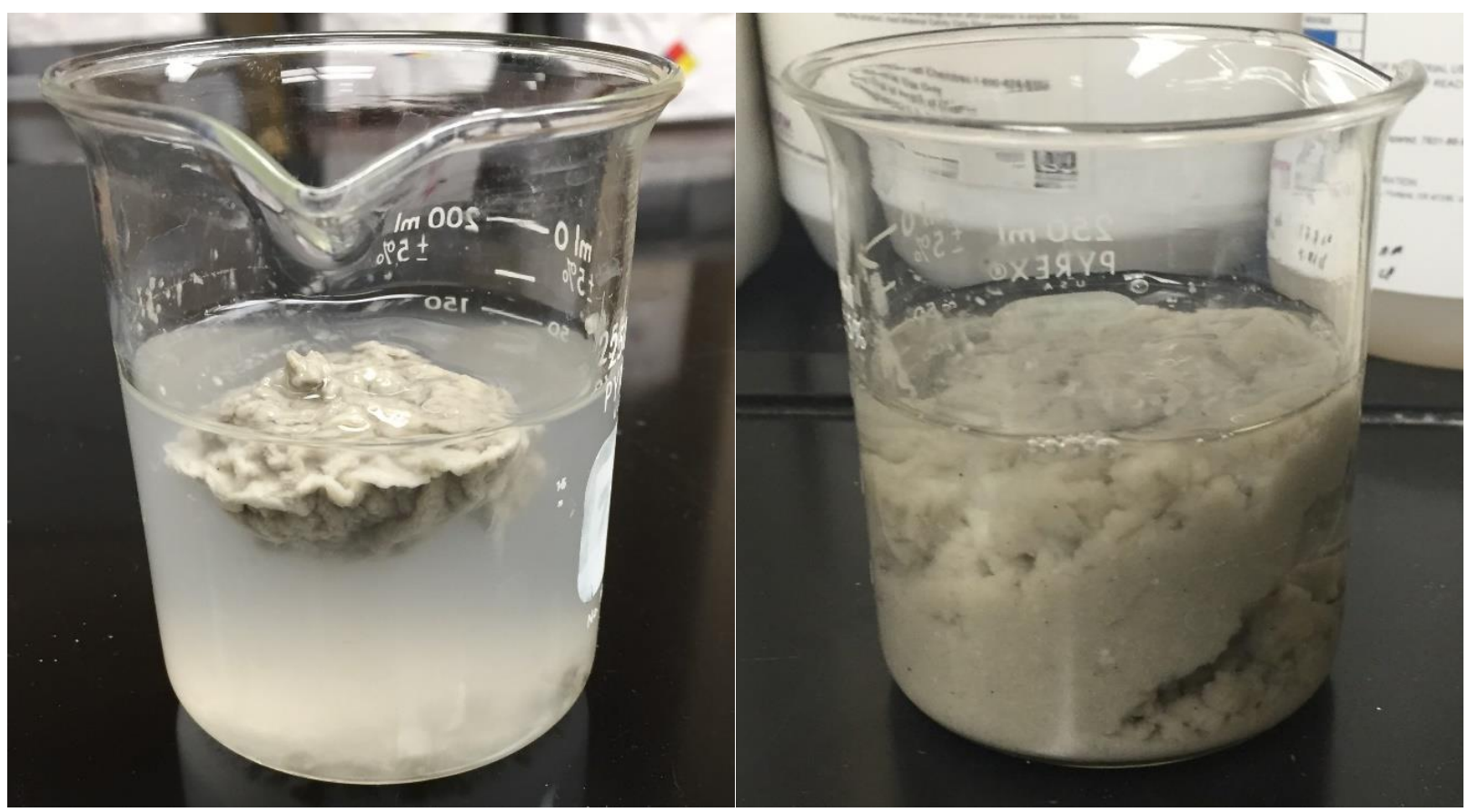

Figure 9: Bentonite hydration after 24 hours

\subsection{Rheological and Physical Properties of Water-Based Mud}

One of the major portion of this study is related to the impact of the nanoparticles on the rheological properties. Drilling mud rheology refers to the flow behavior of the mud under certain conditions such as pressure, temperature, and shear rate value. Graphically, the relation between an applied shear rate force on the fluid and the resulted shear stress can represent the flow behavior inside drill sting and annular spaces based on different models.

Shear rate refers to the mud velocity gradient generated by the mud pumps in the wellbore. Therefore, it is related to the mud pumps speed. For the lab tests, shear rates are represented or simulated by the rotation speeds per minute (RPM) of the mud viscometer. Shear rates of 600 , $300,200,100,6$, and 3 are the common rotational speeds used. Hence, higher RPM ranges (300600 ) can represent the shear rates in the drillpipe and drill bit. The moderate RPM ranges (100200) can represent the shear rates in the annulus. More so, the lowest RPM ranges (3-6) can represent the shear rates of mud inside the mud tanks. Shear stresses refer to the forces required to maintain these specific shear rates. Therefore, it is related to the mud pumps pressure loss. In the lab tests, shear stresses are simulated by the viscometer readings for the above mentioned shear rates. 
Three mathematical models simulate the relation between shear rate and shear stress for the nonNewtonian muds. Figure 10 illustrates these models. Bingham Plastic model always provide greater value of the primary force to initiate the flow, yield point, than the actual force. It shows a leaner relation between the shear rate and stress, constant viscosity with increasing shears. Also, it does not simulate the very low share rate viscosities. However, it accurately represents the rheological behavior of low weight muds and high share rate viscosities.

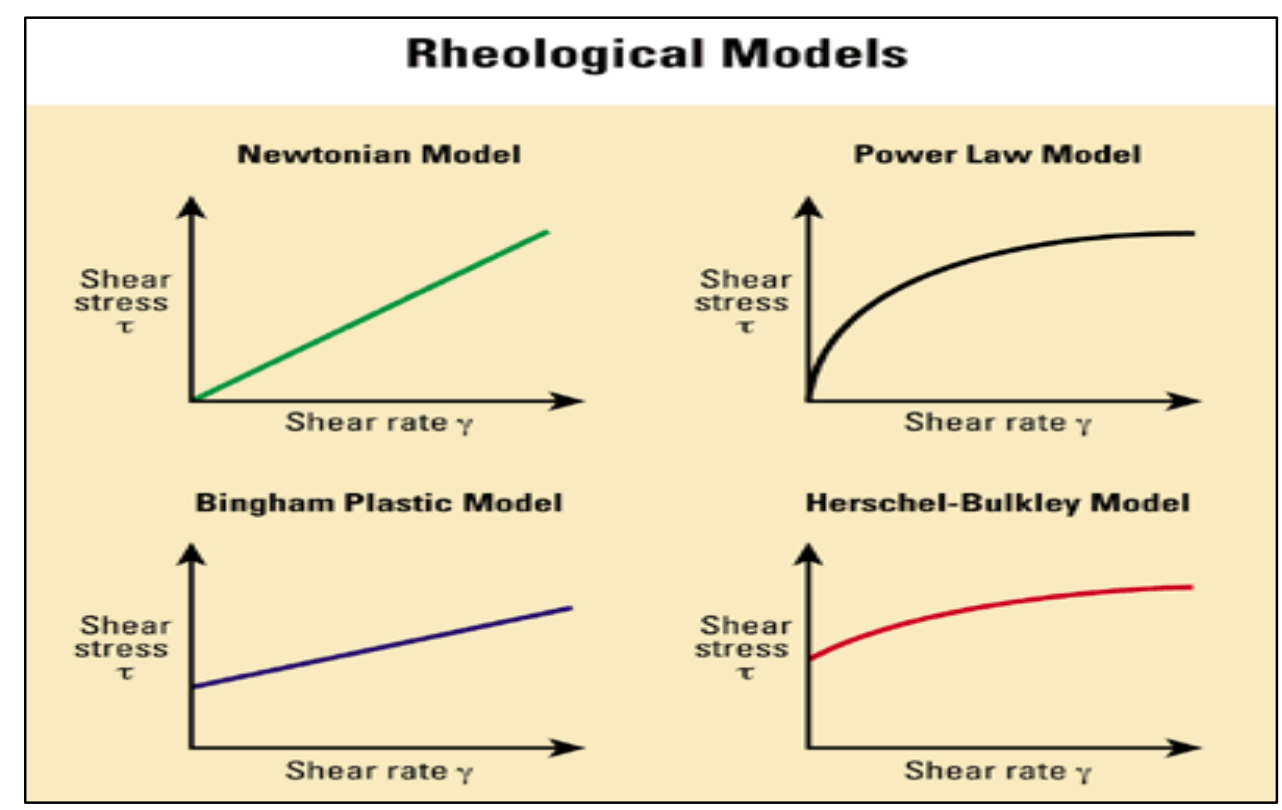

Figure 10: The rheological models (profiles) for Newtonian and non-Newtonian fluids (Drilling Formula.Com)

Power Law model is more accurate than Bingham Plastic model in representing the flow behavior. It reflects the actual relation between the shear rate and shear stress, which is not a linear. Further, it considers two indexes that help in flow simulation-flow behavior (n) and consistency $(\mathrm{K})$ indexes. However, it does not provide a value for the yield point as an initial force to start the flow. Most of the polymer muds follow this model.

The most accurate model that reflects the behavior of the water-based mud, as a non-Newtonian fluid, under different shears is the Herschel-Bulkley model. This model considers the yield point, flow behavior and consistency indexes. Newtonian fluids, such as water, are represented by Newtonian model. This is not a suitable model for the drilling muds because of the linear relation between the shears and no representation for the yield point. 
Based on the shear rate-stress relation, certain measurements and calculations can be determined and then the rheological properties of the mud can be driven. Generally, viscosity is the most well-known term related to the rheology of the mud. Plastic viscosity, yield point, apparent viscosity, effective viscosity, low shear rate viscosity, and gel strength are the major terms of viscosity that represent and describe the rheology of the water-based mud. The mud density represents the physical property of the mud that can be measured by the Mud Balance.

Considering a well's uniqueness, these properties control different aspects for perfect drilling operation such as drilled cuttings suspension and surface-removing, maximum hydraulic energy transfer from the mud pump to the drill bit with less pump pressure, formation pressure controlling, wellbore stability, etc. Not all these properties have positive impact on these aspects. Hence, the mud rheological and physical properties need to be balanced to optimize the mud performance and thereby fulfilling the previously explained functions.

\subsubsection{Plastic Viscosity}

Plastic viscosity is the resistance to flow caused by primarily the frictional forces and secondarily by the electro-chemical attractive forces in the mud. It is a function of the mud's three phases as the frictional force occurs between the solids themselves, the solids and liquid particles, and the liquid particles themselves. Thus, it is affected by the size, shape, concentration, distance, and distribution of the solids consciously added to the mud such as Barite, drilled cuttings, and other chemicals. In addition, the high Bentonite hydration leads to an increase in the plastic viscosity because it reduces the free water and the distance between the particles in the water-based mud leading to an increase in the solids fraction (Swaco 2001).

In all cases, plastic viscosity must be decreased to the lowest value in order to enhance the drilling performance. High plastic viscosity results in a slow rate of penetration, excessive overall heat, wear \& tear on the downhole and surface equipment, high pump pressure, and poor energy at the drill bit, thereby causing insufficient hole cleaning. Particularly, these problems are well-known in the directional drilling.

Replacing the currently used chemicals featuring micro/macro size and high concentration with tiny size and very low concentration chemicals to perform the same purpose can considerably 
reduce the plastic viscosity. Also, keeping the hydration in reasonable levels by using the nanoparticles reduce the plastic viscosity. Additionally, nanoparticles help in lubricating the movement of the solids, thereby reducing the fractional force between them.

\subsubsection{Yield Points-Bingham and Actual Yield Points}

Yield Point is the measure of resistance to flow caused by mainly the electro-chemical attractive forces and secondarily by the fractional forces between all particles dispersed in a moving mud. Based on the Herschel-Bulkley and Bingham models, yield point is the force required to initiate the flow at zero shear rate. For the non-Newtonian water-based muds, it is used as indicators for the drilled cuttings carrying capacity and for the shear thinning of the fluid. Lower yield point reflects lower carrying capacity, but higher shear thinning which is desirable. On the other hand, higher yield point reflects higher carrying capacity, but it leads to high pump pressure loss.

The yield point is a function of repulsive or attractive forces occurred between the Bentonite particles. Consequently, it depends on the Bentonite concentration, particle distances, hydration level, and flocculation due to various cations adsorption. It increases in the flocculation cases due to the high attractive forces that lead to small distances between the particles; for example, in contamination with cement - $\mathrm{a} \mathrm{Ca}^{+2}$ resource - and increasing the $\mathrm{pH}$. It also increases when the solids concentration increases in the mud which leads to closed-particles movement. Drilling in shale increases the yield point because of the positive charges coming from the shale contribute in increasing the yield point. However, it can be lowered by introducing any anionic chemicals that neutralize the positive charges on the edges of Bentonite particles.

Based on that, yield point has to be balanced by proper amounts of chemicals in order to optimize the drilling operation. Addition of water will not control the yield point because it will not reduce the attractive force. In addition, it negatively affects the filtration and the density of the mud. Nanoparticles as electrochemically charged particles are used to increase or decrease the yield point significantly. Based on the previously discussed models, there are two kinds of yield points: Bingham and Actual yield points. Actual yield point is the more accurate value that represents force required to initiate the flow. It can be obtained from Herschel-Bulkley model. 


\subsubsection{Gel Strengths}

Like the yield point, gel strength represents the attractive forces occurring between water-based mud particles, but under static conditions - when the mud pumps are off during the drillpipe connection times. Therefore, it is a measure of the drilled cuttings and solids suspension capacity and the pump pressure loss when the mud pumps resume displacing the mud. Very high gel strength results in high pump pressure required to move the mud. This will increase the backpressure exerted on the exposed formations by the mud, thereby breaking them. In addition, it increases surge and swap pressures, allows the air to trap in the mud, and restricts running in hole with light equipment such as well logs. On the other hand, the very low gel strength causes solids and cuttings settling in the wellbore annulus, which is critical in the horizontal wells.

Gel strengths can be classified into three types as fragile, progressive, and high-flat gels (Hughes 2006). Figure 11 illustrates the development of these types. It seems only fragile gel is desirable in the suspension and pressure loss functions because there is no big gap between 10 seconds and 10 minutes' gel values. In this case, minimum pump pressure is required to resume the circulation of the mud with less energy.

Gel Strength is a function of the Bentonite hydration, flocculation, clay solid concentrations and types, static time (API test periods; 10 seconds and 10 minutes), temperature, charges density on the surface of these solids, and charges and ions of the continuous phase. Hence, gel strength increases in the flocculation cases because of the small spaces between the particles that leads to high attractive forces; for example, in the contamination cases with cement and in the high $\mathrm{pH}$ mediums. Drilling in shale formations increases the gel strength because the positive charges coming from shale will increase the total charge density in the mud. 


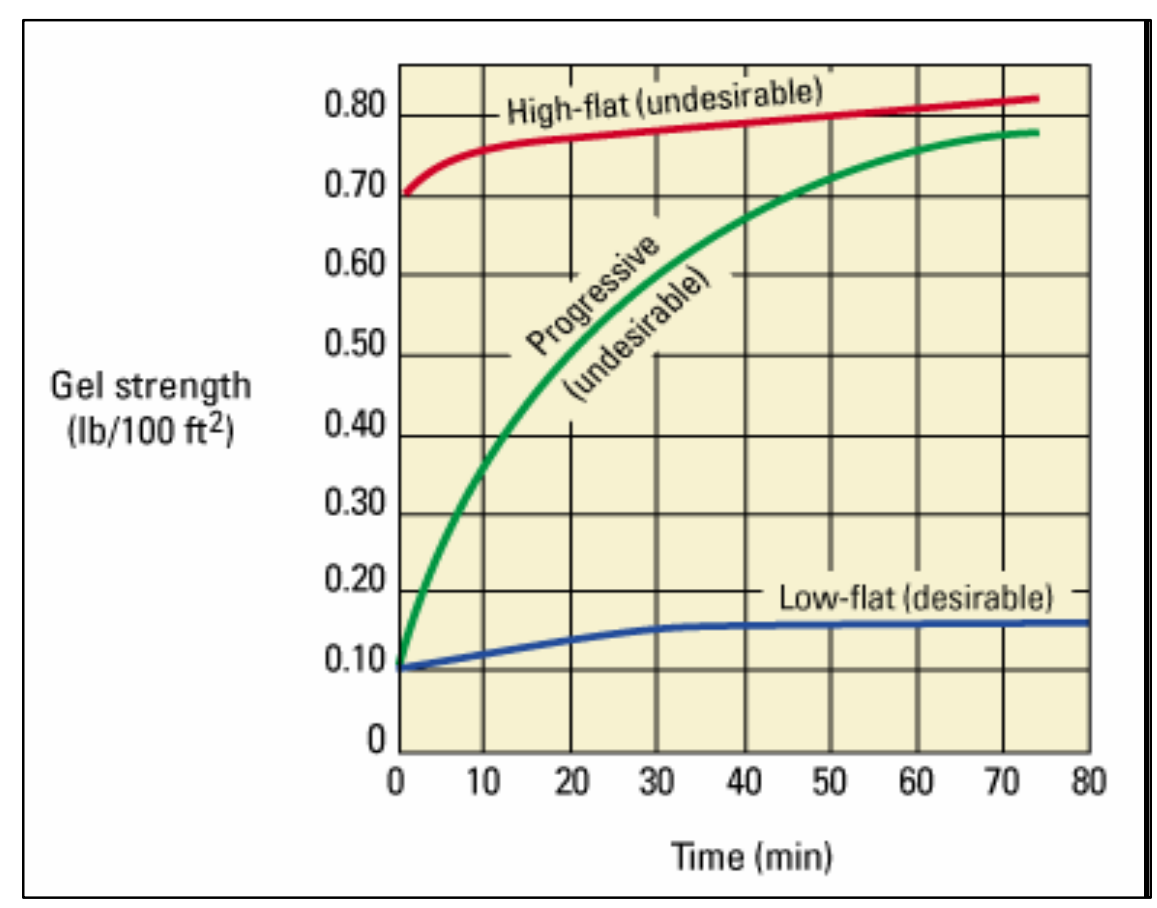

Figure 11: Mud gel strength types (Hughes 2006)

Therefore, controlling the gel strength and maintaining the fragile type is very important for high performance drilling operations. Gelation should not exceed the necessary levels that are required for cutting and solid suspensions. Any chemical allowing or preventing the interaction between the mud particles will increase or decrease the gel strength, respectively. Since gel strength and yield point are directly linked, the same treatments or chemicals such as nanoparticles will impact them in the same trend.

\subsubsection{Apparent Viscosity}

Apparent viscosity of a water-based mud is an image of combination of plastic viscosity and yield point and it increases when they increase and decreases when they decrease (Amoco 1994). It equally depends on the fractional and attractive forces between the mud particles and the chemicals used to treat the yield and/or plastic viscosity will impact the apparent viscosity in the same trend. It is used to describe the nature of the current flow and the history of the past flow of mud (Swaco 2001). 


\subsubsection{Effective Viscosity}

Unlike Newtonian fluids, non-Newtonian fluids do not have constant viscosity at different shear rates. Therefore, the effective viscosity is used to describe this property. It is a calculated value that reflects the resistance to flow of the fluid at specific shear rates. In other words, it is a shear rate/stress-dependent viscosity (Rabia 2002). Also, effective viscosity implies the shear thinning process in the water-based muds. For shear thinning behavior, the well-designed mud reflects high viscosity at low shear rates and low viscosity at high shear rates. In this case, low shear rates promote strong connection between the Bentonite particles. High shear rates associated with easy breaking of the bonds between particles. This means no additional force is needed to continue the flow and it is the reason behind the nonlinear relation between the shear stress and shear rate for the muds.

Shear thinning is very desirable behavior that supports drilled cuttings transportation and suspension in the low flow rate-areas such as wellbore annulus. On the other hand, it is very important to use mud with low effective viscosity through the drill bits' nozzles for perfect bit hydraulics and less energy losses (Hughes 2006).

The opposite behavior is named shear thickening which is not desirable in the field. It increases the pressure required to circle the mud in a well and reduces the efficiency of the solids control equipment at the surface. Therefore, effective viscosity has to be enhanced to optimize the shear thinning of the mud. In this study, nanoparticles are used to improve the shear thinning of the water-based mud.

\subsubsection{Mud Density}

Mud density as a physical property is the weight in grams per cubic centimeters or pounds per gallons of mud. Mud density controls the hydrostatic pressure in a wellbore that in turn controls many critical aspects. Lost circulation, blowout, formation fracturing, wellbore stability, drilled cuttings and Barite sagging, and rate of penetration are functions to the mud density (hydrostatic pressure). Mud density and rheology as directly related properties have to make balance between these functions. It should be restricted to the minimum value that fulfils them. Also, mud density 
is a function of the downhole temperature, pressure, weighting materials, and invasion of formation fluids such as gas.

Chemicals used with low concentrations do not affect the mud density values. Hence, low concentrations of nanoparticles will keep the same density of the untreated muds. However, high mud density can be minimized by dilution with water, which is not the correct way, or by using available mechanical processes in the rig site, such as Shale Shakers, de-Sander, and de-Silter machines.

\subsubsection{Mud pH (Hydrogen Ion Concentration)}

The $\mathrm{pH}$ value is defined as the negative log of the hydrogen ion $\left(\mathrm{H}^{+}\right)$concentration in the waterbased mud $\left(\mathrm{pH}=-\log \left[\mathrm{H}^{+}\right]\right)$. On the other hand, hydroxyl ions $\left(\mathrm{OH}^{-}\right)$also exist in the mud and work against hydrogen ions. The hydrogen ions represent the acidity while the hydroxyl ions represent the basicity of the mud. Hydroxyl ions concentration and then $\mathrm{pH}$ values usually increase simultaneously when the base chemicals are added to the mud, such as $\mathrm{NaOH}$. Contrary, the $\mathrm{pH}$ decreases when the hydrogen ions concentration increase. For example, the $\mathrm{pH}$ decreases throughout drilling a formation containing $\mathrm{H}_{2} \mathrm{~S}$, anhydrite, and acid gas. The maximum hydroxyl ions concentration leads to a $\mathrm{pH}$ of 14 , while the maximum hydrogen ions concentration leads to a pH of 0 (Hughes 2006). Both cases result in poor drilling fluid performance.

The chemical treatments and the resulted rheological properties are governed by muds' $\mathrm{pH}$. Hence, Bentonite interactions are controlled by the $\mathrm{pH}$. It is well-known that mud components interact efficiently in base environments and poorly in acidic environments (Rabia 2002). The optimum $\mathrm{pH}$ values resulting in high mud performance have been found in the range of 8 to 10 . Values less than the optimum values, acidic environment, cause equipment corrosion and diminish the rheological properties. On the other hand, the higher $\mathrm{pH}$ values result in high gel strength, viscosity, yield point, mud flocculation, and high filtration, which are undesirable properties. Figure 12 illustrates the impact of different $\mathrm{pH}$ values on the viscosity of the mud. 


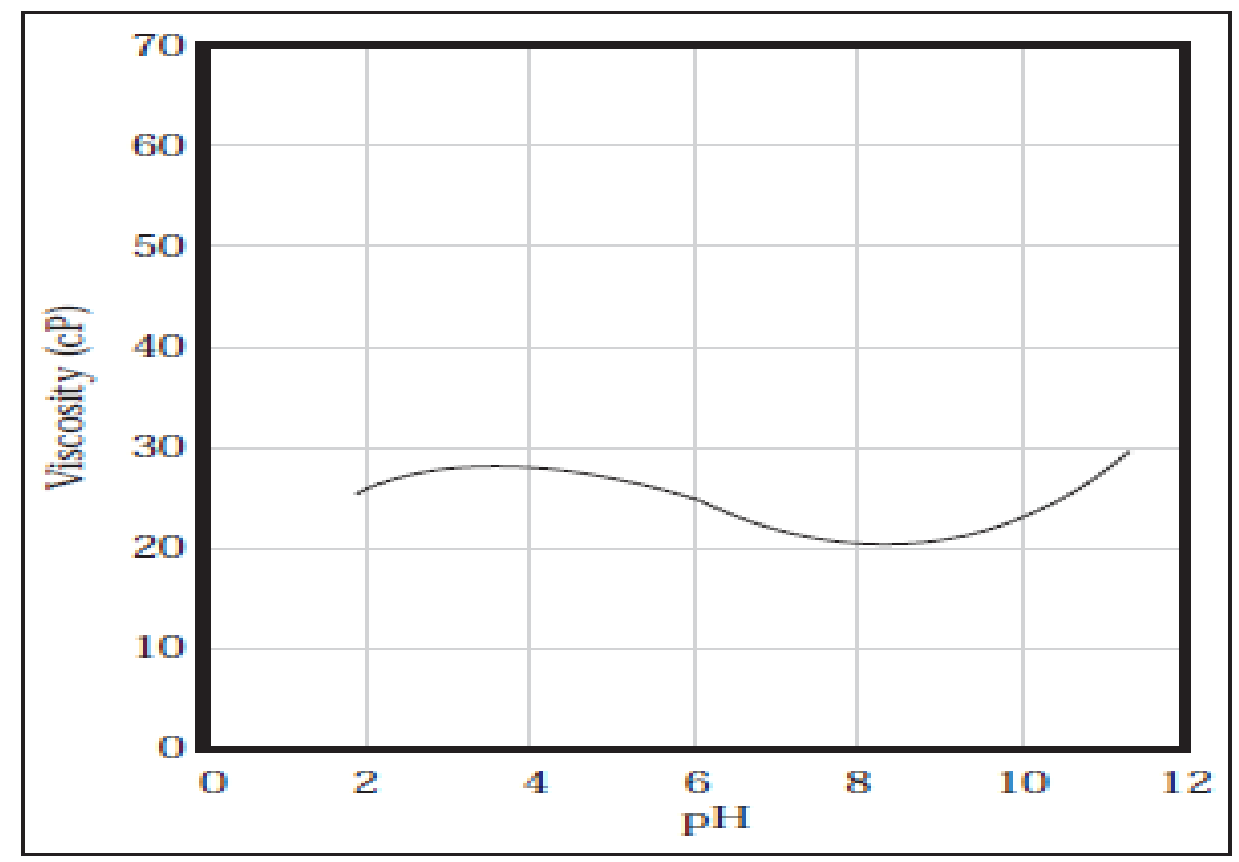

Figure 12: The impact of mud pH on the viscosity of the mud (Swaco 2001)

The $\mathrm{pH}$ of the mud is a function of downhole temperature and chemical additive types such as $\mathrm{NaOH}, \mathrm{KOH}$, and $\mathrm{Mg}(\mathrm{OH})_{2}$. These hydroxyl ion-rich chemicals are used to increase the $\mathrm{pH}$ to the optimum levels. On the other hand, the $\mathrm{pH}$ can be decreased when acidic materials are added to the mud such as lignosulphonate, lignite, and hydrochloric acid. The $\mathrm{pH}$ is a function of different undesirable contaminants that invade the mud during different drilling operations such as cement contaminant $\left(\mathrm{Ca}(\mathrm{OH})_{2}\right)$ after the cement jobs. This will result in uncontrolled elevation of $\mathrm{pH}$ and thereby negatively impact the rheological properties of the mud. However, some formations having anhydrite $\left(\mathrm{CaSO}_{4}\right)$ contaminate the mud by decreasing the $\mathrm{pH}$. As acidic or basic chemicals, nanoparticles can be used to control the $\mathrm{pH}$ as needed.

\subsection{Filtration Properties}

Mud filtration is the splitting of the continuous phase (water) of water-based mud from the inert and reactive phases and then passing through permeable mediums such as filter papers or drilled formations. In this process, a specific pressure such as the API lab pressure (100 psi) or the mud hydrostatic pressure forces the water to pass through the permeable mediums. However, it cannot force the solid to pass through the mediums. As a result, the solids deposit on the mediums and form a mudcake. The amount of the escaped water, with different soluble ions such as salt and 
chemicals, is known as filtrate loss. The filtrate loss occurring at the initial time-at the beginning of the filtration process - is named as spurt loss. Filtration properties refer to the physical and chemical properties of the filtrate loss, the spurt loss amount, and the mudcake thickness and structure. Optimizing these properties is very important to overcome numerous problems related to the drilling mud.

Filtration properties are functions of several aspects of both drilling mud and drilled formations. For example, the formation pressure that is the basis of the hydrostatic pressure, permeability and porosity are directly related to the amount of filtrate loss and its associated mudcake. Higher values of these characteristics result in higher spurt and filtrate losses and thicker mudcake. For the drilling mud, mud density (hydrostatic pressure), type and temperature of continuous phase, clay solids concentration and size, clay types (Bentonite or Attapulgite), and particle links of the mud control these properties.

High mud density increases the amount of the loss and thickness of the mudcake. Oil-based mud results in optimum filtration properties. Bentonite-based mud with plate-like surface particles reduces the filtration and the thickness of the mudcake more than the Attapulgite-based mud. This type of clay consists of needle-like particles that form mudcake with higher permeability. More so, the flocculated mud results in higher filtration and thicker mudcake because of the poor particle distribution and arrangement due to the flocculation, edge to edge or edge to surface particles connection. Moreover, the filtration properties are directly proportional to the filtration time.

Poorly designed mud, with high filtrate and spur losses and thicker mudcake, leads to several problems that have been explained previously. Studying the impact of nanoparticles on the filtration properties as a second objective of this research is one of the efforts to control these properties and to minimize the mud related problems. The basic function of the nanoparticles is to plug and thereby developing low permeability and very thin cake in order to prevent the water invasion to the exposed formations. Also, the addition of nanoparticles should neutralize the electrochemical charges on the clays. This overcomes the attraction that results in edge-to-edge and/or edge-to face bonding between clay particles, namely flocculation. That means 
nanoparticles simultaneously work as deflocculant and as plugging agent to seal the spaces between the flattened clay platelets.

\subsection{Mud Hydraulics}

The resistance to flow of mud in the drill string, annular space, and drill bit's nozzles has to be overcome by a minimum amount of power provided by the mud pump. It is expressed by pressure loss throughout the system. Keeping the overall pressure loss at minimum values and the flow rate at high levels save the energy and reduce the drilling cost. The pressure loss is dependent on various parameters such as the mud rheological properties, flow regimes, and wellbore and downhole tool geometries. This study tries to minimize the pressure loss by enhancing the rheological properties of the mud.

Mud hydraulics is defined as the management of the pressure loss based on the mud behavior. In other words, hydraulics means transferring maximum energy to the drill bit. Thus, mud rheology and hydraulics are related aspects since they deal with flow behavior of the mud. Basically, the flow behavior is controlled by the rheological properties. Hence, optimum rheological properties result in an optimum hydraulic system. Therefore, enhancing the mud flow behavior by means of rheological properties have to be achieved before optimizing the hydraulics of the mud. Based on that, hydraulics of the mud can be a perfect reference to the mud treatments.

Hydraulics optimization considers various parameters that need to be balanced based on proper rheological properties, assuming the mud density is constant at the lowest and safest level. These are well blowout control, surge and swab pressures, hole cleaning, pump pressure, equivalent circulation density (ECD), and pressure drop across the drill bit. Good hydraulics are developed based on minimum rheological properties (viscosities) without stimulation for the pressurized formations, in order to prevent the blowout. The same levels of mud viscosity should be used to prevent swab and surge pressures and minimize pump pressure loss and ECD. Simultaneously, optimum hole cleaning should be considered based on the mud viscosity achieving it. This study focuses on studying the impact of the nanoparticles as rheological modifiers on the rheological properties of the mud and then on the hydraulics. For the hydraulics, the ECD and the pump pressure loss are the interesting items. 


\section{Chapter 4: Research Methodology}

Based on the objective of this study, the lab experiments include the rheological and the filtration tests for several water-based mud samples. These tests are classified into two sections. The first section is the measurement of the rheological and filtration properties for low $\mathrm{pH}$ mud samples with and without nanoparticle additives. The second section is the measurement of rheological and filtration properties for high $\mathrm{pH}$ mud samples with and without nanoparticle additives.

For both sections, the water-based mud samples without nanoparticles are regarded as the basic samples, and they are used as references for comparison purposes. Based on the comparisons with the basic muds, the best concentrations are determined. For the hydraulic investigation, the measured rheological data is used to study as inputs to determine the impact of the nanoparticles on the equivalent circulation density and the pressure loss in a $9000 \mathrm{ft}$ long $12 \frac{1 / 4}{4}$ directional wellbore by using the Drillbench Software.

\subsection{Experimental Apparatuses}

The experiments were carried out using API standard devices, which are commonly used by mud engineers for both lab and field measurements. These devices are available in the Mud Laboratory of the Petroleum and Natural Gas Engineering of West Virginia University.

Figure 13 shows the ultrasonic processor (A\&B), digital weighing scale mud (C), and multimixer (D) used in the preparation of the mud samples throughout the experiments. Sonic VCX130PB Ultrasonic Processor was used to mix the nanoparticles with the water-based muds in order to avoid nanoparticles aggregation due to using the mechanical blender. Also, it is impossible to mix nanoparticles with any liquid by using the typical mixers with rotation technique, due to the volatilization of the particles during the pouring process. Figure 13 (A\&B) also illustrates the mixing process of the nano particles with water. 


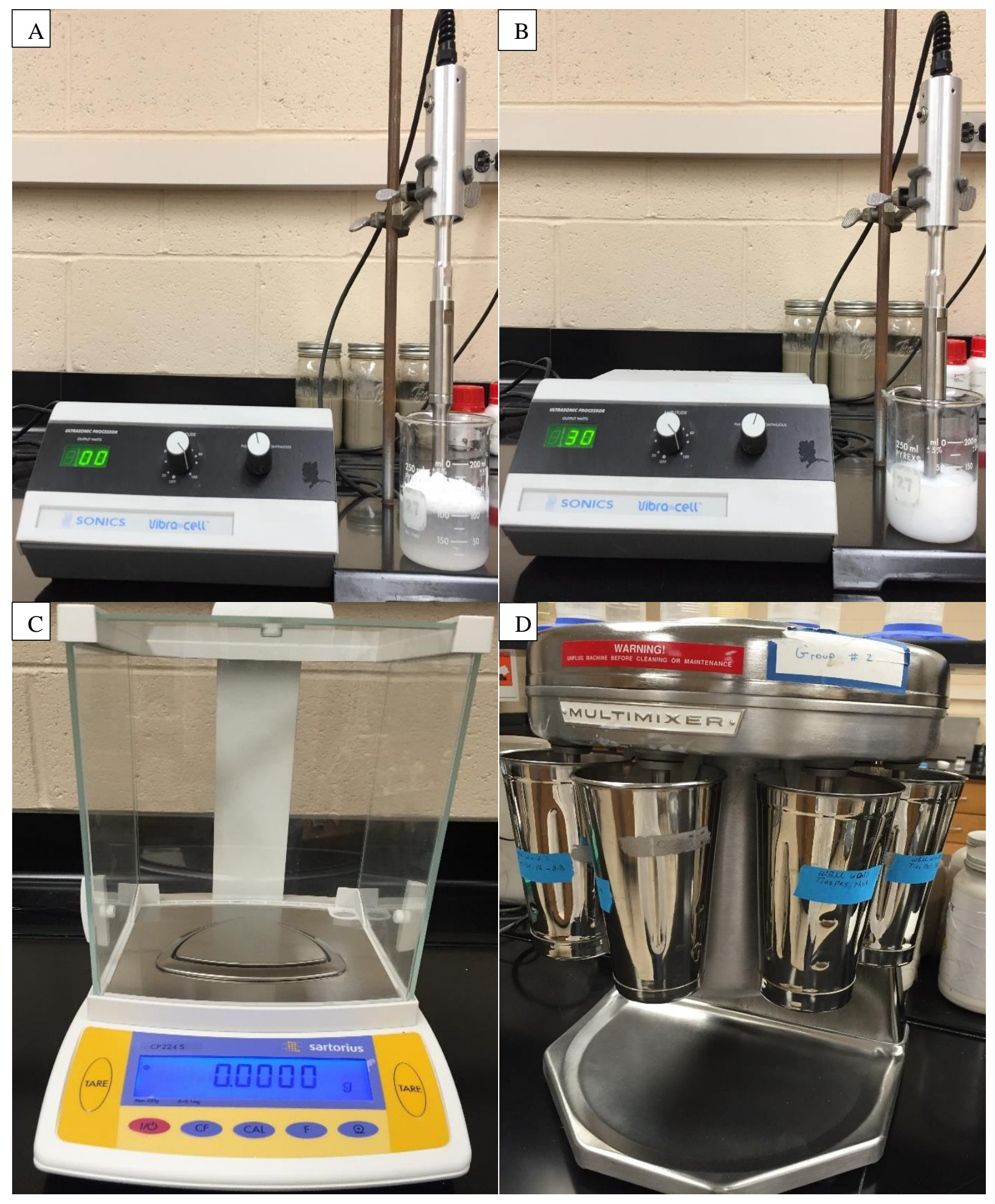

Figure 13: The Sonic VCX130PB Ultrasonic Processor, Digital Weighing Scale, and Multimixer

For the mud $\mathrm{pH}$ and the density measurements, the Digital Pocket $\mathrm{pH}$ Meter and the well-known Mud Balance shown in the Figure 14 were used. 

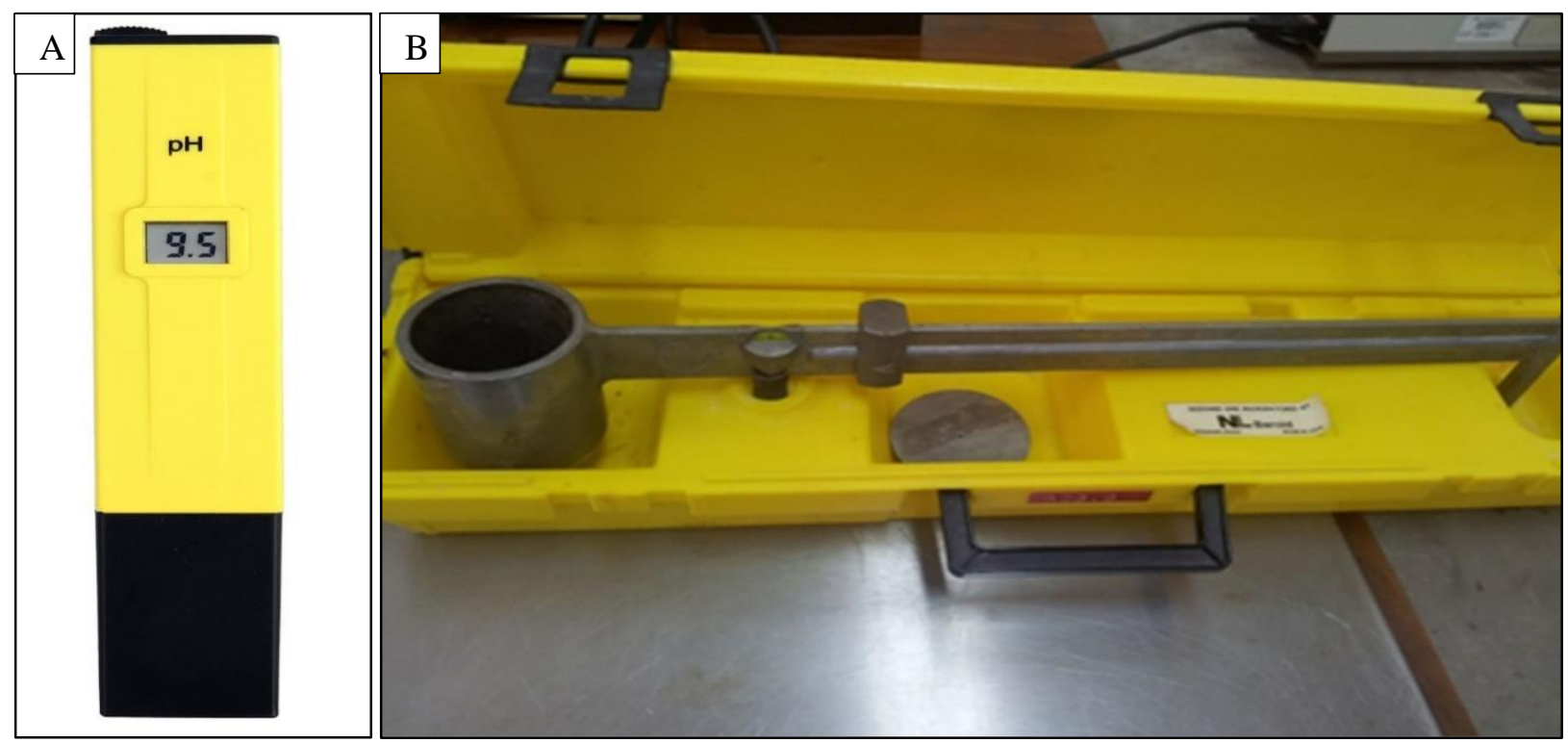

Figure 14: The Digital Pocket pH Meter and the Mud Balance

For the rheological properties measurements, The Fann RheoVADR® Variable Automated Digital Rheometer shown in the Figure 15 was used.

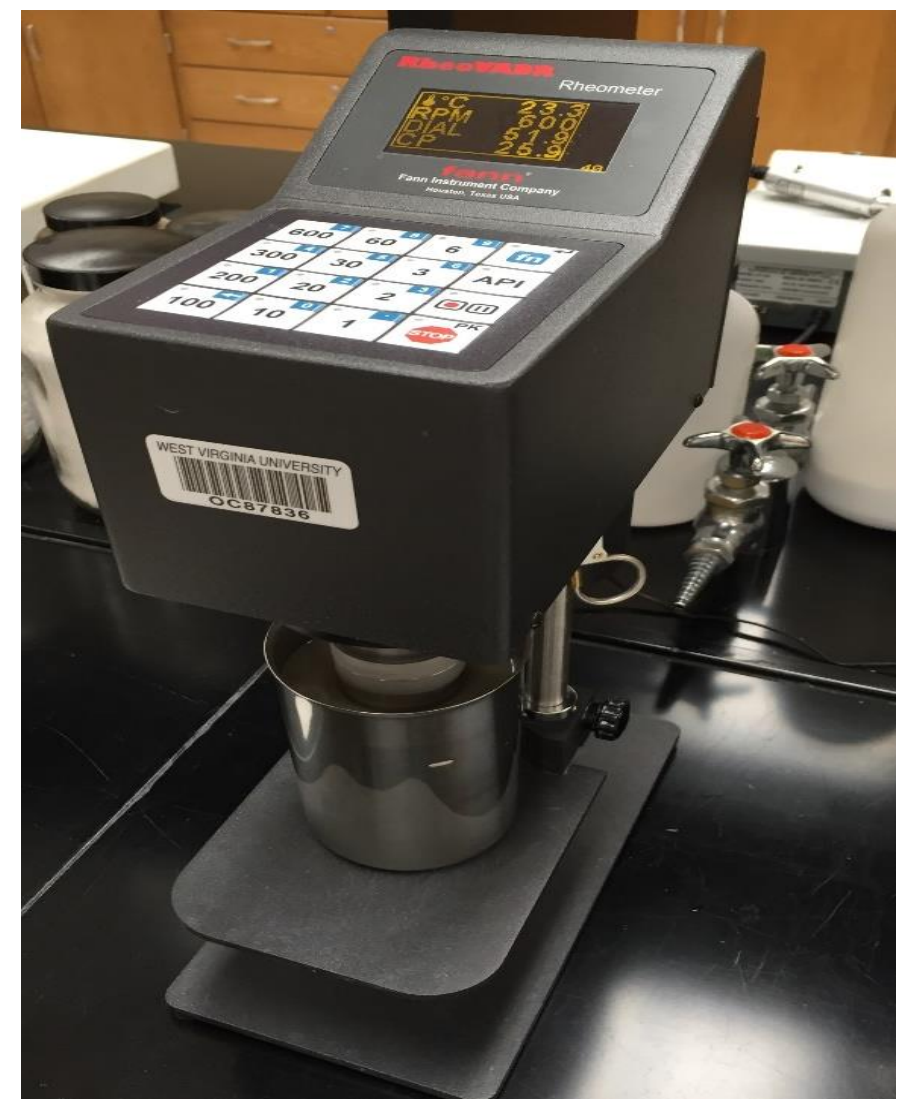

Figure 15: The RheoVADR® Variable Automated Digital Rheometer 
Figure 16 (A\&B) shows the devices used for the filtration measurements. The Multiple Unit Filter Press (A) was used, which permits simultaneous running of six filtration tests. The Dial Caliper gage (B) was used to measure the mudcake thickness. The API filter papers (C) were used to collect the mudcakes.

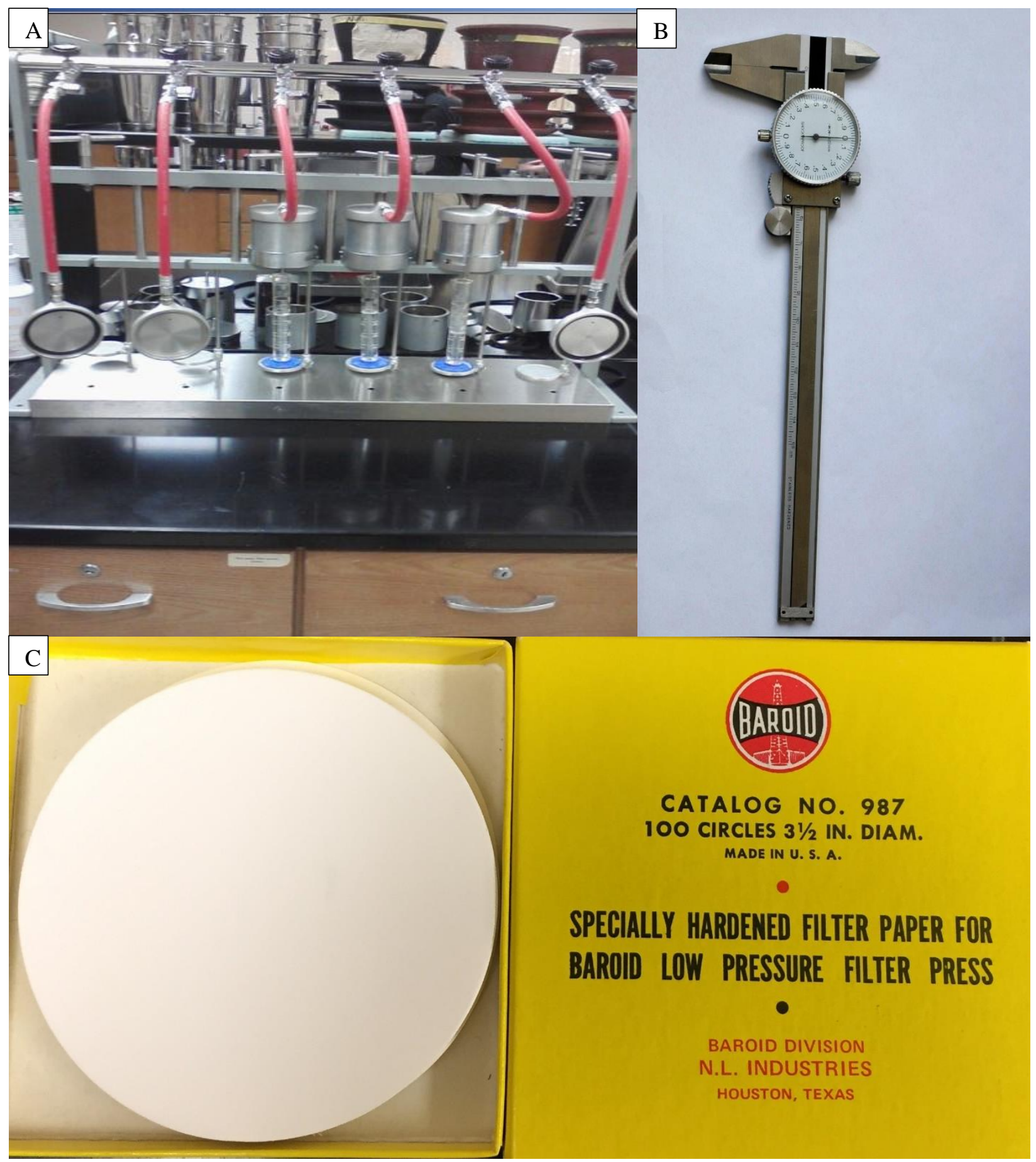

Figure 16: Baroid multiple unit filter presses, dial caliper gauge, and filter paper 


\subsection{The Materials Used in the Experiments}

The basic mud samples were prepared by mixing the common raw materials used for waterbased mud preparation such as Bentonite, Barite, and water, and if necessary, the caustic soda $(\mathrm{NaOH})$ was added to increase the $\mathrm{pH}$ in high $\mathrm{pH}$ mud systems. The Aquagel (Bentonite) was used in this experimental work. It is important to mention that the basic samples don't have any other chemicals. That allows to investigate the impact of the nanoparticles on the mud properties without the side effects of the chemicals. Table 1 shows the composition of the basic water-based mud samples for both systems.

\begin{tabular}{|l|c|c|}
\hline \multicolumn{1}{|c|}{ Materials Used } & Low $\mathrm{pH}$ Water-Based Mud & High $\mathrm{pH}$ Water-Based Mud \\
\hline Water (cc) & 500 & 500 \\
\hline Bentonite (\% by weight) & 5.6 & 5.6 \\
\hline Barite (\% by weight) & 5.2 & 5.2 \\
\hline Caustic Soda (NaOH) (gm) & 0 & 0.5 \\
\hline
\end{tabular}

Table 1: The raw materials used to prepare basic water-based muds-low and high $\mathrm{pH}$ mud systems

Furthermore, four nanoparticle types were used throughout the experiments to treat the basic mud samples for both mud systems. They are cationic and anionic nanoaluminum, anionic nanosilica, and anionic nanotitanium. Each treated sample has one of these nanoparticles with concentrations of $0.1 \% \mathrm{wt} / \mathrm{wt}$, or $0.3 \% \mathrm{wt} / \mathrm{wt}$, or $0.5 \% \mathrm{wt} / \mathrm{wt}$, or $0.7 \% \mathrm{wt} / \mathrm{wt}$ for each run. The nanoparticles were provided by Evonik Corporation. The following Table 2 shows the nanoparticles' specifications. Nanoparticles used in this study are shown in Figure 17. 


\begin{tabular}{|l|c|c|c|c|}
\hline Trade Name & IDISIL SI 0518 & $\begin{array}{c}\text { AERODISP W } \\
740 \mathrm{X}\end{array}$ & $\begin{array}{c}\text { AERODISP W } \\
640 \mathrm{ZX}\end{array}$ & $\begin{array}{c}\text { AEROXIDE Alu } \\
\text { C }\end{array}$ \\
\hline Chemical Name & Silica Dioxide & $\begin{array}{c}\text { Titanium } \\
\text { Dioxide }\end{array}$ & $\begin{array}{c}\text { Aluminum } \\
\text { Dioxide }\end{array}$ & $\begin{array}{c}\text { Aluminum } \\
\text { Dioxide }\end{array}$ \\
\hline Physical State & Colloidal & Colloidal & Colloidal & Powder \\
\hline Color & Milky & White & Milky & White \\
\hline Density (gm/cc) & 1.106 & 1.41 & 1.38 & 3.27 \\
\hline $\begin{array}{l}\text { Particle Size } \\
(\mathrm{nm})\end{array}$ & $5 \mathrm{~nm}$ & $100-200 \mathrm{~nm}$ & $100-200 \mathrm{~nm}$ & $100-200$ \\
\hline $\begin{array}{l}\text { Surface } \\
\text { Charging }\end{array}$ & Negative & Negative & Negative & Positive \\
\hline \begin{tabular}{l} 
pH \\
\hline
\end{tabular} & 10 & $6-7$ & $6-9$ & 7 \\
\hline
\end{tabular}

Table 2: Nanoparticles' physical and chemical properties

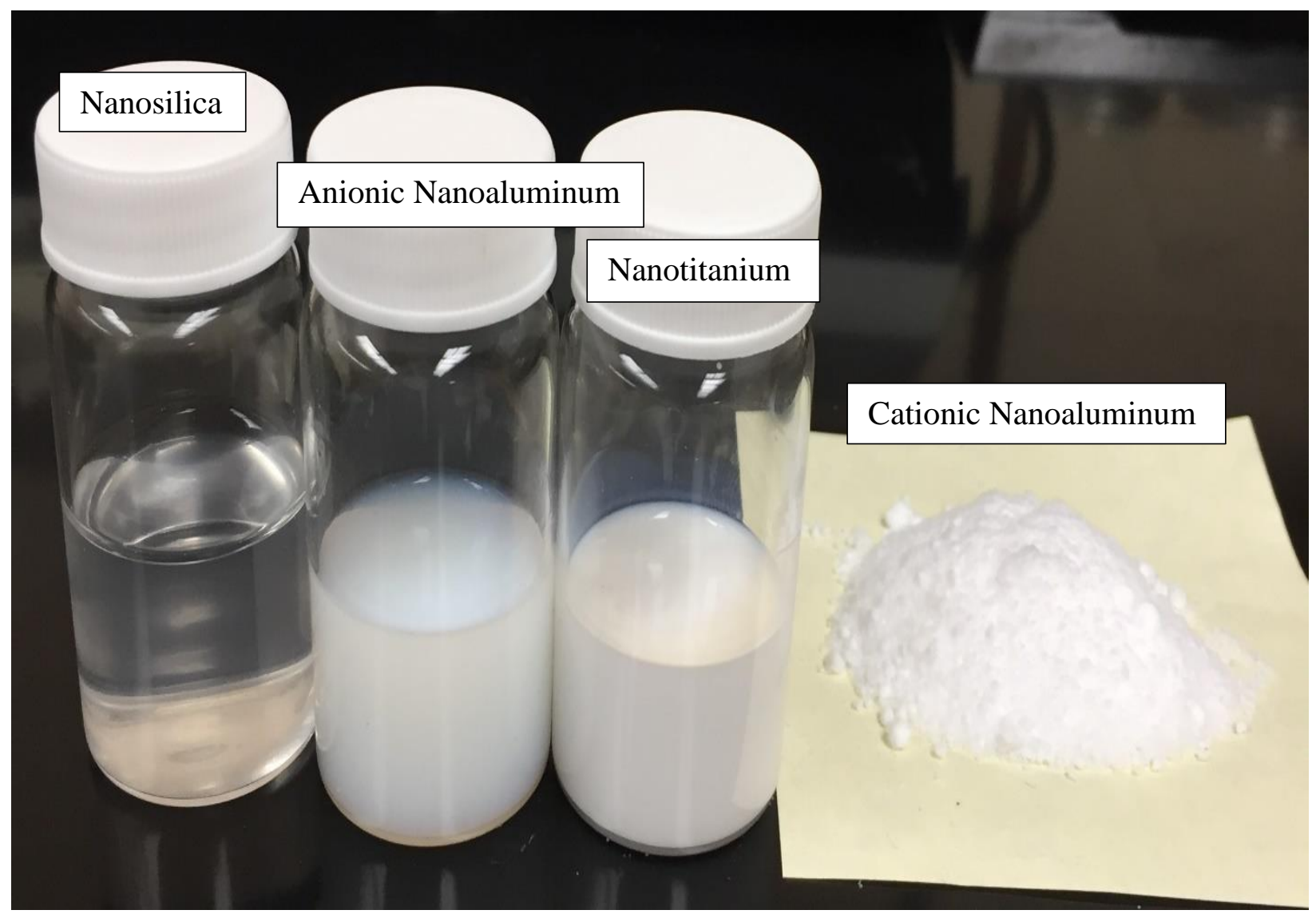

Figure 17: Samples of the nanoparticles used in study 


\subsection{Mud Samples Preparation}

\subsubsection{Basic Water-based Mud Samples Preparation}

Each basic water-based mud sample was prepared at lab conditions according to the following procedure:

1. First, $500 \mathrm{cc}$ of water was poured into the multi-mixer's cup. The cup was placed in the mixer then the mixer was turned on.

2. While the mixture was blending, $32 \mathrm{gm}$ of Bentonite was gently poured into the cup.

3. In a similar step, $29 \mathrm{gm}$ of Barite was weighed and poured.

4. The mixture was blended for 15-20 minutes until a homogenous solution was obtained.

5. The mud density was measured by the mud balance. The desired density was $9 \mathrm{gm} / \mathrm{cc}$.

6. For Bentonite hydration and expansion, the samples were kept in closed bottles under static conditions for at least 6 hours.

7. For the high $\mathrm{pH}$ system, $0.5 \mathrm{gm}$ of caustic soda was added in order to increase the $\mathrm{pH}$ from 9.4 to more than 11.4.

The following Table 3 summarizes the above-mentioned steps.

\begin{tabular}{|c|c|c|c|c|c|c|c|c|c|c|}
\hline $\begin{array}{c}\text { Continuous } \\
\text { Phase }\end{array}$ & \multirow{2}{*}{\multicolumn{4}{|c|}{ Dispersed Phase }} & \multicolumn{4}{|c|}{ Inert Solids (Unreacted Materials) } & \multicolumn{2}{|c|}{$\begin{array}{c}\mathrm{NaOH} \\
(\mathrm{gm})\end{array}$} \\
\hline Water (cc) & & & & Bentonite & \multicolumn{4}{|c|}{ Barite } & $\begin{array}{c}\text { Low } \\
\text { pH }\end{array}$ & $\begin{array}{c}\text { High } \\
\text { pH }\end{array}$ \\
\hline \multirow{4}{*}{500} & $\begin{array}{c}\text { Weight } \\
\text { (gm) }\end{array}$ & $\begin{array}{c}\text { S. } \\
\text { Gravity }\end{array}$ & $\begin{array}{c}\text { New } \\
\text { Density } \\
\text { (lb/gal) }\end{array}$ & $\begin{array}{l}\text { New } \\
\text { Vol. } \\
\text { (cc) } \\
\end{array}$ & $\begin{array}{c}\text { Weight } \\
\text { (gm) }\end{array}$ & $\begin{array}{c}\text { S. } \\
\text { Gravity }\end{array}$ & $\begin{array}{c}\text { Final } \\
\text { Density } \\
\text { (lb/gal) }\end{array}$ & $\begin{array}{c}\text { Final } \\
\text { Vol. } \\
\text { (cc) } \\
\end{array}$ & \multirow{4}{*}{0} & \multirow{4}{*}{0.5} \\
\hline & 32 & 2.65 & 8.65 & 511.9 & 29 & 4.2 & 9 & 519 & & \\
\hline & \multicolumn{4}{|c|}{ \% wt. of Bentonite in the Mud } & \multicolumn{4}{|c|}{$\%$ wt. of Barite in the Mud } & & \\
\hline & \multicolumn{4}{|c|}{5.6} & \multicolumn{4}{|c|}{5.2} & & \\
\hline
\end{tabular}

Table 3: The initial composition of the basic water-based muds 


\subsubsection{Preparation of Water-based Nanomud Samples}

In this part of the preparation, the above-mentioned steps were followed. However, to prepare the nanomuds, four concentrations of each of the nanoparticle types were added individually to the basic muds after the hydration for the low $\mathrm{pH}$ muds and after the $\mathrm{pH}$ elevation for the high $\mathrm{pH}$ muds. These concentrations are $0.1 \%, 0.3 \%, 0.5 \%$, and $0.7 \% \mathrm{wt}$. and they are equivalent to $0.6,1.7,2.8$, and $3.9 \mathrm{gm}$, respectively. These percentages do not significantly impact the mud density because their weights are too low compared to the weight of the basic samples (519 gm). For the cationic nanoaluminum (powder), the Bentonite and Barite were mixed first with $400 \mathrm{cc}$ of water by using the mixer. Then, one of the above mentioned nanoparticles at selected amounts was mixed with $100 \mathrm{cc}$ of water using the Ultrasonic processor for 10 minutes and added to the mud sample in the mixer's cup.

\subsection{Measurements and Calculations}

\subsubsection{Rheological Measurements and Calculations}

The impact of the nanoparticles with different concentrations on the API rheological properties for each prepared sample was obtained using the Fann RheoVADR® Variable Automated Digital Rheometer. For this purpose, six dial readings (shear stress) were measured for six rotational speeds (shear rates). They are $\theta 600, \theta 300, \theta 200, \theta 100, \theta 6$, and $\theta 3$ for $600 \mathrm{rpm}, 300$ rpm, $200 \mathrm{rpm}, 100 \mathrm{rpm}, 6 \mathrm{rpm}$, and $3 \mathrm{rpm}$, respectively. After that, the following calculations were carried out to obtain the rheological properties:

1. Plastic Viscosity (centipoise) $=\theta 600-\theta 300$

2. Apparent Viscosity (centipoise) $=\theta 600 / 2$

3. Bingham Yield Point $(\mathrm{lb} / 100 \mathrm{sq} \mathrm{ft})=\theta 300-\mathrm{PV}$

4. Shear Rate $(\gamma)(1 / \mathrm{sec})=1.703 *$ Rotational Speed

5. Flow Behavior Index $(n)=\frac{\log \left(\frac{\theta 600-\theta 3}{\theta 300-\theta}\right)}{\log \left(\frac{\gamma 600}{\gamma 300}\right)}$

The Flow Behavior Index for Power Law gives an accurate indication of the Newtonian and nonNewtonian behaviors of drilling muds for a specific shear rate range. If $\mathrm{n}$ less than 1 , the fluid is non-Newtonian and shear thins at high shear rates. if $\mathrm{n}$ is equal to 1 , the fluid is Newtonian. If $\mathrm{n}$ is greater than 1, the fluid is dilatant, shear thickening, at high shear rates. 
6. Consistency Index $(\mathrm{k})\left(\mathrm{lb}-\mathrm{sec}^{-\mathrm{n}} / 100 \mathrm{sq} \mathrm{ft}\right)=\frac{0.2088 *(\theta 300-\theta 3)}{\gamma 300^{n}}$

The consistency index is the shear stress at 1 shear rate. It is a measure of the low shear rate viscosity. Therefore, it indicates the hole cleaning and suspension capacity of the muds. The high consistency index means an efficient hole cleaning. It increases when the general viscosity increases, and so on. At flocculation, the consistency and flow behavior indexes are very high.

7. Effective Viscosity (centipoise) $\mu e=\left(100 * k * \gamma^{n-1}\right)$

8. Actual Yield Point (modified power law yield point) $(\mathrm{lb} / 100 \mathrm{sq} \mathrm{ft})=\left(\theta 3-k * \gamma^{n}\right)$

9. Apparent Viscosity (centipoise) $=\frac{300 * \theta}{\gamma}$

Moreover, two gel strength measurements were carried out for each prepared mud sample according to the API standard. The first measurement was carried out by stopping the fluid's movement for 10 seconds, then measuring the maximum dial reading (shear stress) at $3 \mathrm{rpm}$. The second measurement was carried out by stopping the fluid's movement for 10 minutes, then measuring the maximum dial reading (shear stress) at $3 \mathrm{rpm}$. Finally, mud density in $\mathrm{gm} / \mathrm{cc}$ for each prepared sample was measured by using the conventional mud balance as shown previously in the Figure 14. The mud densities were always around $9 \mathrm{gm} / \mathrm{cc}$ for the samples with and without nanoparticle additives. The following Table 4 shows the rheological results of the basic muds for both systems.

\begin{tabular}{|l|c|c|}
\hline \multicolumn{1}{|c|}{ Rheological Properties } & Low $\mathrm{pH}$ Basic Mud & High $\mathrm{pH}$ Basic Mud \\
\hline Plastic Viscosity (PV) $(\mathrm{cp})$ & 17.5 & 22 \\
\hline Bingham Yield Point $(\mathrm{YP})\left(\mathrm{lb} / 100 \mathrm{ft}^{2}\right)$ & 27 & 76 \\
\hline Apparent Viscosity $(\mathrm{cp})$ & 31 & 60 \\
\hline 10 sec. Gel $\left(\mathrm{lb} / 100 \mathrm{ft}^{2}\right)$ & 19.7 & 58 \\
\hline 10 min. Gel $\left(\mathrm{lb} / 100 \mathrm{ft}^{2}\right)$ & 34 & $11.5-12$ \\
\hline $\mathrm{pH}$ & 9.4 & 9 \\
\hline Mud Density $(\mathrm{gm} / \mathrm{cc})$ & 9 & 97 \\
\hline
\end{tabular}

Table 4: The rheological properties for the basic high and low pH mud systems

Based on the same above-mentioned procedure, the rheological properties of the treated muds were measured and/or calculated. 


\subsubsection{Filtration Measurements}

For each prepared mud sample, the API standard low pressure and low temperature (LPLT) filtration test was carried out by using the aforementioned multiple unit filter presses. At the lab temperature, $100 \mathrm{psi}$ was applied on the mud, which was in the filter press cup, to force the water component to filter through a piece of filter paper. The water was collected in a graduated cylinder. This collected water loss is called filtrate loss. A mudcake was built on the filter paper during this process. The test was run for 30 minutes, which is the standard API time duration for filter press measurements. During the 30-minutes time interval, filtrate loss was measured at every 1 minute. This test was repeated for each mud sample. At time zero, the spurt loss was measured and recorded.

\subsubsection{Mudcake Measurements}

After 30 minutes, the filter press' parts were disassembled and the filter paper was taken off and the filter cake thickness was measured in millimeters. The thickness of the mudcake was measured using a unit caliper.

\subsection{Mud Hydraulic Simulation}

Drillbench software was used to evaluate the impact of the nanoparticles on the equivalent circulation density (ECD) and the circulation pressure loss. The enhanced rheological properties were used as input data. Several runs were conducted using a $9000 \mathrm{ft}$ long $12 \frac{1}{1 / 4}$ inches diameter deviated wellbore. Figures 18 and 19, and Table 5 show the trajectory, geometry, and survey of this well, respectively.

\begin{tabular}{|c|c|c|c|c|c|c|c|}
\hline $\begin{array}{l}\text { Measured } \\
\text { Depth } \\
(\mathrm{ft})\end{array}$ & $\begin{array}{l}\text { Inclination } \\
(\mathrm{deg})\end{array}$ & $\begin{array}{l}\text { Azimuth } \\
(\mathrm{deg})\end{array}$ & $\begin{array}{l}\text { Horizontal } \\
\text { Displacement } \\
(\mathrm{ft})\end{array}$ & $\begin{array}{l}\text { North } \\
(\mathrm{ft})\end{array}$ & $\begin{array}{l}\text { East } \\
(\mathrm{ft})\end{array}$ & $\begin{array}{l}\text { Vertical } \\
\text { Depth } \\
(\mathrm{ft})\end{array}$ & $\begin{array}{l}\text { Dogleg } \\
\text { Severity } \\
(\mathrm{deg} / 100 \mathrm{ft})\end{array}$ \\
\hline 0.0 & 0.0 & 0.0 & 0.0 & 0.0 & 0.0 & 0.0 & 0.0 \\
\hline 2067.0 & 0.0 & 0.0 & 0.0 & 0.0 & 0.0 & 2067.0 & 0.0 \\
\hline 5281.0 & 32.0 & 6.9 & 874.4 & 868.1 & 105.2 & 5116.5 & 1.0 \\
\hline 9000.0 & 32.0 & 6.9 & 2845.2 & 2824.6 & 342.1 & 8270.4 & 0.0 \\
\hline
\end{tabular}

Table 5: The directional wellbore survey 


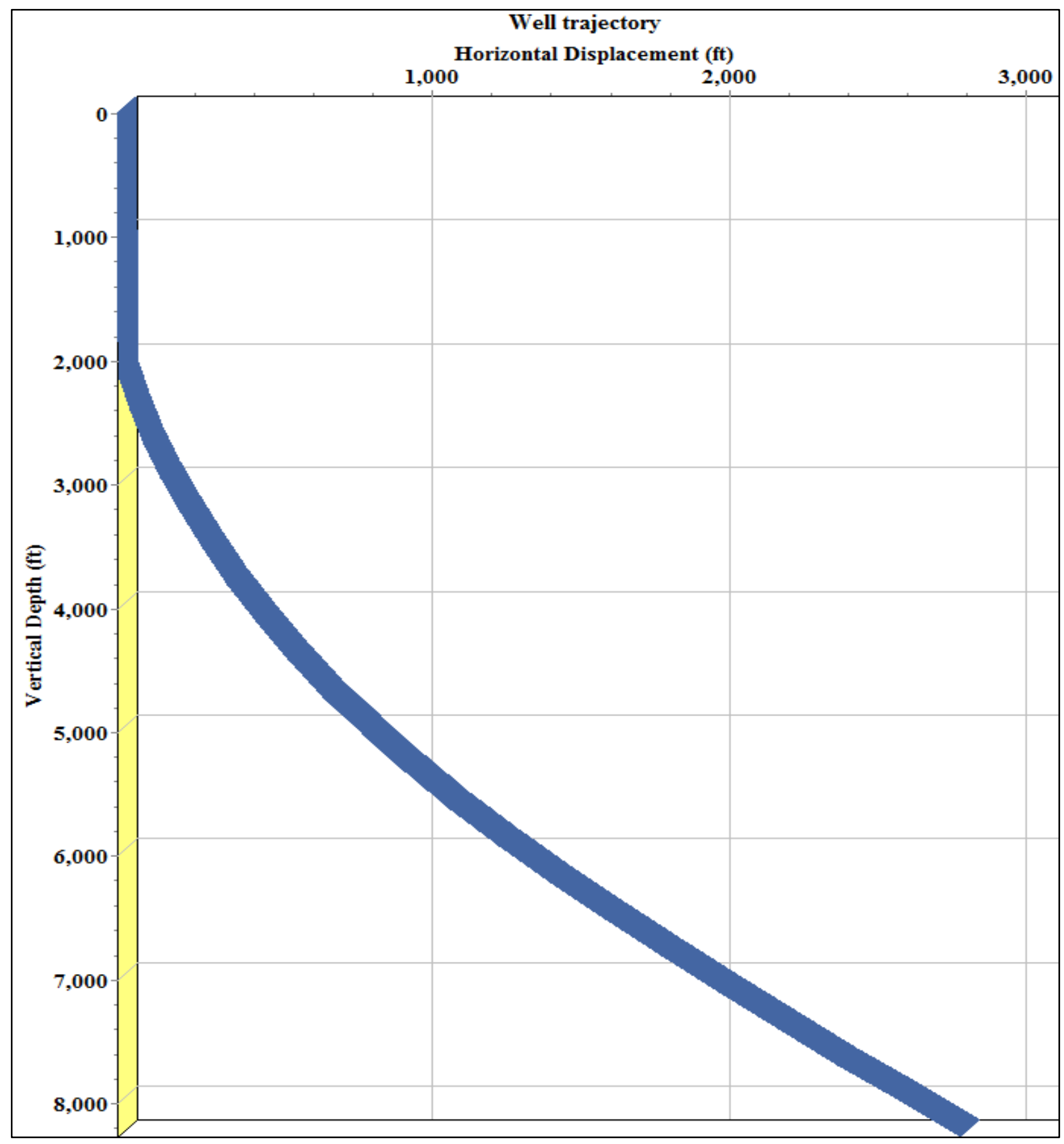

Figure 18: The trajectory of the directional well 


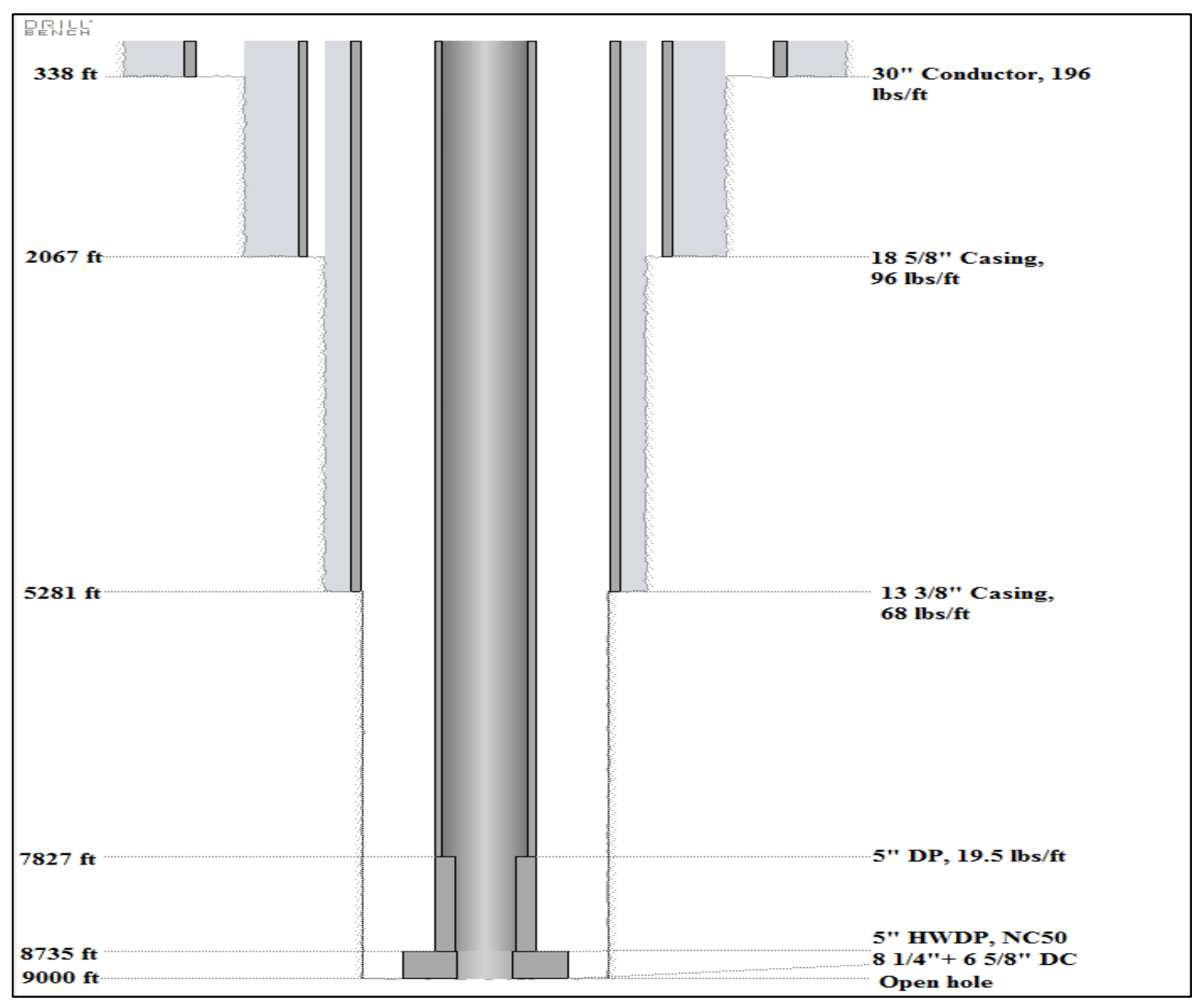

Figure 19: The geometry of the directional well

The operational hydraulic parameters (Table 6) were extracted from an actual well program.

\begin{tabular}{|l|c|}
\hline \multicolumn{1}{|c|}{ Operational Parameter } & Specifications \\
\hline Drill Bit & $121 / 4$ PDC \\
\hline Nozzles & $3 * 13 / 32^{\prime} \& 3^{*} 12 / 32^{\prime} "$ \\
\hline Drilled Cuttings Diameters & $0.13^{\prime \prime}$ \\
\hline Cuttings Mode & Slip \\
\hline Cuttings Density & $22 \mathrm{lb} / \mathrm{gal}$ \\
\hline Cuttings Concentration & $(10-20) \%$ \\
\hline Rate of Penetration (ROP) & $100 \mathrm{ft} / \mathrm{hr}$ \\
\hline Rotational Speed (RPM) & $100 \mathrm{rpm}$ \\
\hline Pump Rate & $850 \mathrm{gal} / \mathrm{min}$ \\
\hline Rheology Model & $0.012^{\circ} \mathrm{F} / \mathrm{ft}$ \\
\hline Geothermal Gradient & \\
\hline
\end{tabular}

Table 6: The hydraulics operational parameters 


\section{Chapter 5: Results and Discussions}

\subsection{Results and Discussions of Using Nanosilica with Water-Based Muds}

\subsubsection{API Rheological Properties of Water-Based Nanosilica Muds}

The rheological profiles of the drilling muds with and without nanosilica for both mud systems are shown in Figure 20. Based on the comparison of the rheological profiles, various rheological properties can be derived considering the difference between the water-based muds with and without nanosilica. Theoretically, it is observed that the flow behavior of the muds with and without nanosilica can be described by Bingham Plastic model for the higher shear rates $(>500$ $\mathrm{sec}^{-1}$ ) and/or by the Modified Power Law model for all shear rates. Furthermore, it is noticed that the treated muds maintain the non-Newtonian behavior after adding the anionic nanosilica, which is a desirable property for the drilling fluids.

Figure 20 (B) shows the behavior of a flocculated basic water-based mud after increasing the $\mathrm{pH}$ with $\mathrm{NaOH}$ and the significant impact of the lowest concentration of nanosilica. Sodium ions are adsorbed between the Bentonite particles leading to more attraction and flocculation. The anionic nanosilica with high surface area to volume ratio is a sensitive and chemically active additive that requires less concentration with smaller particle sizes. In other words, the addition of small concentrations of the nanoparticles is sufficient to cause major physio-chemical changes in the systems. In this study, $0.1 \%$ wt. of nanosilica with the current design was sufficient to do that.

It has been reported that the $\mathrm{pH}$ of the mud, $\mathrm{pH}$ of the nanoparticles, nature of the particle's surface, particle's size, and particle's interaction forces play a significant role in changing the rheological behavior of the drilling muds (Zakaria et al. 2012). Therefore, $5 \mathrm{~nm}$ particles of silica with negative surface charges and a $\mathrm{pH}$ of 10 plays a more substantial role in avoiding the flocculation and enhancing the rheological behavior of the mud with high $\mathrm{pH}$ than the low $\mathrm{pH}$.

For both systems, the shear stress of the mud is reduced and the pumpability of the mud is increased which are desirable in the drilling operations because they reduce the energy required to circulate the mud in the wellbore. 


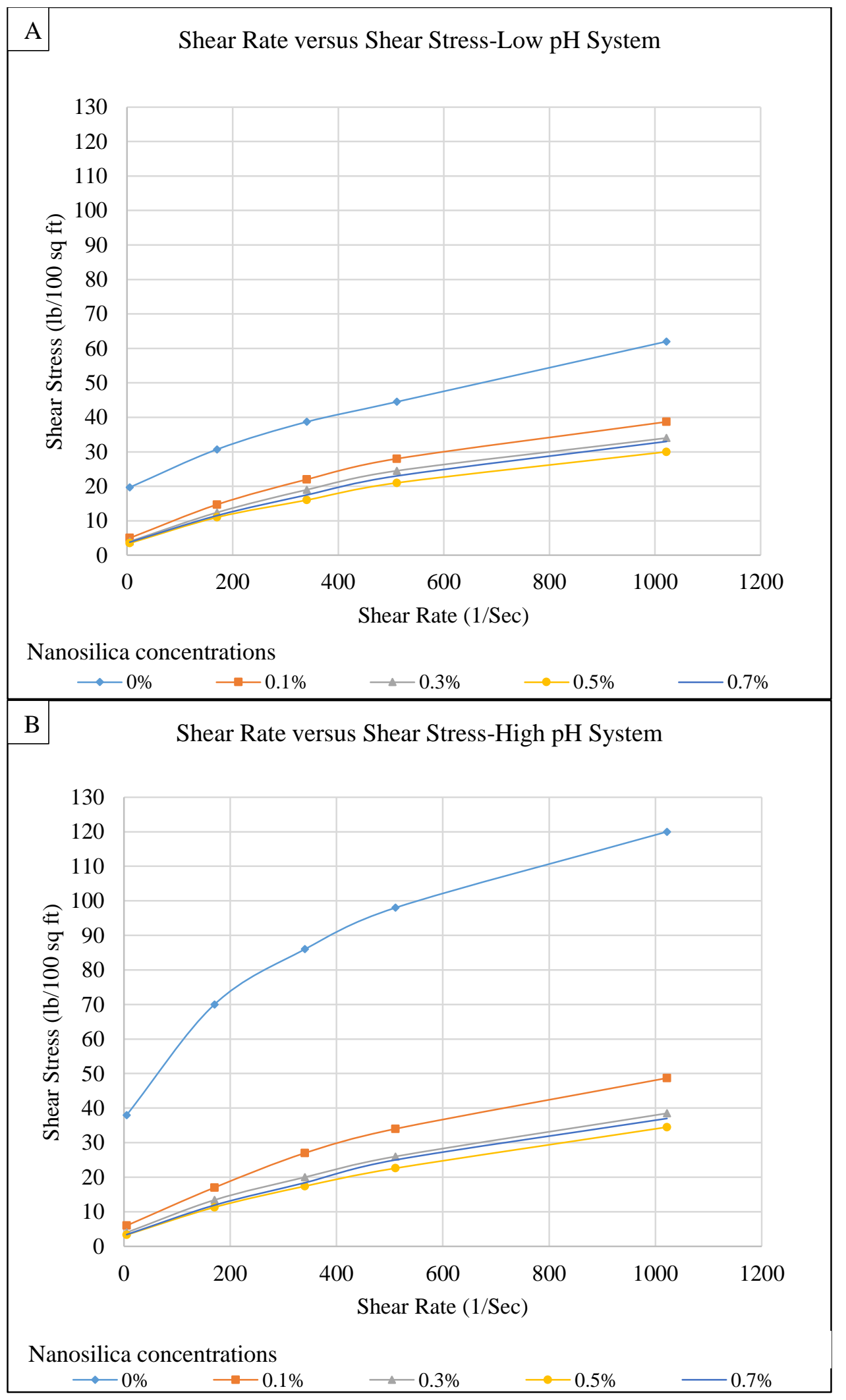

Figure 20: The rheological profiles for muds with and without nanosilica 
Based on the amount of nanosilica used, the results of low and high $\mathrm{pH}$ systems show a reduction trend in the shear stress required to maintain a specific shear rate as the nanosilica concentrations increase. Each concentration results in a different fluid behavior though the difference in the concentrations was low. Thus, nanosilica provides a wide range of rheological properties that can be used for different drilling conditions.

Figure 21 (A, B, C, and D) show the impact of nanosilica on the rheological properties for low and high pH systems. Significant impacts of the nanosilica on the plastic viscosity, yield points, and apparent viscosity for high and low $\mathrm{pH}$ mud systems can be seen. As anionic particles, nanosilica weaken the electro-chemical attractive forces between the Bentonite particles and increase the repulsive force. They neutralize the forces at the edges of the Bentonite particles, thereby leading to domination of the negative charges which are located on the Bentonite platelets. This will increase the repulsive forces between the Bentonite particles leading to low yield point. Additionally, they increase the distance between clay solids in the mud.

It shows that the plastic viscosity of the low and high $\mathrm{pH}$ muds is impacted in a same trend, but the impact on the low $\mathrm{pH}$ mud is greater as the concentration increases. Plastic viscosity is mainly caused by the frictional force and secondarily caused by the attraction between the particles in the mud. Both of them depend on the distance between the clay particles and the way the particles are arranged. It seems nanosilica works as a lubricant by increasing the distance between the mud solids. This reduces the frictional forces for both systems. Furthermore, it is believed that nanosilica with the current chemical properties helps in distributing the low $\mathrm{pH}$ mud's solids in such a way that reduces the friction more. The nanosilica reduce the attraction due to flocculation in the high $\mathrm{pH}$ muds helping in further reduction of plastic viscosity.

Results shown in Figure 21 (B, C, and D) illustrate the significant reduction in yield points and apparent viscosity by using $0.1 \%-0.3 \%$ wt. of the nanosilica. This means the lowest nanosilica concentrations are sufficient to mitigate the attractive forces between the Bentonite particulates. No further big changes in these properties were observed after increasing the nanosilica concentration for both mud systems.

In conclusion, the reduction in the mud viscosities are due to repulsive forces between nanosilica particles, water molecules, and clay particles, due to the enhancement in solids' distribution, and 
due to increasing the distance between the solids in mud. It is well known that fluids with high viscosity may cause excessive pump pressure loss and decrease the rate of penetration.

Therefore, it is important to design a suitable fluid rheology by using nanosilica with small amounts to improve the drilling performance.

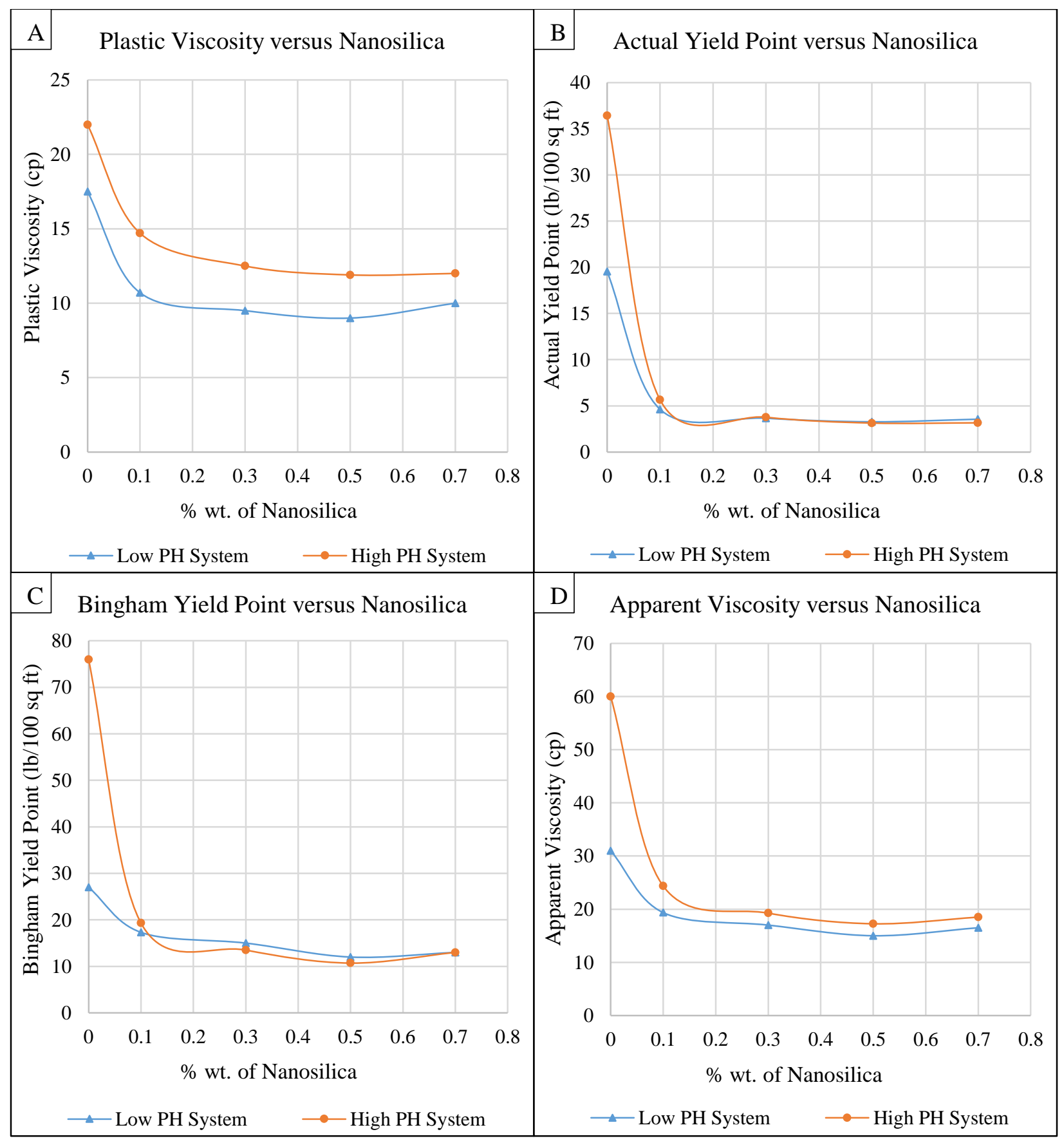

Figure 21: The impact of nanosilica on the rheological properties 
Most of well-designed non-Newtonian fluids exhibit shear-thinning behavior so that the effective viscosity decreases with increasing shear rate and increases with decreasing shear rate. Figure 22 shows the impact of the nanosilica on the effective viscosity at low and high shear rates. For the low $\mathrm{pH}$ mud system, the muds with nanosilica exhibit more shear thinning than the basic mud at all concentrations. Thus, they exhibit higher viscosity at lower shear rate and lower viscosity at higher shear rate.

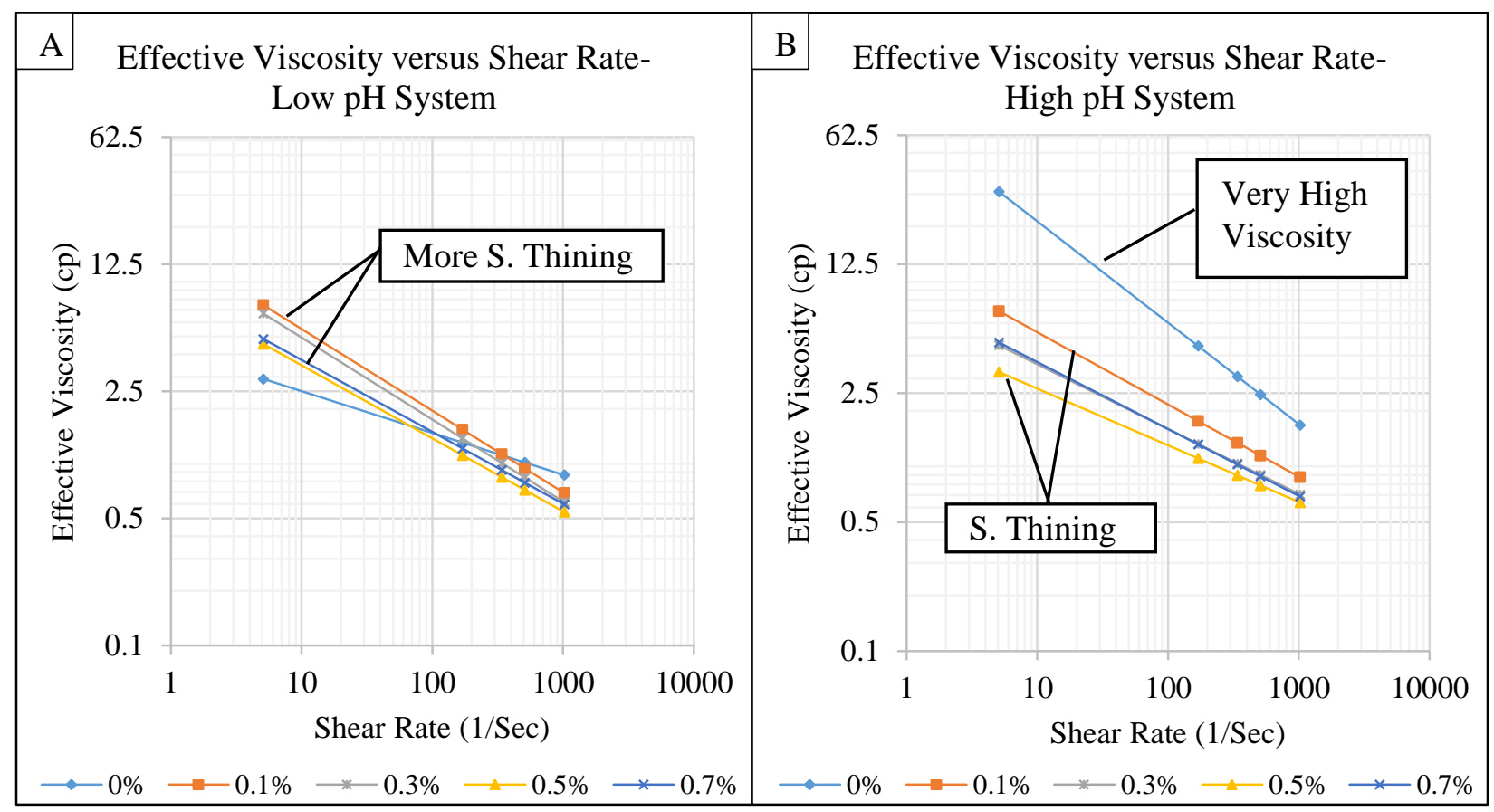

Figure 22: The impact of nanosilica on the effective viscosity

For the high $\mathrm{pH}$ mud system, the basic mud exhibits shear thickening or no shear thinning that implies the low pumpability at low and high shear rates. Results show that the nanosilica played a significant role in enhancing the shear thinning for this mud, especially at the range from $0.1 \%$ $0.5 \%$ wt. concentrations. It makes the bonds between the Bentonite's particles easy to be broken.

Shear thinning based on nanosilica has very important implications in the drilling operations. At high mud velocities in the drill string and through the bit, the nanomud shear thins to low viscosities. This reduces the circulating pressure loss. With lower mud velocities in the annulus, the nanomud has higher viscosities, and aids in hole cleaning and suspension capacity. At very low velocities, the nanomud has its highest viscosities, and when not circulating will develop gel strength. This aids in suspending weight materials and drilled cuttings when a mud pump stops. 
For the mud gelation, Figure $23(\mathrm{~A} \& \mathrm{~B})$ show that the basic muds exhibit higher gel for both systems, which is a progressive type of gel in the field. Also, shown is the high $\mathrm{pH}$ basic mud with higher gel strength values than the low $\mathrm{pH}$ basic mud due to the flocculation of the mud and attraction between the Bentonite particles. Flocculation is a detrimental phenomenon because it results in excessive viscosity, gel, and low mud pumpability.

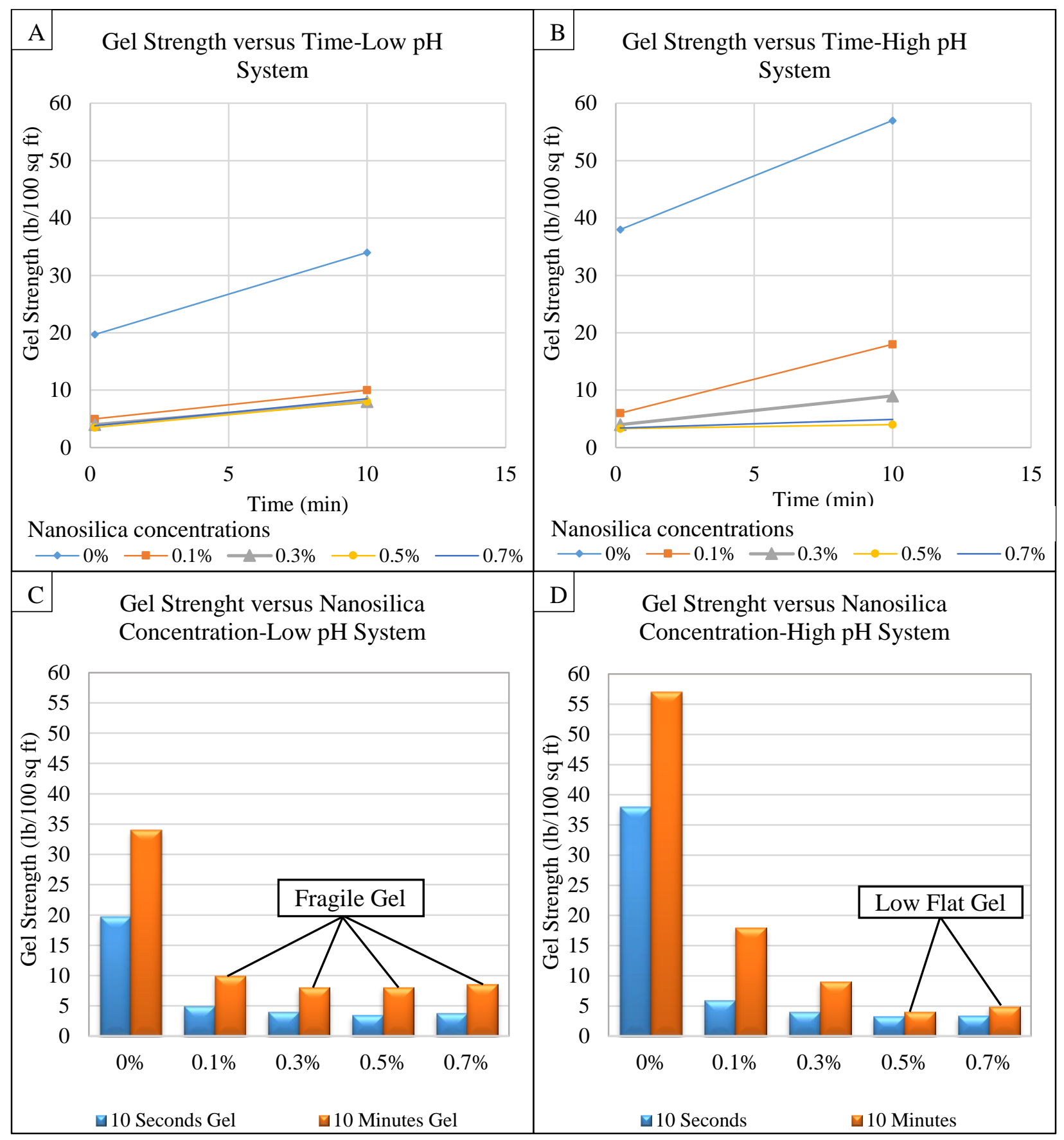

Figure 23: The impact of nanosilica on the gel strength 
Also, Figure 23 (C\&D) show a gradual reduction in the gel strength as a result of the increased repulsive forces as nanosilica concentration increases. The nanoparticles work as a dispersion and as a deflocculant agent in this case. The results show that the best concentrations for the gel strength and the fluid behavior enhancement are $0.1 \%-0.3 \%$ wt. for both low and high $\mathrm{pH}$ mud systems, resulting in fragile gels. Fragile gel is important to resume the mud circulation easily, cutting suspension, and cuttings removal at the surface shale shakers.

For the high $\mathrm{pH}$ mud systems, however, results show negative impact of the $0.5 \%-0.7 \%$ wt. of the nanosilica on the gel strength. They result in very low flat gel which is undesirable because it causes solids to sag, such as Barite sag, and does not allow a sufficient cutting suspension capacity while a mud pump is off. This is the only limitation for using nanosilica with the muds.

\subsubsection{API Filtration Properties of Water-Based Nanosilica Muds}

The comparisons between the API filtration profiles of the water-based muds with and without nanosilica are shown in Figure $24(\mathrm{~A} \& \mathrm{~B})$. The nanosilica reduces the filtration as its particle concentration increases gradually. The $0.1 \%$ wt. concentration has the sufficient enhancement in the filtration property for the low and high $\mathrm{pH}$ mud systems. For spurt loss, no significant difference was observed between all muds. However, it completely stopped with nanosilica and only a small loss was recorded for the basic muds. The spurt loss of the drilling fluid is considered as one of the well-known sources of solids invasion that causes formation damage (Zakaria et al. 2012). Thus, the nanosilica with the current design plays a significant role in reducing the formation damage, thereby increasing the oil and gas production.

Results show more filtration loss for the high $\mathrm{pH}$ basic mud than for the low $\mathrm{pH}$ basic mud due to the flocculation with increasing $\mathrm{pH}$. According to (Zakaria et al. 2012), stable Bentonite particles form dense and compact sediments, while flocculated particles form more voluminous sediments. In this case, the mud's particles link in the form of open networks or fragile fabrics. Therefore, the water can pass through the soft mudcake easily. The degree of the flocculation of the water-based muds determines the quality of the mudcake and the filtration volume. Higher clay flocculation leads to more filtration and thicker mudcake that increase the probability of differential stuck pipe problems. In addition, Amanullah et al. (2011) reported that the point type contact of micro particles and flocs created due to poorly dispersed clays along with their 
nonparallel orientation within mudcake matrix are some of the factors causing more filtration loss.

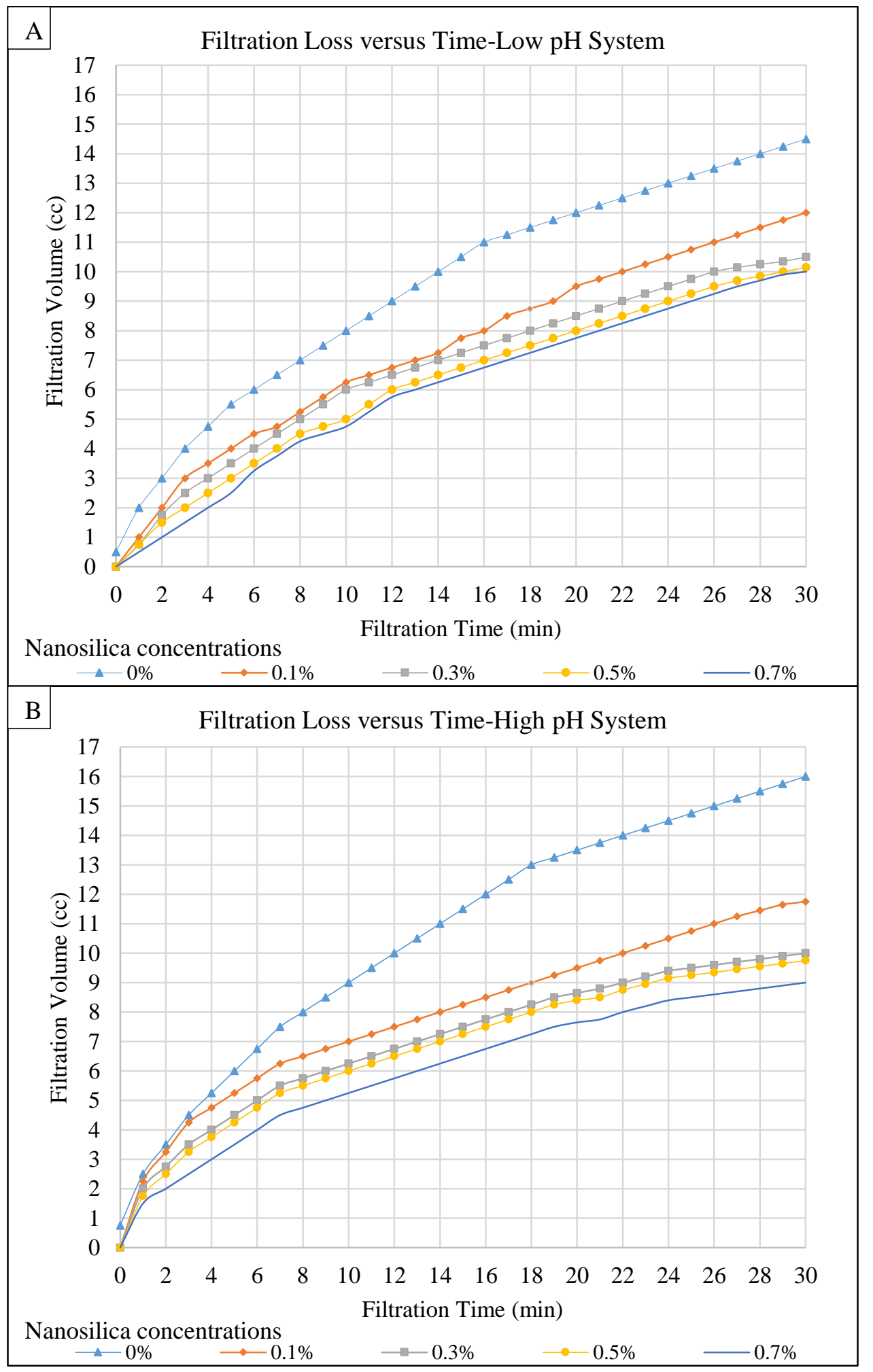

Figure 24: The filtration profiles for muds with and without nanosilica 
Due to high possibility of parallel type of contact among the well-dispersed mud particles of a well-designed nano-mud, the deposited mudcake is likely to have a very low permeability due to the formation of extremely narrow pathways within the mudcake matrix. It is believed that the nanosilica occupy the space between the Bentonite platelets leading to a seal that prevents some water from passing through the mudcake. This highlights the importance of using dispersed nanosilica in the water-based mud design with no spurt loss and low filtration. The big difference in particle size between the nanosilica and the clay helps in less filtration.

Nanosilica with different concentrations causes different degrees of filtration reduction. Figure 25 (A\&B) show the results of the percent reductions and volumes of the filtration loss with different concentrations of nanosilica for both mud systems. The reduction increases as the concentrations increase for both systems. The best enhancement for the current mud design was obtained at the highest concentrations of nanosilica. For example, at $0.7 \%$ wt. of nanosilica, $44 \%$ and $31 \%$ filtrate reductions were obtained for the high and low $\mathrm{pH}$ mud systems, respectively.

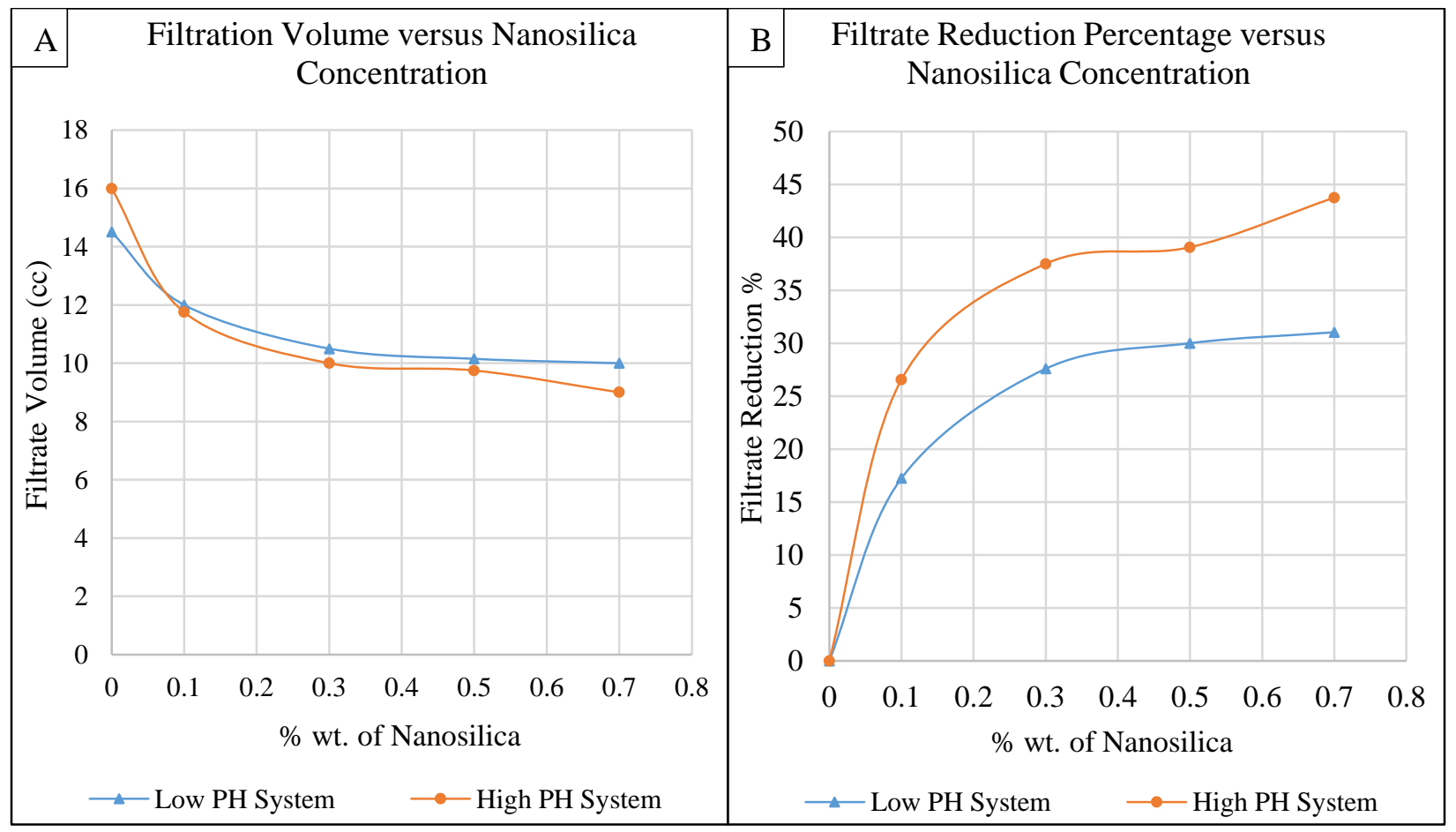

Figure 25: The impact of nanosilica on the filtration

For the mudcake properties, Figure $26(\mathrm{~A} \& \mathrm{~B})$ show the impact of nanosilica on the deposited cake thickness for both mud systems. The results show that the nanosilica in the high $\mathrm{pH}$ mud 
system plays a more significant role than the low $\mathrm{pH}$ mud in reducing the cake thickness. The thinner mudcake was obtained after increasing the nanosilica concentration gradually. The best concentration that gives the lowest cake thickness is achieved when $0.7 \%$ wt. of nanosilica is used. For example, $1 \mathrm{~mm}$ and $1.25 \mathrm{~mm}$ were obtained by using $0.7 \%$ wt. of nanosilica in the high and low $\mathrm{pH}$ muds, respectively. This means $70 \%$ and 55\% thickness reductions can be achieved for the current nano-mud design.

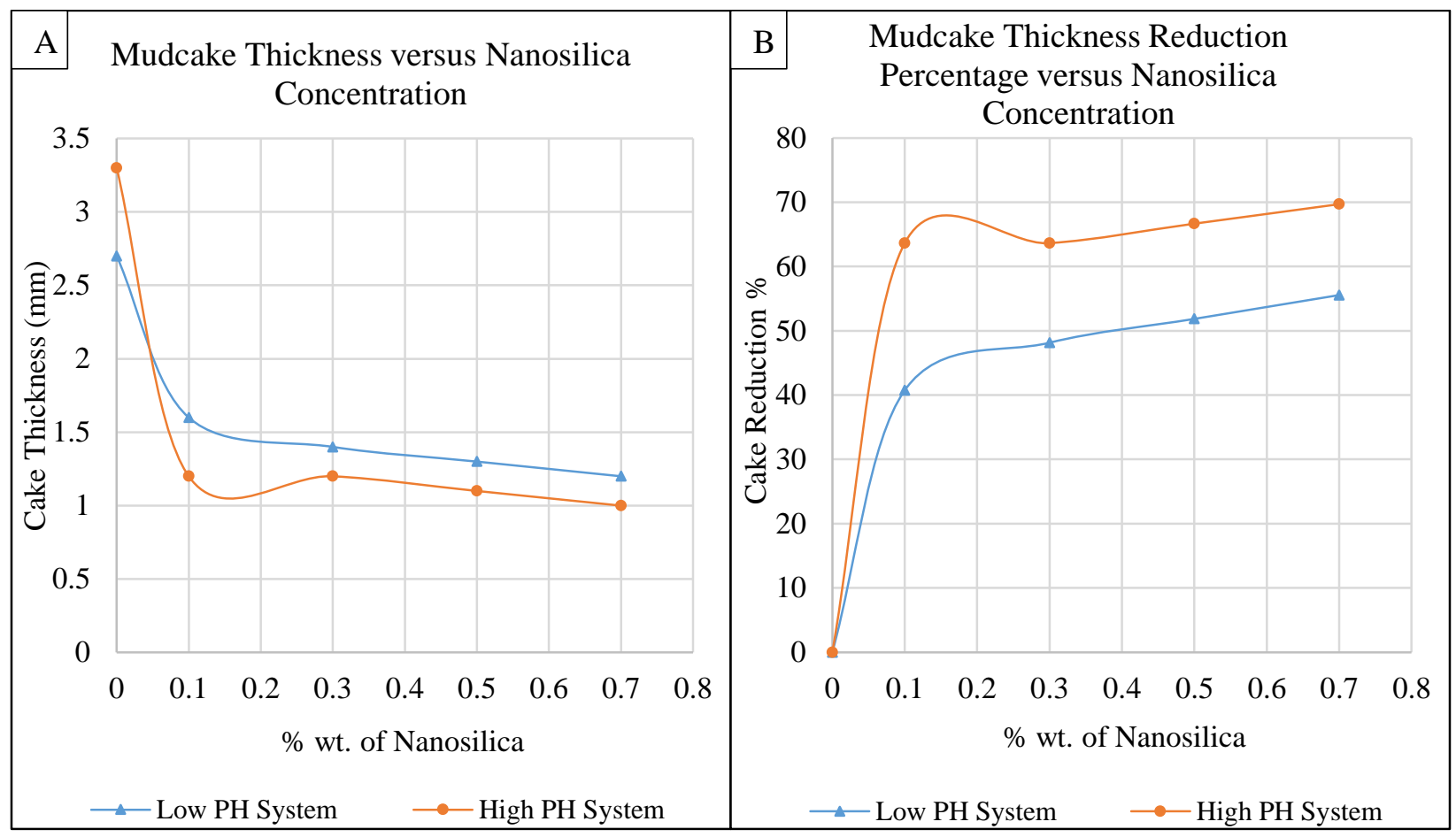

Figure 26: The impact of nanosilica on the mudcake thickness

The trapped nanoparticles in the space between the Bentonite platelets do not increase the mudcake thickness. Instead, they provide much better sealing, lower the permeability of the mudcake as the clay particles deposit, and lead to a smooth cake surface. Table 7 shows the mudcake' structure properties with the presence and absence of nanosilica for both mud systems. The high dispersion and small size of the nanosilica particles resulted in a very smooth surface of the mudcake as the nanoparticles fill the tiny holes located on the surface of the mudcake. 


\begin{tabular}{|c|c|c|}
\hline Description & Low pH Mud System & High pH Mud System \\
\hline Basic Muds & & \\
\hline $\begin{array}{l}\text { Water-Based Mud with } \\
0.1 \% \text { wt of Nanosilica }\end{array}$ & & \\
\hline $\begin{array}{l}\text { Water-Based Mud with } \\
0.3 \% \text { wt of Nanosilica }\end{array}$ & & \\
\hline $\begin{array}{l}\text { Water-Based Mud with } \\
0.5 \% \text { wt of Nanosilica }\end{array}$ & & \\
\hline $\begin{array}{l}\text { Water-Based Mud with } \\
0.7 \% \text { wt of Nanosilica }\end{array}$ & & \\
\hline
\end{tabular}

Table 7: Mudcake development for muds with and without nanosilica

The very thin mudcake deposited by nanosilica muds aid in reducing the mudcake related problems such as stuck pipe. The very smooth, compacted, thin, impermeable, and plaster-like mudcake also helps in strengthening a well's wall, especially in the unconsolidated formations and deviated wells. Nanomuds without spurt loss and internal mudcake result in an external 
mudcake that can be removed easily prior to the cement job by the washer liquids. It has been reported by Amanullah et al. (2011) that the high surface area to volume ratio of the nanoparticles and the high interactivity help in a quick interaction between the washers and the nano-mudcake. In addition, the mudcake deposited by deflocculated nanosilica mud is more easily removable due to the weak links between their solids as a result of the neutralized charges on the solid surfaces. These features along with the erosion of the washers effectively displace the entire mudcake from the wellbore, thereby allowing an efficient bond between the cement and the formations.

\subsubsection{Impact of Nanosilica on Drilling Mud Hydraulics-ECD \& Circulating Pressure}

Equivalent circulation density (ECD) and circulation pressure loss as hydraulic parameters were studied to reflect the impact of the anionic nanosilica particles on the hydraulics system for the current well. The ECD is equal to the mud density plus the density due to the circulation pressure loss in the annulus, due to the friction. The equivalent density due to circulation pressure loss is a viscosity-dependent parameter. Therefore, it can be improved by enhancing the mud rheology. The circulation pressure loss represents the energy exerted by the mud pumps to circle the mud.

The resulting ECD profiles are shown in the Figures 27 and 28 for both high and low $\mathrm{pH}$ mud systems. In comparison to the basic muds, both systems show clear enhancements in the mud hydraulics due to a decrease in the ECD, which is undoubtedly desirable. For example, Figure 27 shows a gradual ECD decrease from $9.7 \mathrm{lb} / \mathrm{gal}$ to $9.2 \mathrm{lb} / \mathrm{gal}$. For both pH systems, the big enhancement was obtained after adding $0.1 \%$ wt. of the nanosilica to the mud. This means using nanosilica with a small concentration is sufficient to change the drilling fluid viscosity and rheological properties.

Hydraulics optimization can be achieved by making balance between well control, hole cleaning, pump pressure, ECD and pressure drop across the drill bit based on the best rheological properties of the muds. Thus, enhancing the drilling fluid rheological properties by means of nanosilica is one of the main factors that help in optimizing the hydraulics. Mud loss and related kicks, particularly, in wells that have a narrow window between the fracture gradient and porepressure gradient, may be avoided by using nanosilica to reduce the ECD. 
It is important to mention that reduction of ECD is based on adding nanoparticles only, thereby on changing the rheology of the mud. It shows the possibility of obtaining different results is very high based on changing other independent parameters such as wellbore geometry, downhole tools dimensions, subsurface temperature, and the raw materials used to prepare muds.

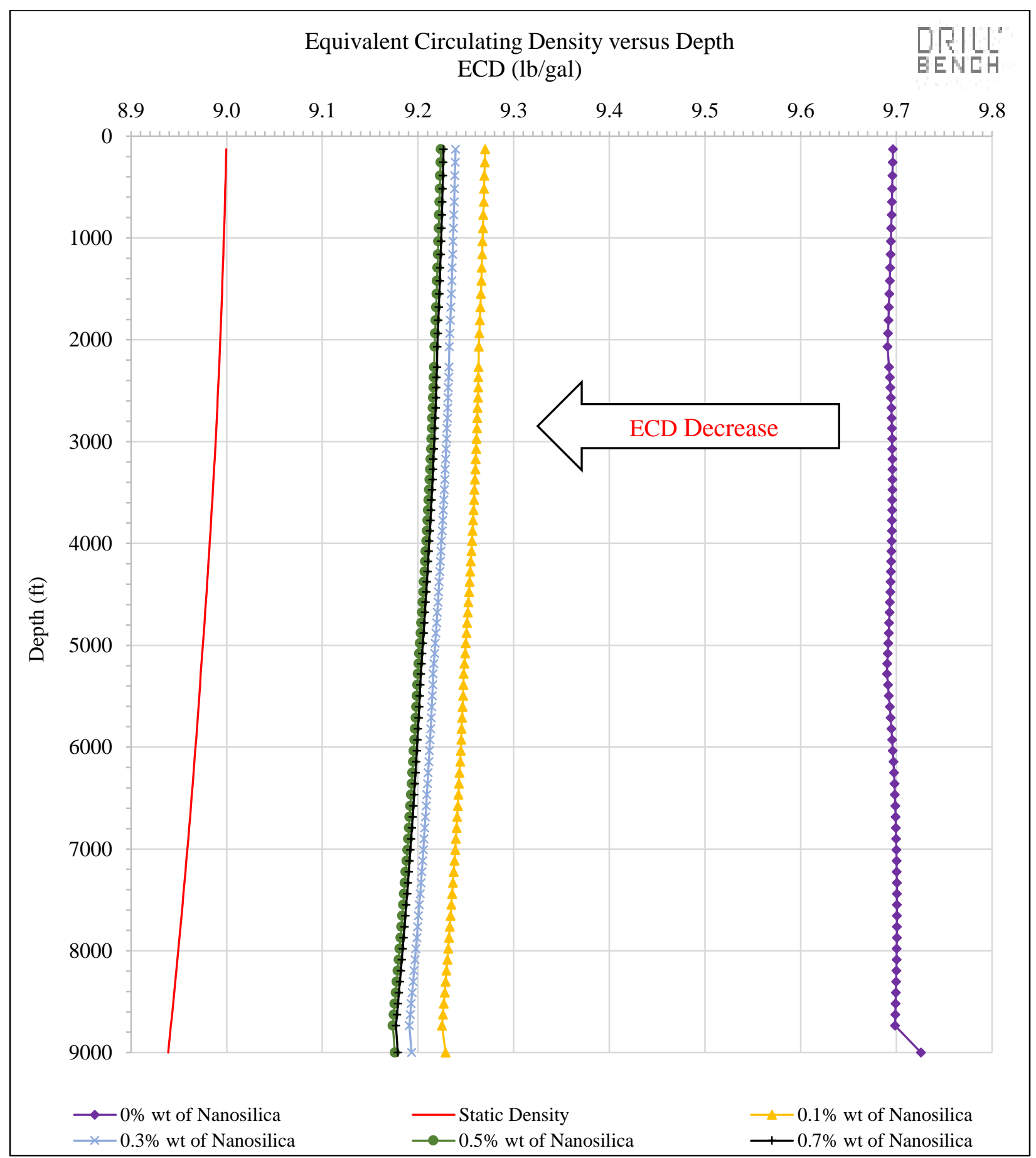

Figure 27: The impact of nanosilica on the equivalent circulating density-high pH mud system 


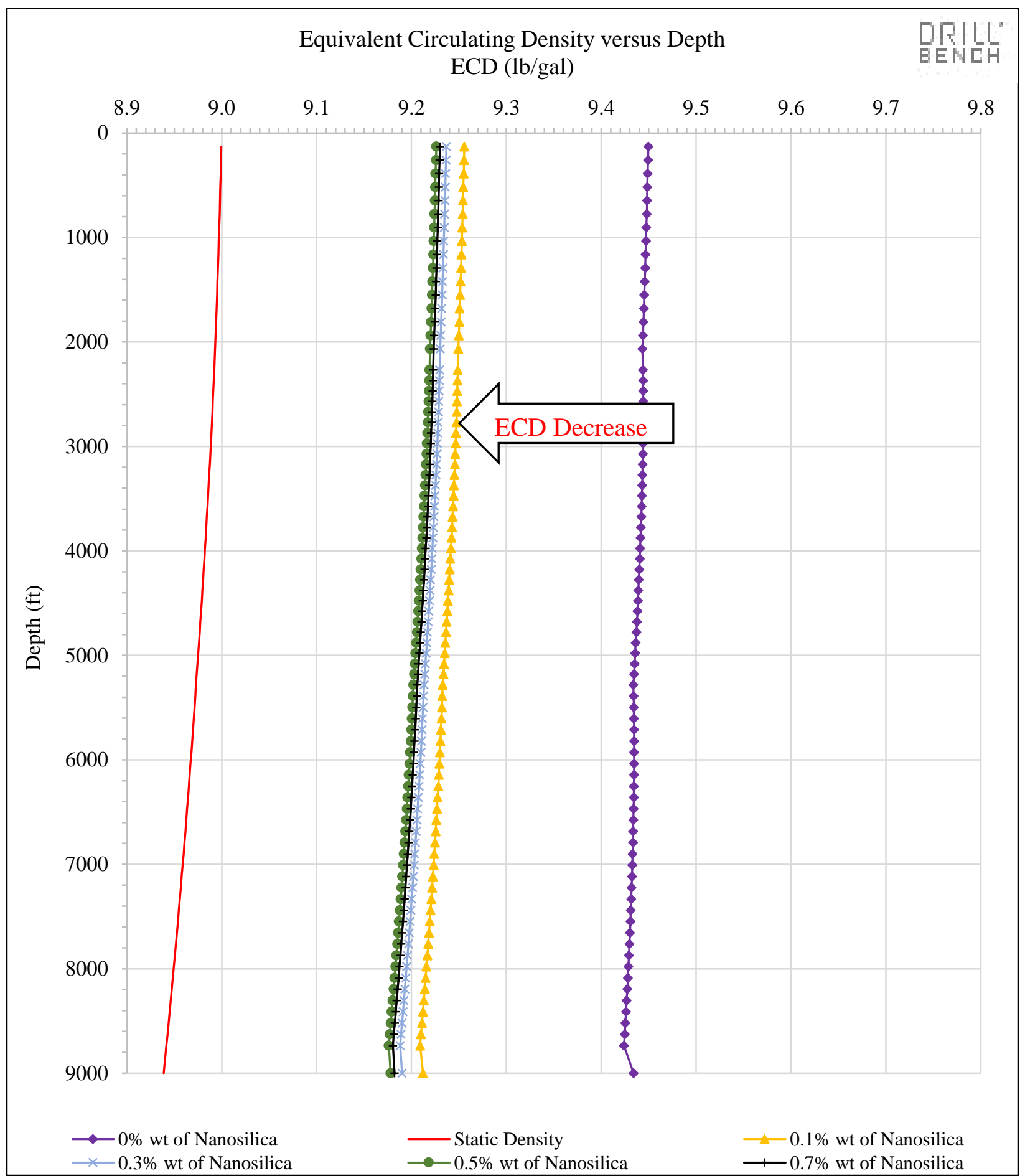

Figure 28: The impact of nanosilica on the equivalent circulating density-low pH mud system

For the circulation pressure, results show a reduction in the drillpipe pressure required to displace the mud into and out of the well after treating basic muds with nanosilica. Figures 29 and 30 show this impact on the circulation pressure measured at the rig floor for both systems. 


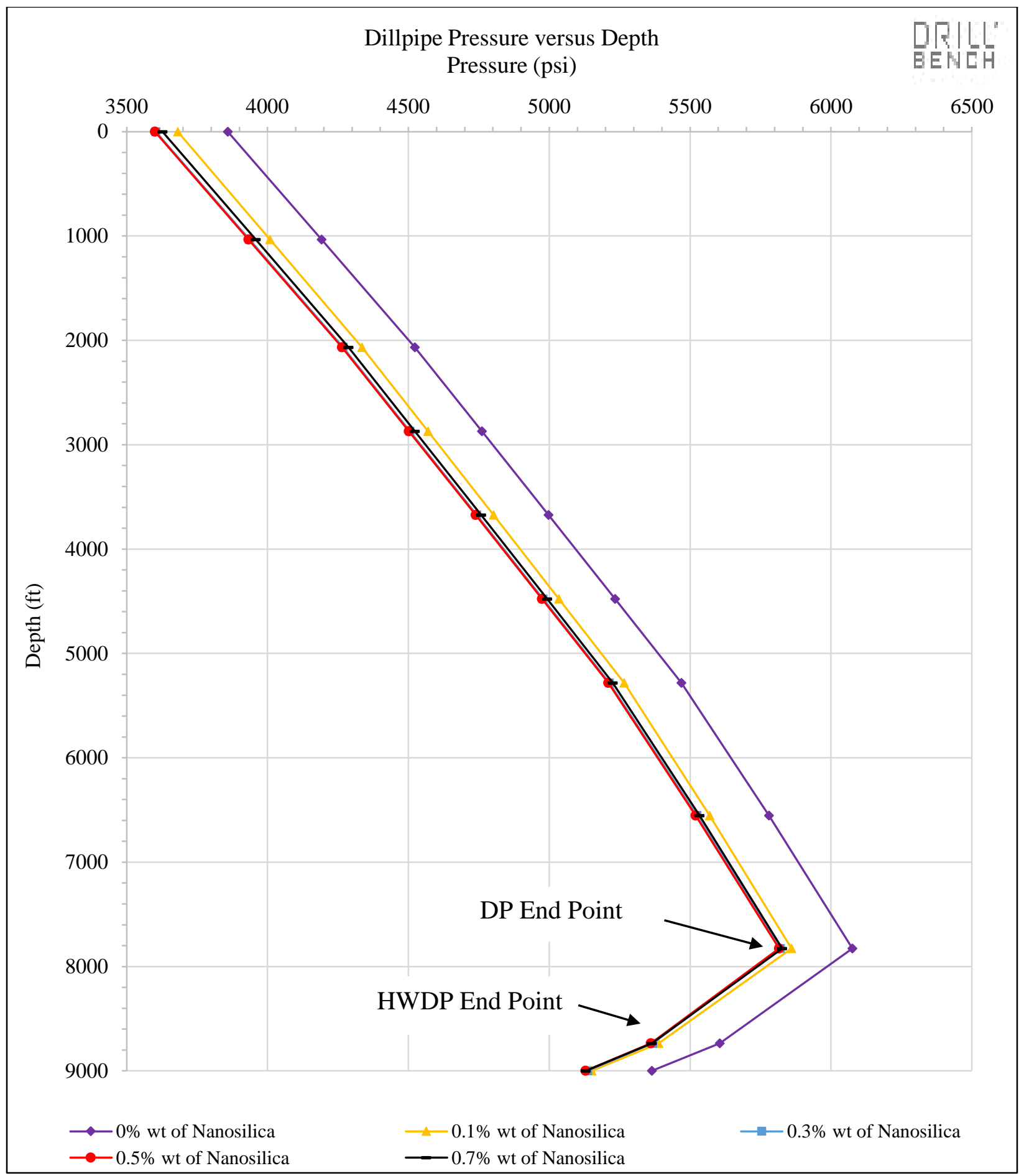

Figure 29: The impact of nanosilica on the drillpipe pressure-high pH mud system

From Figure 29, the surface drillpipe pressure was reduced by 300 psi based on the current nanomud design. Minimizing pump pressure to a certain level while keeping other hydraulics parameters in required levels is an important factor in minimizing the energy exerted by mud 
pumps This is essential in terms of obtaining long life for downhole equipment and surface pumps. Again, $0.1 \%$ wt. of nanosilica was enough to make the major reduction in the pump pressure loss throughout the $9000 \mathrm{ft}$ directional well for both systems.

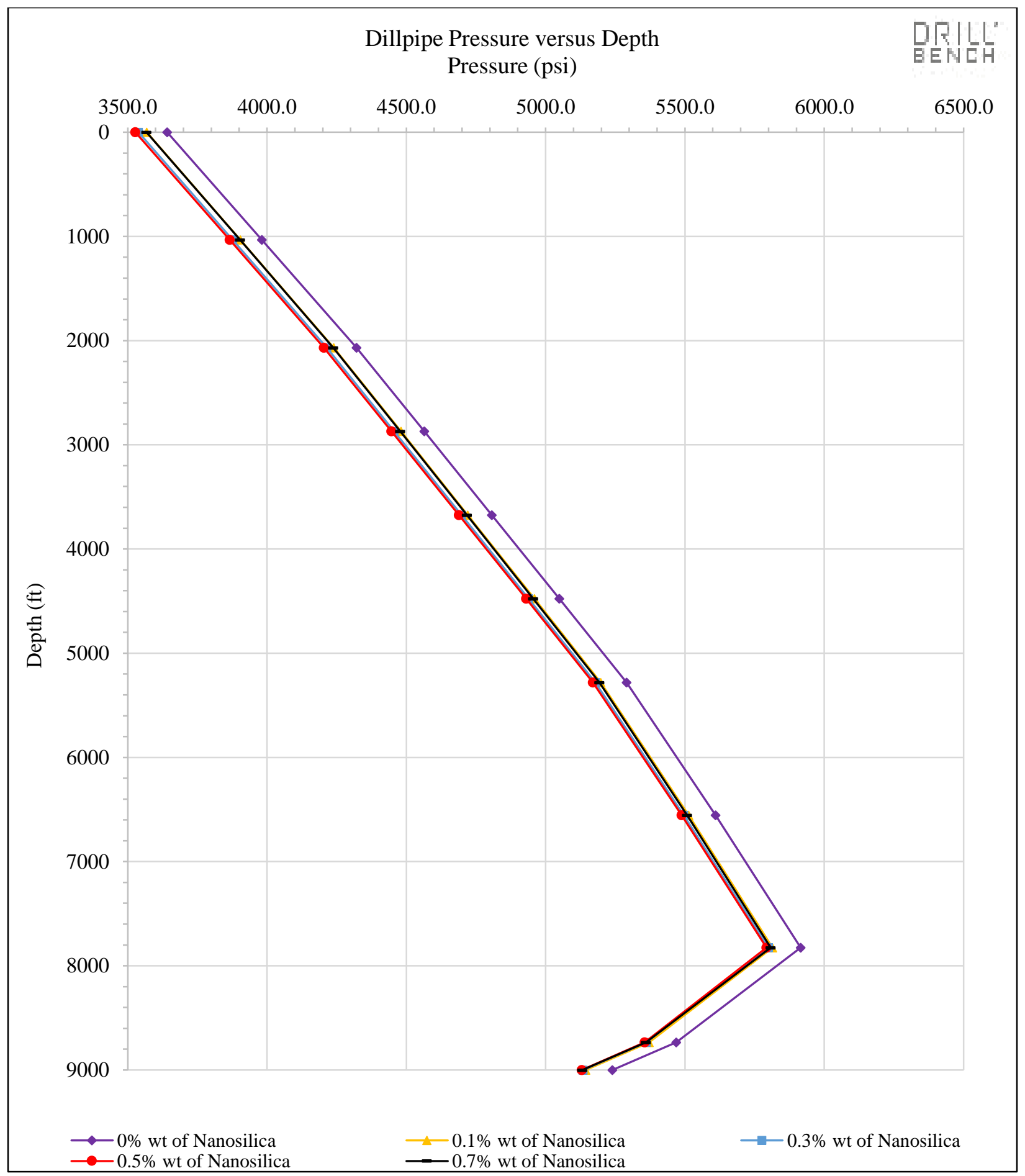

Figure 30: The impact of the nanosilica on the drillpipe pressure-low $\mathrm{pH}$ mud system 


\subsection{Results and Discussions of Using Nanotitanium with Water-Based Muds}

\subsubsection{API Rheological Properties of Water-Based Nanotitanium Muds}

The rheological properties of the nanotitanium and nanosilica muds for both $\mathrm{pH}$ systems follow the same trend since they are anionic particles, but the values are different since their physical properties are different. Hence, the results of low and high $\mathrm{pH}$ systems show a reduction trend in shear stresses required to maintain specific shear rates as the concentration increases. The rheological profiles of the drilling muds with and without nanotitanium are shown in Figure 31 $(A \& B)$. Based on the comparison of the rheological profiles, significant differences in the flow behaviors can be seen between the basic and treated muds. Like nanosilica, the flow behavior for the muds with and without nanotitanium can be described by the Bingham Plastic model for the higher shear rates (>500 $\left.\mathrm{sec}^{-1}\right)$ and/or by the Modified Power Law model for all shears. Further, it is noticed that the treated muds keep the non-Newtonian behavior after adding the nanotitanium, which is a necessary property for the drilling fluids.

Figure 31 (B) shows the flow behavior of flocculated and deflocculated muds. Unlike nanosilica, nanotitanium with concentration less or equal to $0.1 \%$ wt. does not significantly influence the behavior. This means the smaller amounts of nanotitanium are not enough to improve the fluid's behavior. However, $0.3 \%$ wt. of nanotitanium is quite enough to make huge changes in the rheological properties. The less surface area to volume ratio due to bigger nanoparticle size, thereby the less sensitivity, makes nanotitanium differs from nanosilica in terms of efficiency.

However, the clear difference between the rheological behaviors (shear stress/rate profiles) obtained based on different amounts of nanotitanium is another observation that is missed in the nanosilica muds. This difference will facilitate the possibility of obtaining turbulent or laminar flow behaviors, as needed, by using small amounts of nanotitanium for different drilling conditions. Like nanosilica, however, these changes in the flow behavior are due to the chemical and physical sensitivities. In a summary, the chemical interaction between the Bentonite's particles and the nanoparticles determines the trend shown in Figure 31. 


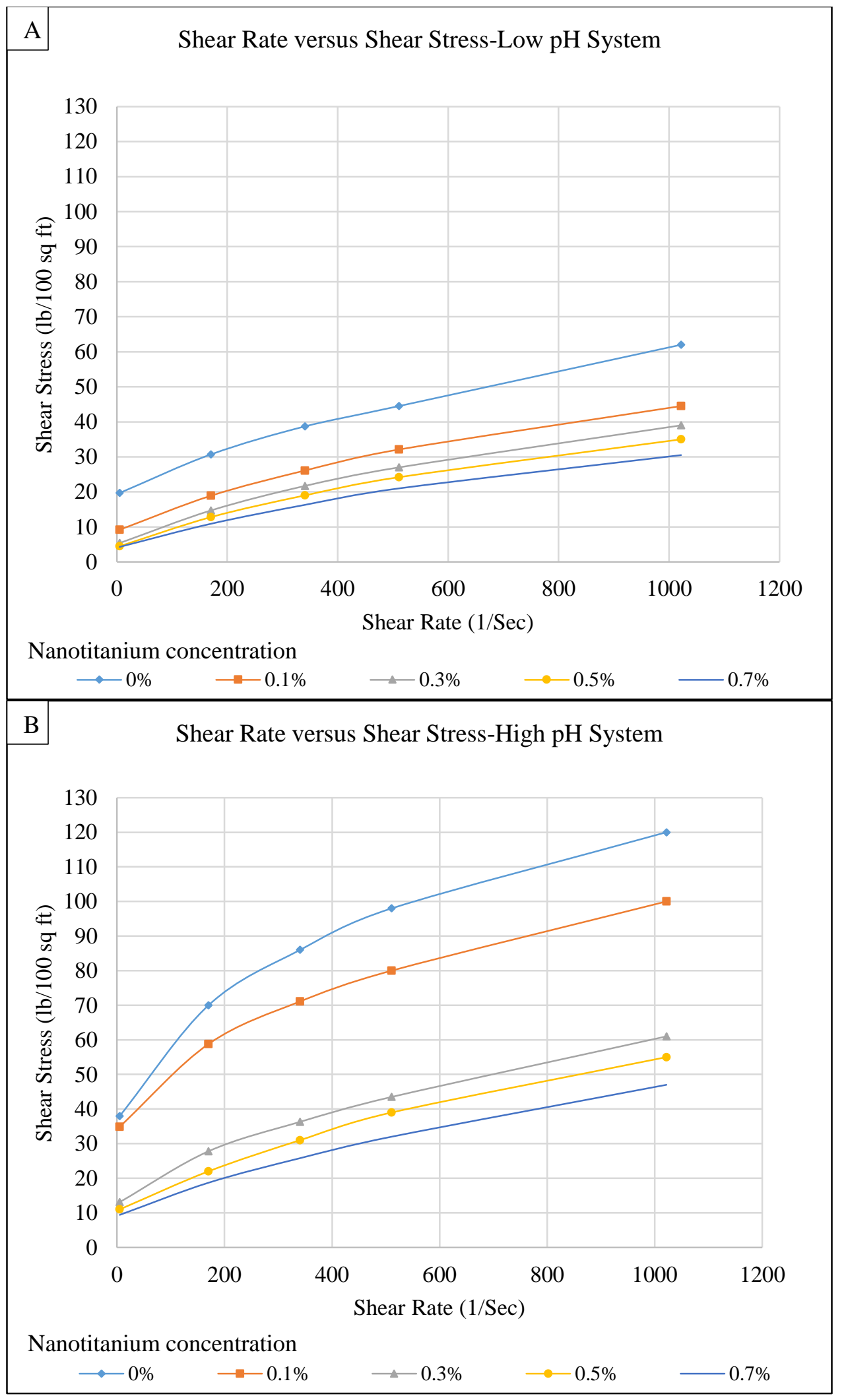

Figure 31: The rheological profiles for muds with and without nanotitanium 
The $\mathrm{pH}$ of mud and nanoparticles change the rheological behavior of the drilling fluids resulting in a new mud. It affects the solubility of nanoparticles and other chemicals in the mud (Zakaria et al. 2012). Therefore, the nanotitanium with the current $\mathrm{pH}$ plays a more significant role in avoiding the flocculation and enhancing the rheological behavior of the low $\mathrm{pH}$ muds. For both $\mathrm{pH}$ systems the shear stress of the mud is reduced and the pumpability of the mud is increased which are required in the drilling operations because they reduce the energy necessary to circulate the mud in a well.

The results shown in Figure 32 (A, B, C, and D) for the rheological properties reflect a significant impact of the nanotitanium on the plastic viscosity, yield points, and apparent viscosity for high and low pH mud systems. Nanotitanium particles exhibit as a repulsive force's resource since they are anionic particles. They weaken the electro-chemical attractive force between the solids in the muds and neutralize the charges on the edges of the Bentonite particles. In addition, they increase the distance between Bentonite particles and reorganize these particles in the muds.

Figure 32 (A) shows that the plastic viscosity for the low and high $\mathrm{pH}$ muds decreases as the concentration increases. Plastic viscosity is mainly caused by the fractional forces and secondarily caused by the attractive forces between the solids in the mud, hence, nanotitanium particles work as lubricant to reduce the fractional force between mud's solids-increasing the distance between the mud's solids and facilitating the movement. However, high pH muds exhibit higher plastic viscosity than lower $\mathrm{pH}$ muds. This is attributed to the higher attractive force existing in the high $\mathrm{pH}$ muds due to the flocculation. Unlike the nanosilica, the nanotitanium with all concentrations dramatically decreases the plastic viscosity linearly.

From Figure 32 (B\&C), 0.3\% wt. of the nanotitanium results in higher impact on yield points properties. Unlike nanosilica, however, the general reduction in these properties increases as the nanotitanium concentration increases gradually. Hence, nanotitanium weakens the attractive forces between the Bentonite particles leading to low yield points. However, the values of the yield points are still in the higher and acceptable ranges that do not lead to solid sagging. The apparent viscosity profile shown in Figure 32 (D) is considered as a combination of the plastic and yield viscosities. Therefore, it is impacted in the same trend. 


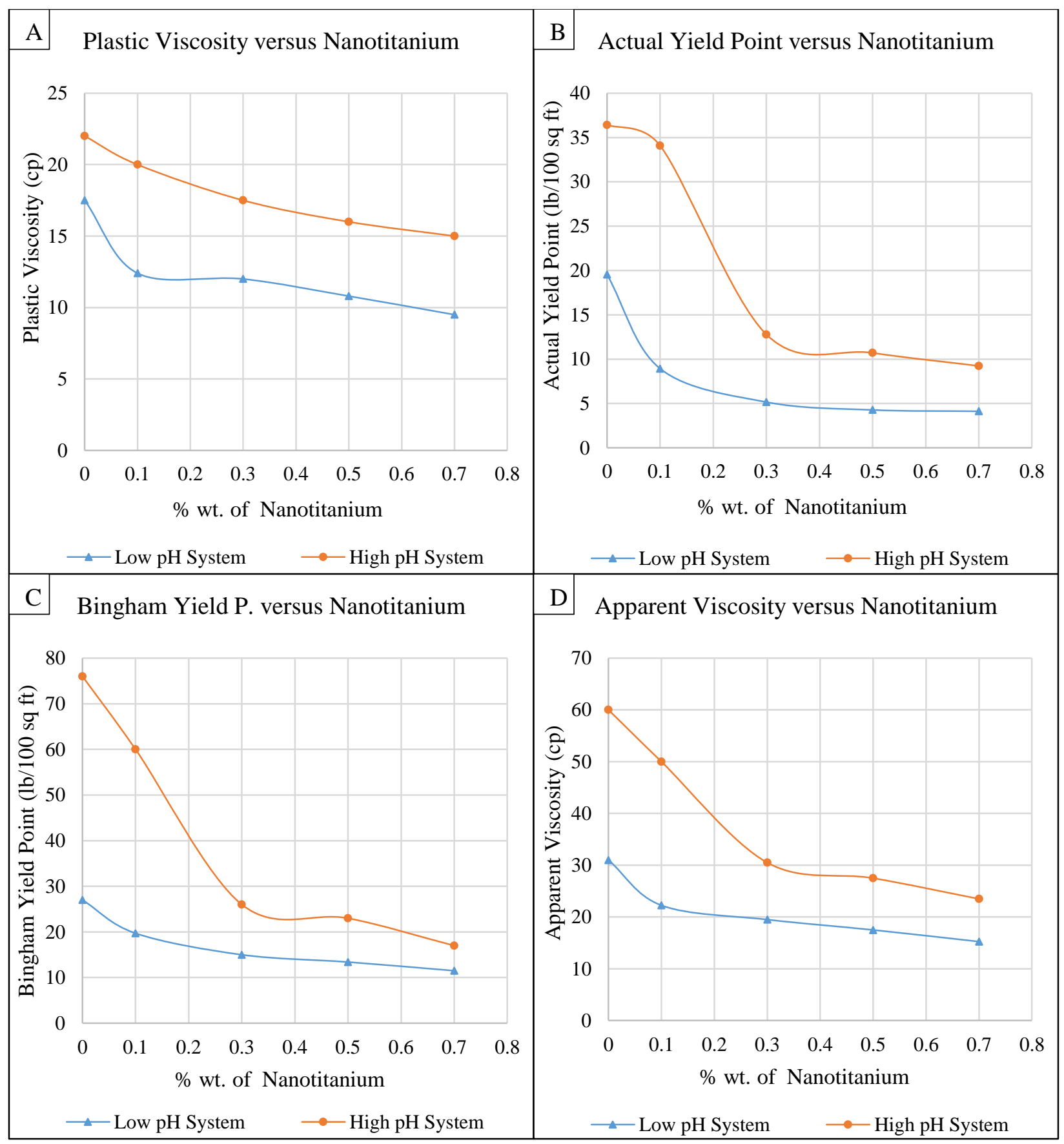

Figure 32: The impact of nanotitanium on the rheological properties

The reduction in the mud viscosities is due to the repulsive forces between negative charging nanotitanium particles, water molecules, and negative/positive charging clay particles, and due to the redistribution of the nanomuds' solids. These low viscosities will increase the mud pumpability and the rate of penetration (ROP). Therefore, it is important to design a suitable 
fluid rheology by using nanotitanium with different concentrations to improve the drilling performance.

Figure $33(\mathrm{~A} \& \mathrm{~B})$ shows the impact of nanotitanium on the effective viscosity at low and high shear rates. Like nanosilica muds, the nanotitanium muds exhibit more shear thinning than the mud without nanotitanium for the low $\mathrm{pH}$ system, for all concentrations. They exhibit higher viscosity at lower shear rate and lower viscosity at higher shear rate, which is desirable in the drilling industry.

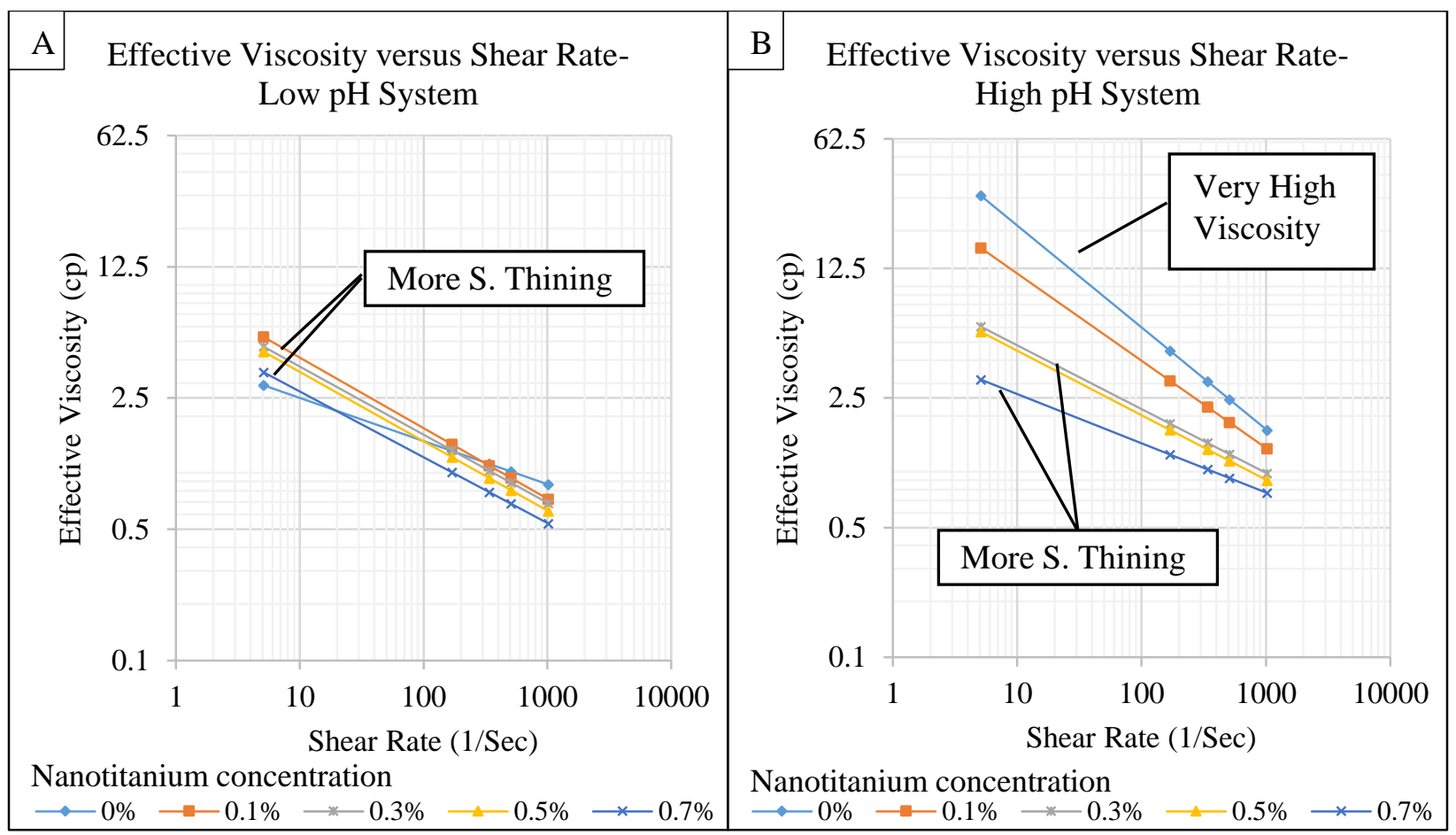

Figure 33: The impact of nanotitanium on the effective viscosity

For the high $\mathrm{pH}$ system, the basic mud exhibits shear thickening which implies the low pumpability at low and high shear rates due to the flocculation. Results show that the nanotitanium enhances the effective viscosity for that mud by lowering it at lower and higher shear rates to acceptable levels. This restores the deflocculated mud's behavior, thereby decreasing the energy required to move the mud.

Practically, the nanotitanium mud shear thins to low viscosities through the drill bit and string. This reduces the circulating pressure requirements. On the other hand, this nanomud has higher viscosities at lower mud velocities. This aids in hole cleaning in the annulus. Then, it develops 
gel strengths at static conditions and aids in suspending heavy materials and cuttings. The weak bonds between the Bentonite particles due to the nanotitanium is the main reason behind this behavior.

Figure 34 shows the impact of the nanotitanium on the gel strength.

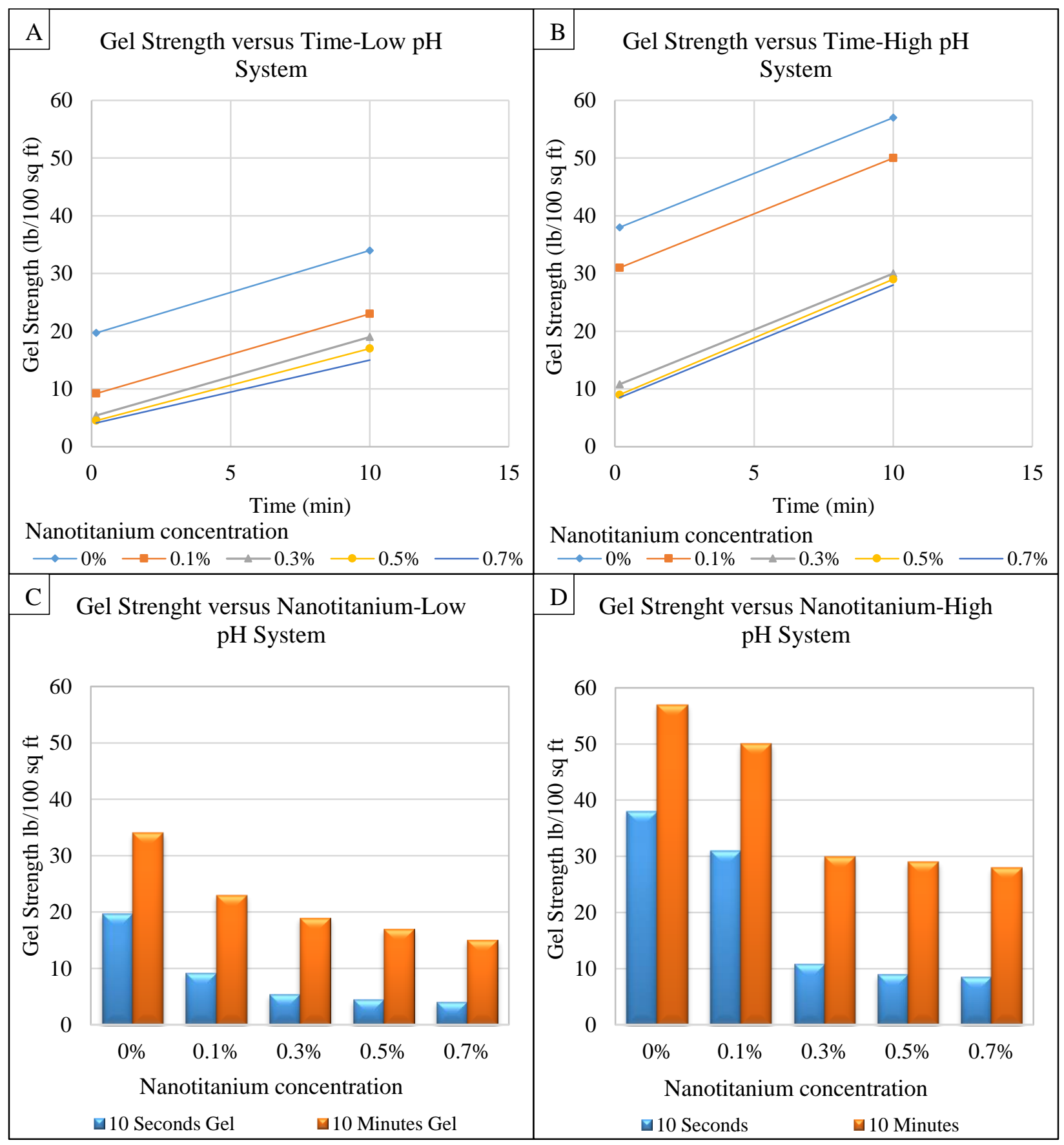

Figure 34: The impact of nanotitanium on the gel strength 
Figure $34(\mathrm{~A} \& \mathrm{~B})$ show that the basic muds exhibit higher 10 seconds and 10 minutes' gels for both systems, which is an undesirable progressive type of gel in the field. In addition, the current mud design provides wide rages of suitable gels that can be used for different drilling conditions. Figure $34(C \& D)$ show a gradual reduction in the gel as nanotitanium concentration increases. This is due to the magnification of the repulsive force between the Bentonite particles as the nanotitanium concentration increases. In this case, the nanotitanium works as a deflocculant agent. Unlike nanosilica, the differences between the 10 seconds and 10 minutes gels are large.

For the high $\mathrm{pH}$ mud system, it can be seen that $0.1 \%$ wt. of nanotitanium does not significantly enhance the gel strength, however; $0.3 \%-0.7 \%$ wt. enhances the gels to acceptable levels, more fragile gel. Fragile gel is important for the mud pumpability, cutting suspension, and cuttings removal at the surface Shale Shakers.

Unlike nanosilica, nanotitanium does not result in a low flat gel, which is undesirable because of the resulting solid sagging and insufficient cutting suspension capacity while a mud pump is off. Also, it can be seen that no clear changes in the 10 minutes' gel strength after adding $0.5 \%-0.7 \%$ wt. of the nanotitanium for the high $\mathrm{pH}$ system. Considering the economic requirements, $0.3 \%$ wt. is sufficient to improve the gel for this mud system.

\subsubsection{API Filtration Properties of Water-Based Nanotitanium Muds}

The comparisons between the API filtration profiles of the water-based nanotitanium muds and the basic muds are shown in Figure 35 (A\&B). Unlike the nanosilica, nanotitanium slightly enhances the filtration as the particle concentration increases gradually due to the larger particle size. It is believed that the nanotitanium particles with the current sizes are not enough to achieve more seal for the spaces and make narrower pathways within the developed mudcake. Using nanoparticles with smaller particle size is superior to enhance the water-based mud's filtration properties. Interestingly, the current mud design does not increase the filtration.

The spurt loss is completely stopped by nanotitanium though only a small loss was recorded for the basic samples. The spurt loss of the drilling fluid is considered as one of the well-known sources of solids invasion that causes formation damages. Thus, the nanotitanium with the current design reduces the formation damage, thereby increasing the oil and gas production. 


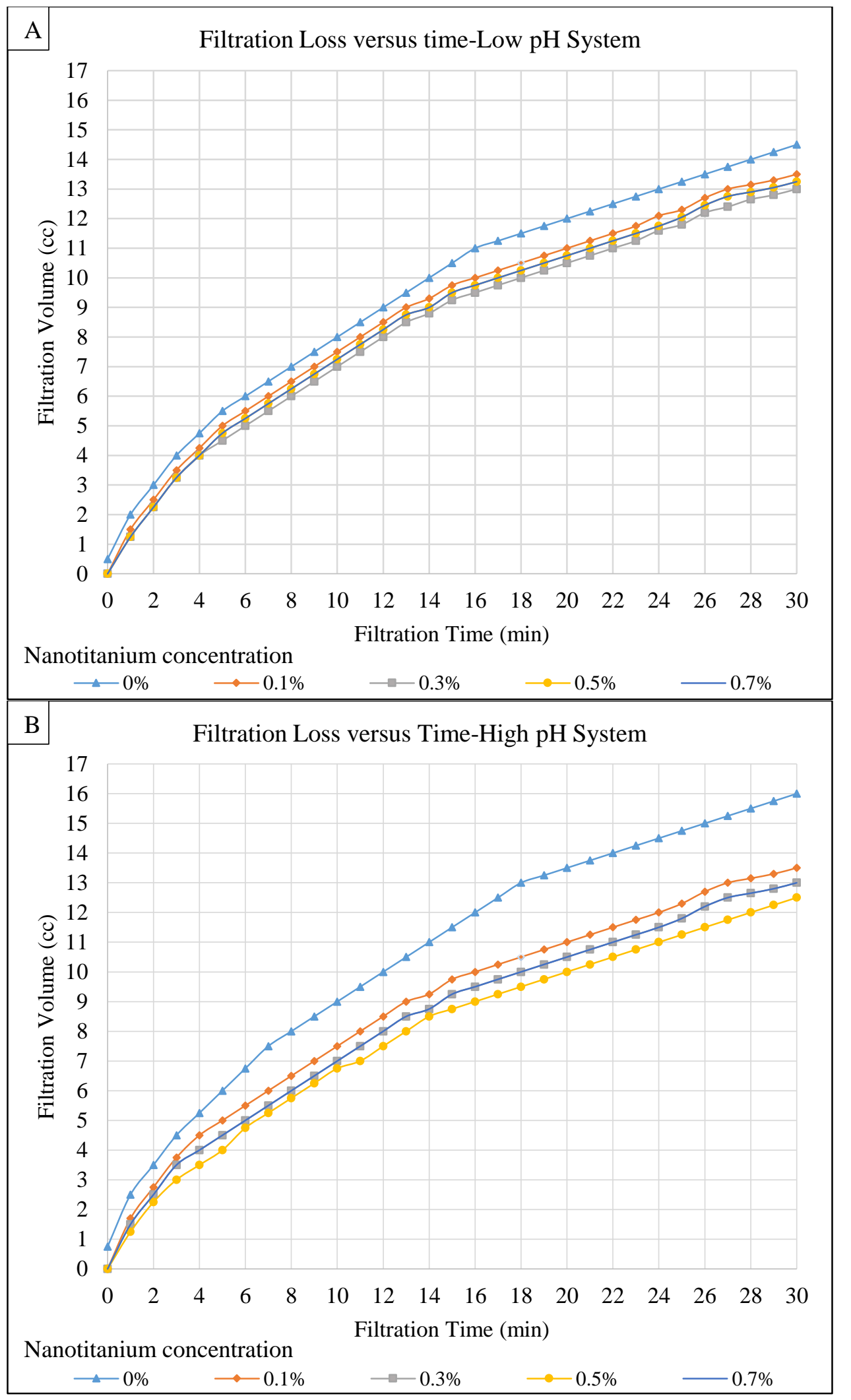

Figure 35: The filtration profiles for muds with and without nanotitanium 
The results show more filtration loss from the high $\mathrm{pH}$ basic mud than from the low $\mathrm{pH}$ basic mud. This is attributed to the flocculation in the mud with high $\mathrm{pH}$. Higher clay flocculation leads to more filtration and thicker mudcake that increases the probability of differential stuck pipe problems. By considering the filtration volume of the flocculated mud, it is noticed that the impact of the nanotitanium on the high $\mathrm{pH}$ mud is more significant than the low $\mathrm{pH}$ mud. The nanotitanium particles arrange the Bentonite's platelets in the parallel position instead of the point type position resulting in a shingle roof-like structure. However, they do not totally occupy the space between the particles. As a result, the amount of filtration is reduced only to the normal level that is obtained from the basic low $\mathrm{pH}$ mud. The point type contact of micro particles and flocs created due to poorly dispersed and linked mud components along with their nonparallel orientation within the mudcake matrix are some of the factors causing more filtration loss.

Figure $36(\mathrm{~A} \& \mathrm{~B})$ illustrates the filtration volumes and the reduction percentages for both mud systems. Unlike nanosilica, the filtration loss does not decrease significantly as the concentrations increase for both systems. However, $0.1 \%$ wt. of the nanotitanium slightly enhances the filtration, especially in the high $\mathrm{pH}$ water-based mud. In this case, around $20 \%$ and $10 \%$ filtrate reductions were obtained for the high and low $\mathrm{pH}$ mud systems, respectively.

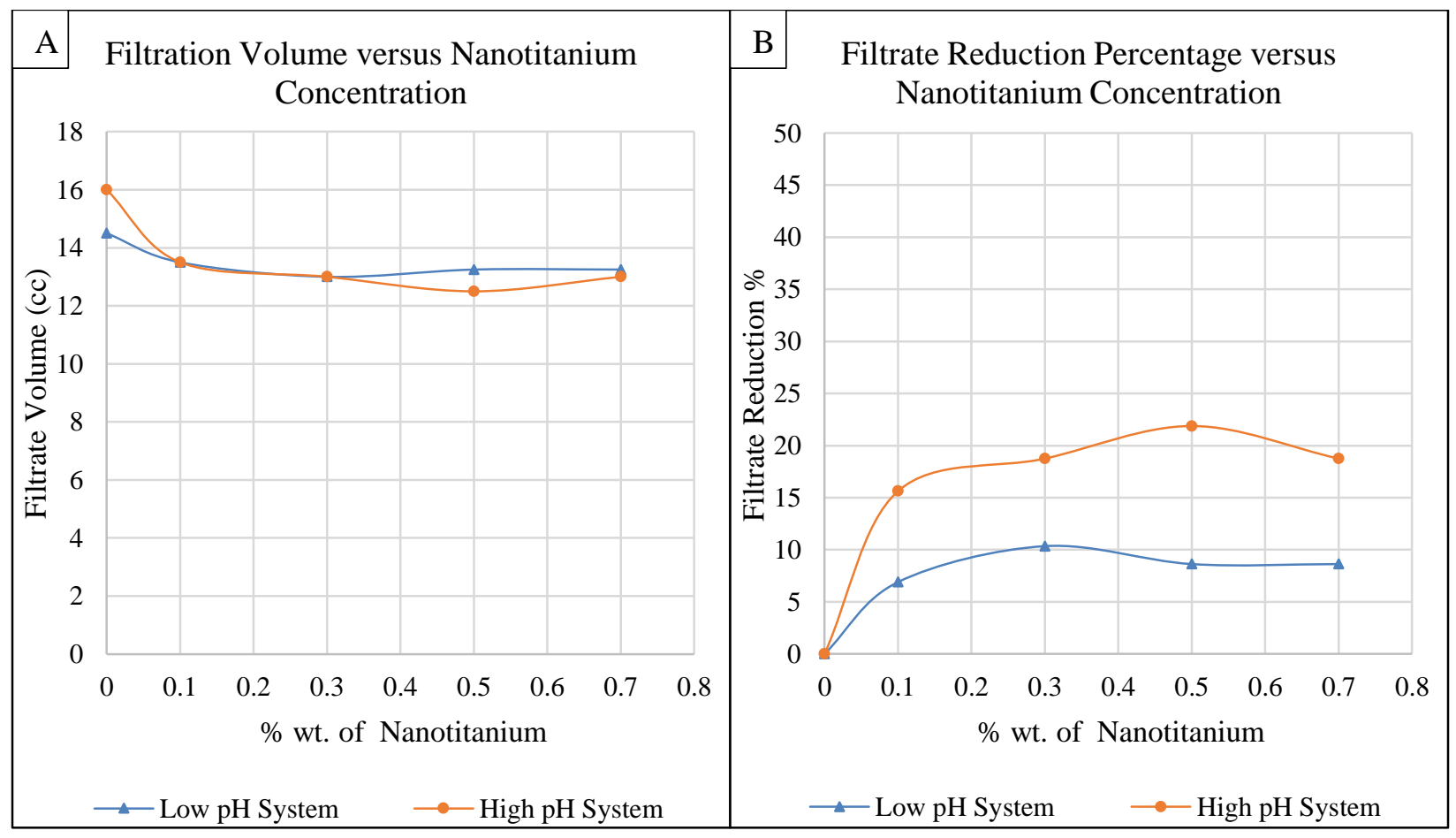

Figure 36: The impact of nanotitanium on the filtration volume 
Figure $37(A \& B)$ demonstrates the impact of nanotitanium on the mudcake thickness for both mud systems. Unlike the mudcakes developed by nanosilica muds, the results show less impact of nanotitanium on the mudcake thickness for both mud systems. This is due to the bigger particle size, nanotitanium chemical properties, and resulting higher filtration amounts. The best concentration that gives the lowest cake thickness $-2 \mathrm{~mm}$ in low $\mathrm{pH}$ muds and $2.5 \mathrm{~mm}$ in high $\mathrm{pH}$ muds - for the current mud design is achieved when $0.5 \% \mathrm{wt}$. of nanotitanium is used. This means $28 \%$ and $38 \%$ thickness reductions can be achieved for high and low $\mathrm{pH}$ muds, respectively. Hence, nanotitanium particles trap the space between the mudcake solids, leading to narrower pathways than the basic muds. The thinner mudcakes deposited by the nanotitanium muds may reduce the mudcake related problems such as stuck pipe. However, it is clear that the nanosilica leads to the narrowest pathways.

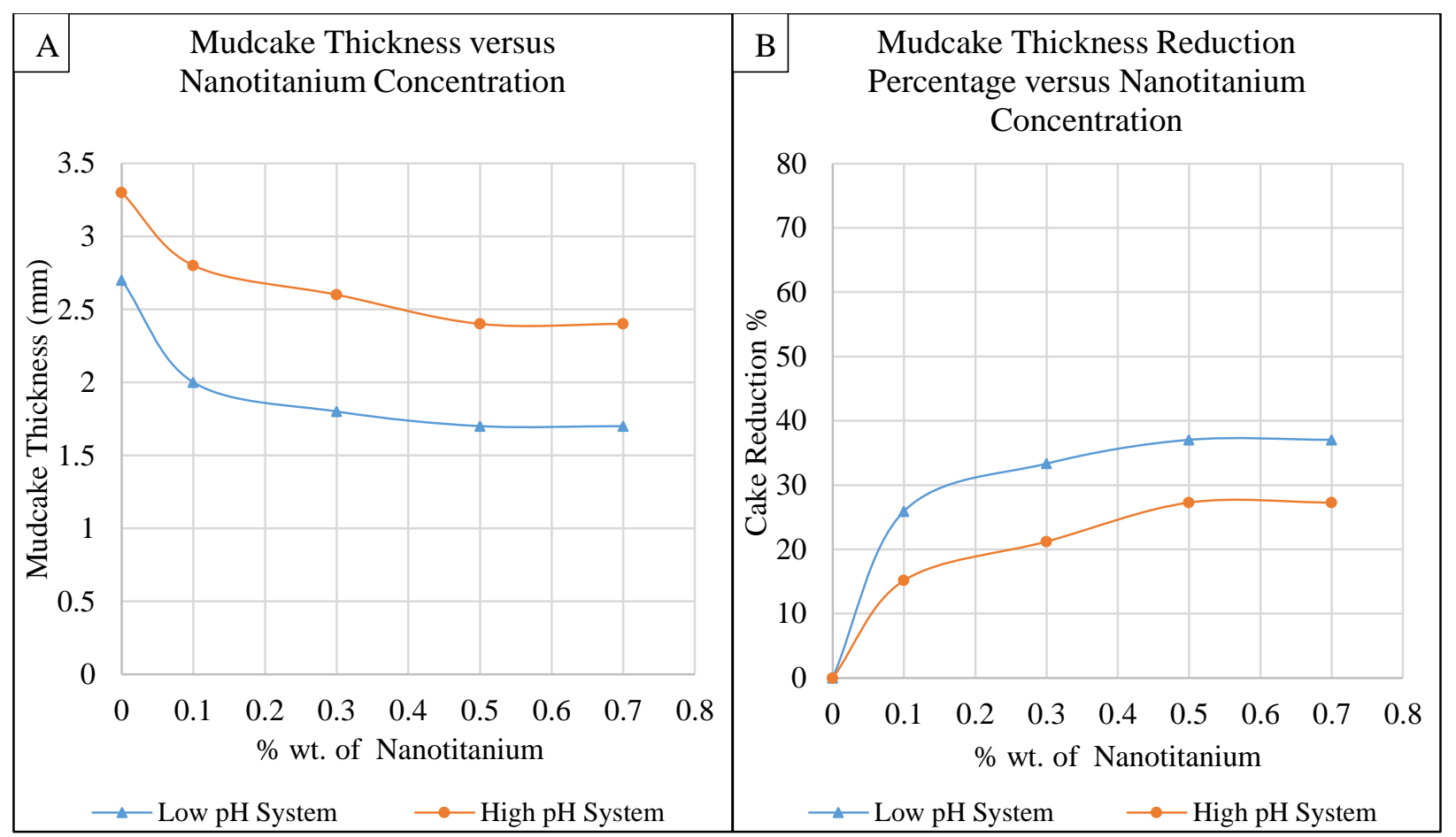

Figure 37: The impact of nanotitanium on the mudcake thickness

The high dispersion and the nano size of the nanotitanium particles resulted in a smooth surface of the mudcake as the well-dispersed nanoparticles fill the tiny holes located on the surface of the mudcake. The smooth, compacted, thin, and plaster-like mudcake helps in strengthening a well's wall, especially in the unconsolidated formations and deviated wells. Nanotitanium muds without spurt loss and internal mudcakes develop an external mudcake that can be removed 
easily prior to the cement job by the washer liquids, which is wanted for high quality cementing of wells. Also, these cakes can be removed easily due to the weak links between the clay particles. The negative charge ions from the nanotitanium are attached to the positive charges on the clay particles leading to equilibrium forces and weak connections. Table 8 shows the mudcake structure properties with the presence and absence of nanotitanium for both systems.

\begin{tabular}{|c|c|c|}
\hline Description & Low pH Mud System & High pH Mud System \\
\hline Basic Muds & & \\
\hline $\begin{array}{l}\text { Water-Based Mud with } \\
0.1 \% \text { wt of Nanotitanium }\end{array}$ & & \\
\hline $\begin{array}{l}\text { Water-Based Mud with } \\
0.3 \% \text { wt of Nanotitanium }\end{array}$ & & \\
\hline $\begin{array}{l}\text { Water-Based Mud with } \\
0.5 \% \text { wt of Nanotitanium }\end{array}$ & & \\
\hline $\begin{array}{l}\text { Water-Based Mud with } \\
0.7 \% \text { wt of Nanotitanium }\end{array}$ & & \\
\hline
\end{tabular}

Table 8: Mudcakes development for muds with and without nanotitanium 


\subsubsection{Drilling Mud Hydraulics-ECD \& Circulating Pressure based on Nanotitanium muds}

Mostly as a rheological modifier, nanotitanium reflects a significant desirable impact on the hydraulics of the mud for both high and low $\mathrm{pH}$ mud systems-reduction in the ECD and drillpipe pressure. Figures $38 \& 39$ show the impact of the nanotitanium on the Equivalent Circulating Density in the $9000 \mathrm{ft}$ long and $12 \frac{1 / 4}{4}$ diameter hole based on the enhanced rheological data.

The comparison to the basic mud shows that there is a significant decrease in the ECD. Unlike nanosilica, the big enhancement was obtained after adding $0.3 \% \mathrm{wt}$. of the nanotitanium to the mud of both $\mathrm{pH}$ systems. This supports the previous observation that implies the use of nanotitanium with a $0.3 \%$ wt. concentration is sufficient to change the drilling fluid rheological properties.

Based on the current water-based nanotitanium muds' design, nanotitanium particles reduce the ECD from $9.7 \mathrm{lb} / \mathrm{gal}$ to $9.3 \mathrm{lb} / \mathrm{gal}$ for the high $\mathrm{pH}$ mud system and from $9.45 \mathrm{lb} / \mathrm{gal}$ to $9.2 \mathrm{lb} / \mathrm{gal}$ for the low $\mathrm{pH}$ mud system. This will help in reducing loss circulation, formation fracture, and their associated blowouts in the fragile and pressurized formations. Nanotitanium can also be considered as a lubricant in the water-based mud. Thus, enhancing the drilling fluid rheological properties by means of nanotitanium is one of the main factors that help in optimizing the hydraulics and then reducing drilling costs.

Reducing the ECD is based on adding nanotitanium particles only, thereby on changing the rheology of the mud only. This means the ECD will be reduced by considering the changes in the other independent parameters such as wellbore geometry, downhole tools' dimensions, and the raw materials being used to prepare muds. 


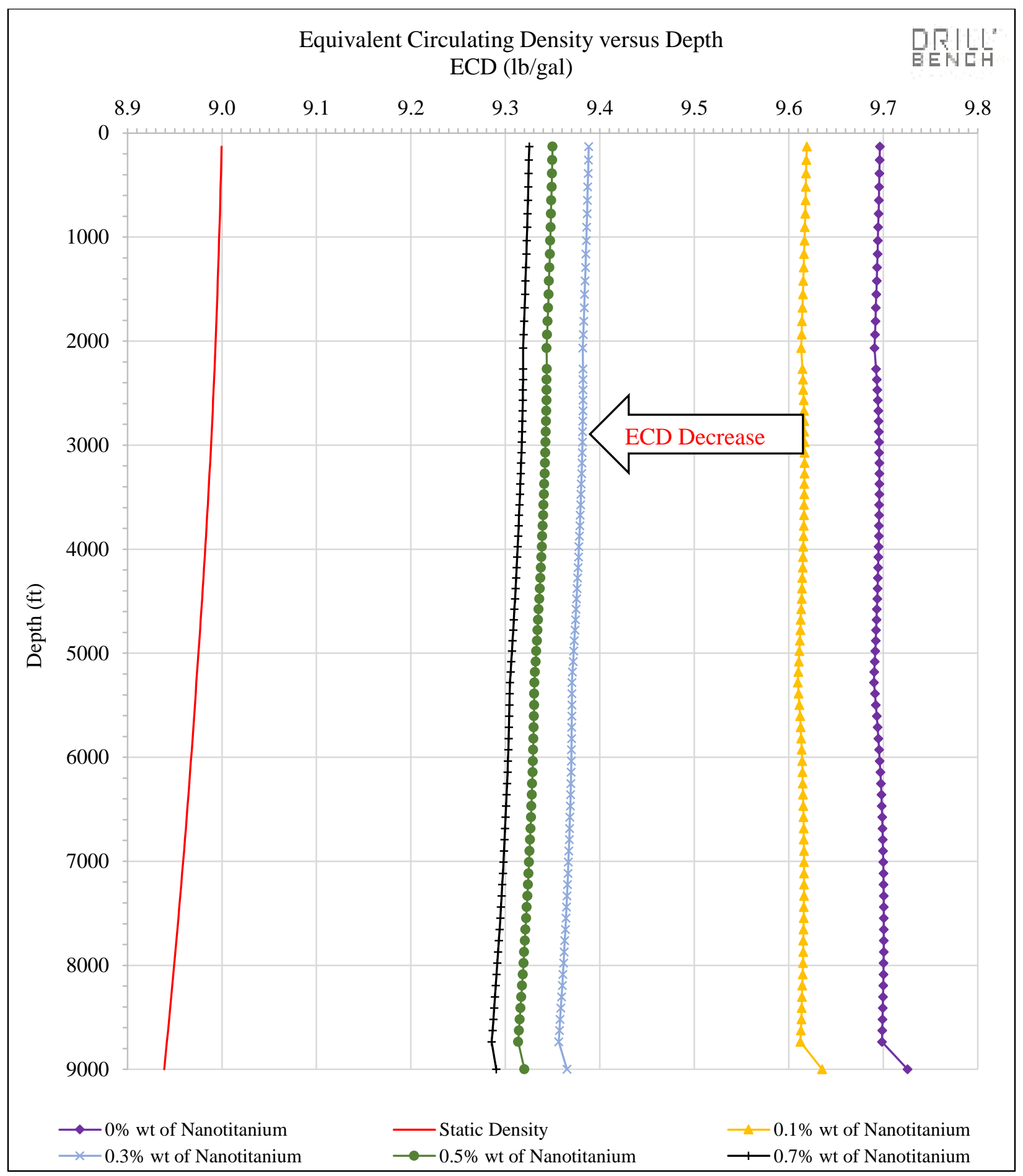

Figure 38: The impact of nanotitanium on the equivalent circulating density-high pH mud system 


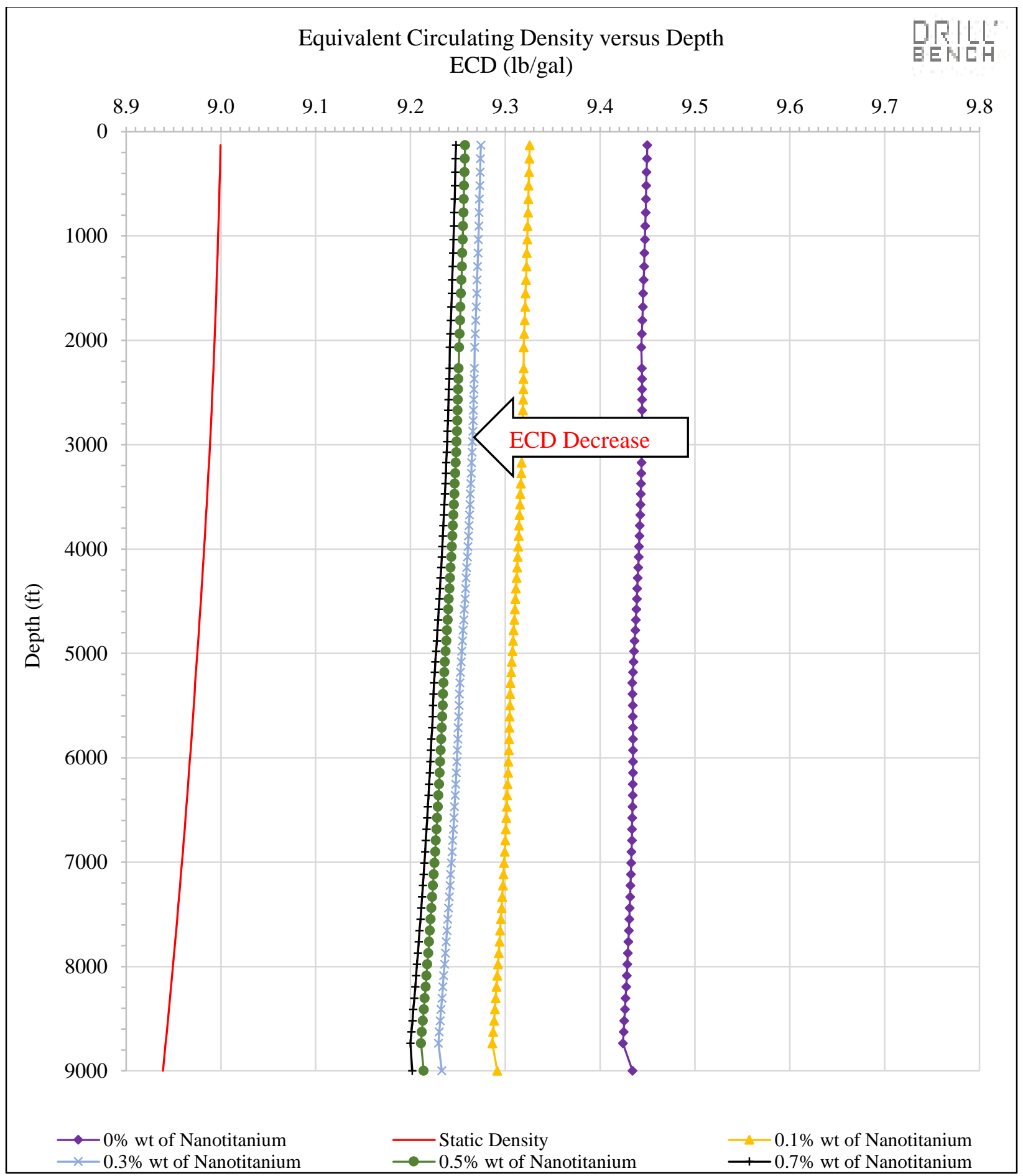

Figure 39: The impact of nanotitanium on the equivalent circulating density-low pH mud system

Results show reductions in the drillpipe's circulation pressure after adding different concentrations of nanotitanium to the basic muds. Figures $40 \& 41$ show the impact of nanotitanium on the pipe pressure for both high and low $\mathrm{pH}$ mud systems. It is seen from Figure 
40 that the nanotitanium reduces the surface drillpipe pressure by 270 psi. The $0.3 \% \mathrm{wt}$. of nanotitanium was enough to make a significant reduction in the pump pressure loss throughout the $9000 \mathrm{ft}$ directional well, whereas only $0.1 \%$ wt. of nanosilica yielded a similar result.

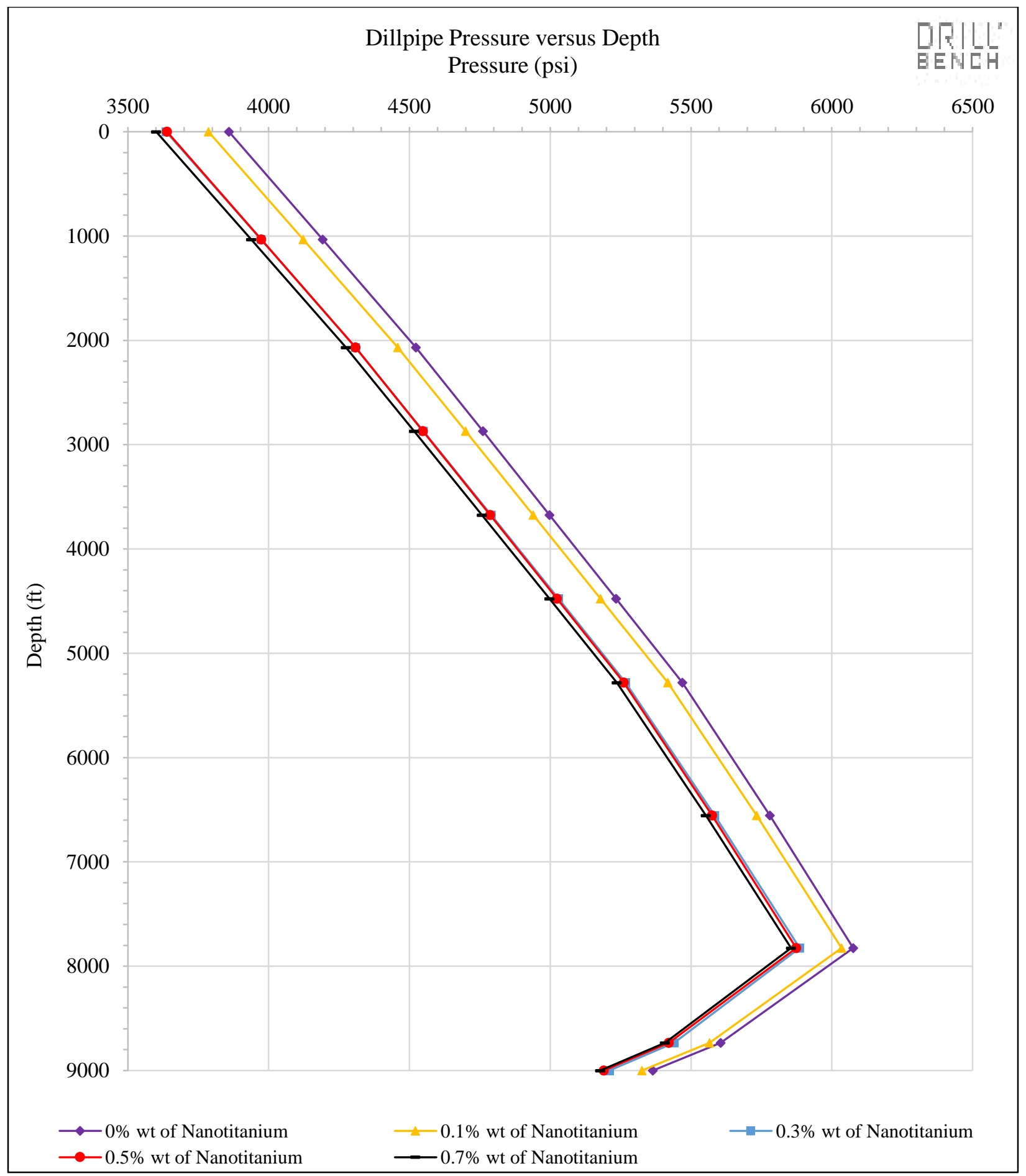

Figure 40: The impact of nanotitanium on the drillpipe pressure-high $\mathrm{pH}$ mud system 


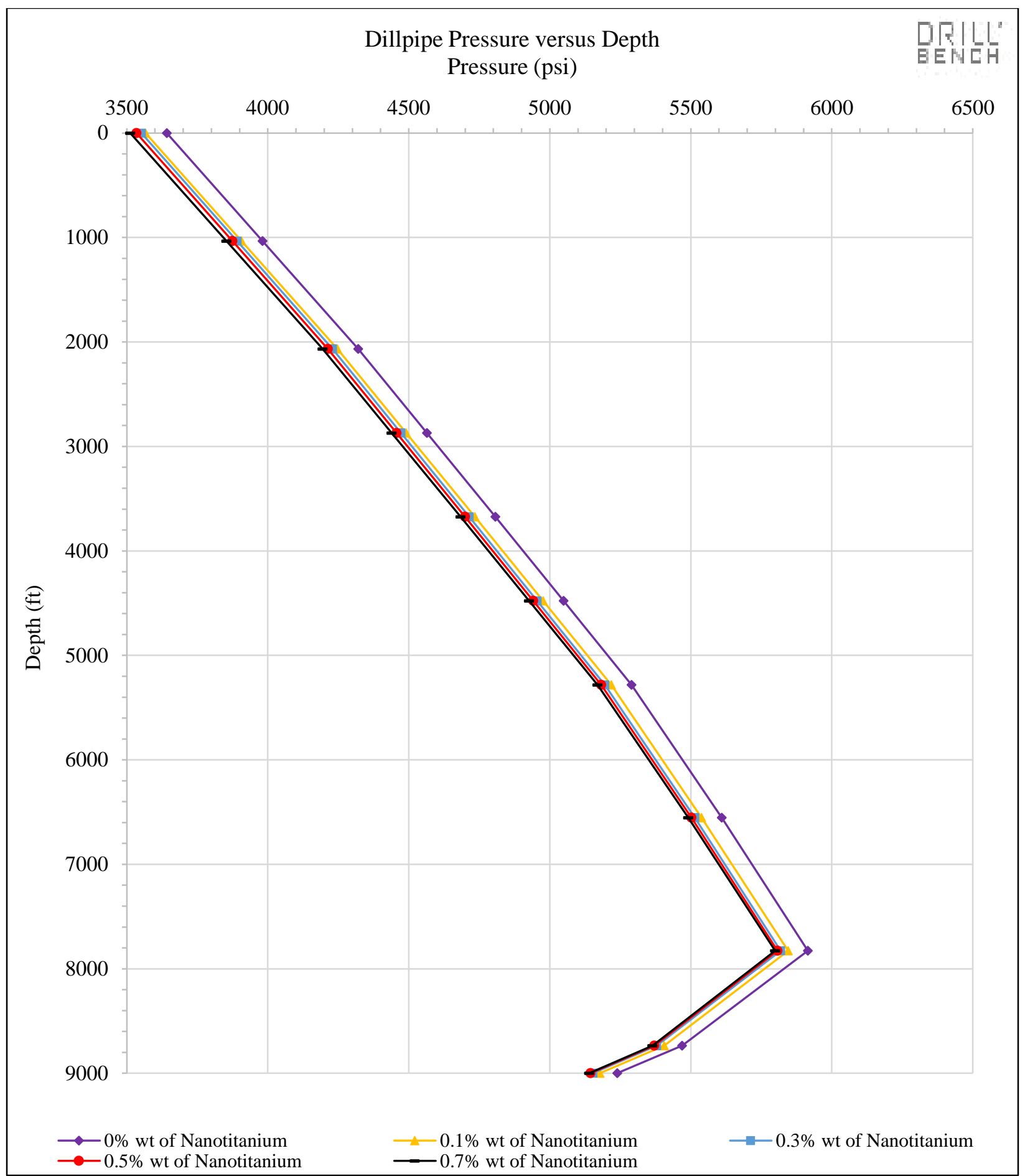

Figure 41: The impact of the nanotitanium on the drillpipe pressure-low $\mathrm{pH}$ mud system

Minimizing pump pressure while keeping other hydraulics parameters in required levels is a desirable factor in minimizing the energy exerted by mud pumps and increasing the operational life of the drilling equipment. 


\subsection{Results and Discussions of Using Nanoaluminum with Water-Based Muds}

\subsubsection{API Rheological Properties of Water-Based Nanoaluminum Muds}

The rheological profiles of drilling muds for both $\mathrm{pH}$ systems are shown in Figure 42 (A\&B). Clear differences in the flow behaviors is seen between the basic muds and muds with different concentrations of nanoaluminum. It is observed that nanoaluminum with the current physical and chemical properties reduces the viscosity and changes the required nonlinear shear rate/stress relation to a leaner relation as the concentration increases. Thus, unlike nanotitanium and nanosilica, the nanoaluminum switch the fluid type from non-Newtonian to Newtonian, especially for the high $\mathrm{pH}$ mud system. Newtonian fluids are not desirable in the drilling industry because they do not have yield point and gel development resulting in a poor carrying capacity of the drilled cuttings and heavy materials.

However, only very small amounts of the anionic nanoaluminum can be used to enhance the rheological properties and result in a better behavior than the basic muds' behaviors. Figure 42 (A) shows the enhanced behavior of the mud with $0.1 \%$ wt. of nanoaluminum and the degraded behavior of the higher concentrations. Similar results can be seen from Figure 42 (B) for high and low $\mathrm{pH}$ systems, however, the shear stress of the mud is reduced and the pumpability of the mud is increased which are needed in the drilling operations as they reduce the energy required to circulate the mud in a well.

Figure 42 (B) shows that the $0.1 \%$ wt. is not enough to overcome the flocculation in the high $\mathrm{pH}$ basic water-based mud. However, $0.3 \%$ wt. of nanoaluminum is enough to make a big change in the rheological properties. This amount changes the behavior of the flocculated mud to mostly a low Power Law-mud behavior. The Modified Power Law model is best for drilling fluid behavior simulation, however; Power Law muds such as polymer muds have acceptable behaviors. The chemical interaction between the Bentonite's particles and the negatively charged nanoaluminum determines the trends shown in the figure. 


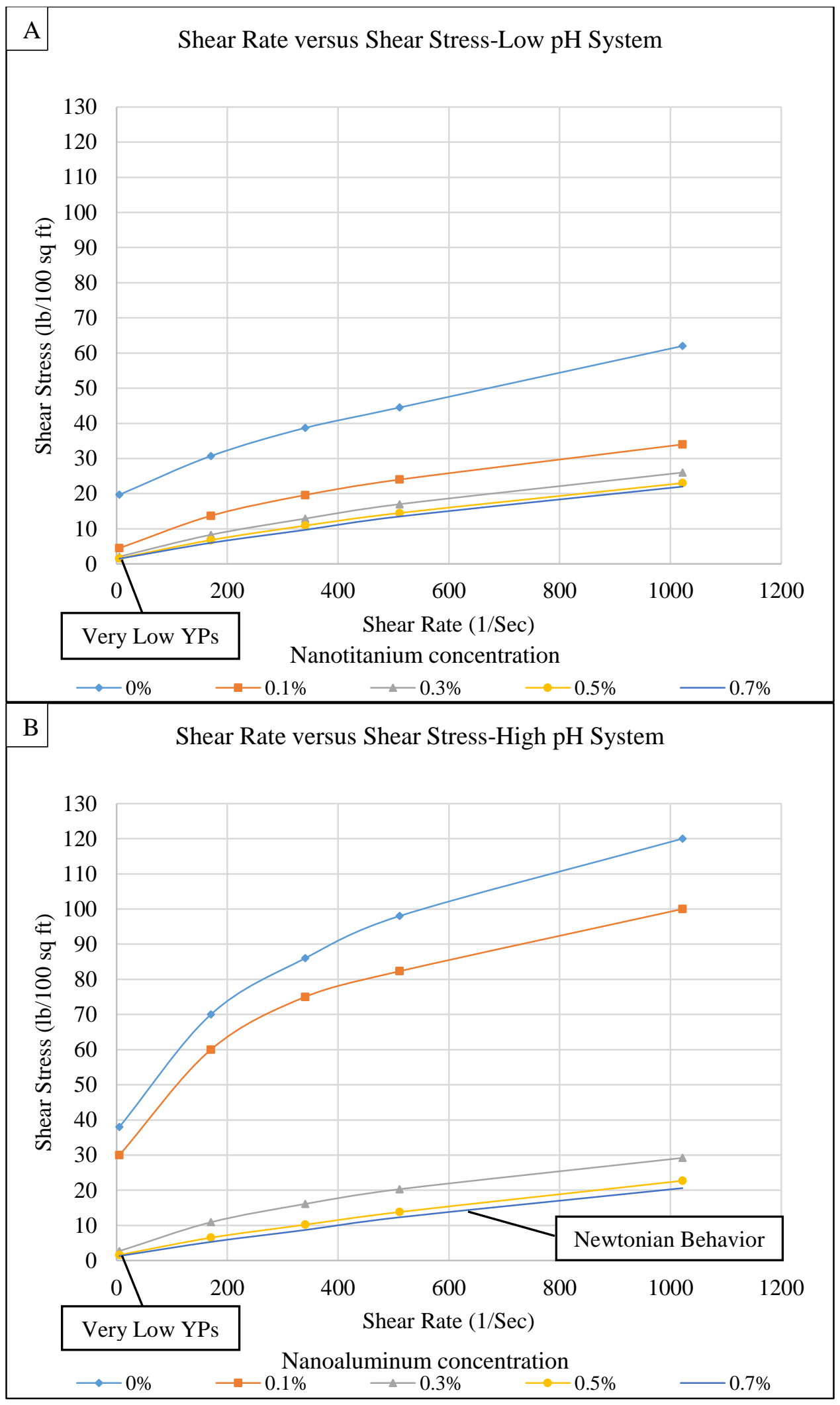

Figure 42: The rheological profiles for muds with and without nanoaluminum 
Figure 43 (A, B, C, and D) show the results for the rheological properties and the impact of the anionic nanoaluminum on the plastic viscosity, yield points, and apparent viscosity for high and low $\mathrm{pH}$ mud systems. Nanoaluminum particles exhibit the strongest repulsive force in this experiment. They also increase the distance between Bentonite particles and cause severe weakness in the electro-chemical attractive forces between the solids in the muds. This may make the nanoaluminum with the higher concentrations a poor rheological modifier agent in the drilling fluids.

Figure 43 (A) shows that the plastic viscosity decreases for the low and high $\mathrm{pH}$ muds as the concentration increases. Nanoaluminum reduces the plastic viscosity for both low and high $\mathrm{pH}$ systems from 17 to $8 \mathrm{cp}$ and from 22 to $8 \mathrm{cp}$, respectively. The plastic viscosity is mainly a particles' geometry-dependent property and also a solids' attractive force-dependent property. This makes the nanoaluminum with nano-size particles a good agent to reduce the plastic viscosity, thereby increasing the drilling efficiency. Using $0.3 \%$ wt. was enough to reduce the plastic viscosity in the tested muds to the lowest values, considering the economic issue. It can be seen that the plastic viscosities are equal at the concentrations greater than $0.3 \%$ wt. due to the severe impact of the nanoaluminum on the solids attractive forces for both $\mathrm{pH}$ systems.

Figure $43(B \& C)$ show the impact of the nanoaluminum on the yield points. Nanoaluminum results in the lowest yield points in this experiment. Hence, concentrations greater than or equal $0.3 \%$ wt. cause very low yield points. A very low yield point may cause Barite and drilled cuttings to sag. This makes the nanoaluminum less desirable than the nanosilica and nanotitanium in terms of cuttings carrying capacity. In some circumstances throughout the drilling operations and mud conditioning, however, nanoaluminum with these concentrations can be used as sagging agent. Sagging agents are used for conditioning drilling fluids in some cases.

Furthermore, $0.1 \%$ wt. of the nanoaluminum reduces the yield points to acceptable ranges. This is very useful to increase the mud pumpability and reduce the energy required to circulate the mud in an oil well, without cutting suspension problems. In addition, it is noteworthy to tread the mud before the cement job by using very small amounts of nanoaluminum to get turbulent flow with less energy. As anionic particles, nanoaluminum weakens the attractive forces between the mud components leading to low yield points. 
The apparent viscosity shown in Figure 43 (D) is considered as a combination of the plastic and yield viscosities.

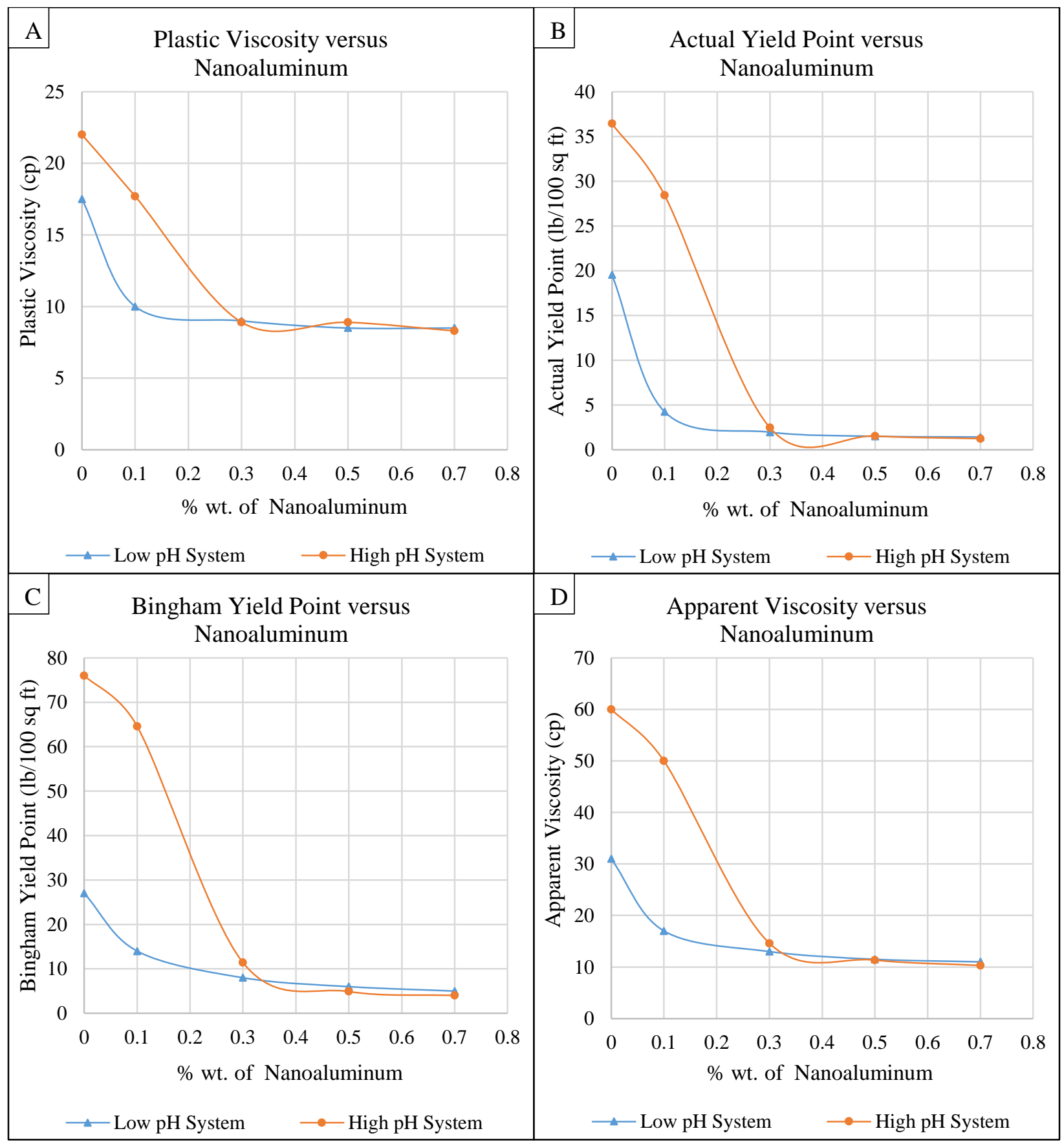

Figure 43: The impact of nanoaluminum on the rheological properties 
Figure $44(A \& B)$ show the impact of nanoaluminum on the effective viscosity at low and high shear rates. Unlike nanosilica and nanotitanium muds, nanoaluminum mud with only $0.1 \%$ wt. exhibits more shear thinning than the basic mud for the low $\mathrm{pH}$ system. This concentration causes higher viscosity at lower shear rate and lower viscosity at higher shear rate, which is desirable in the drilling operations. Thus, nanoaluminum enhances the mud performance in the drill string, annulus, and mud tanks. The higher concentrations cause lower viscosity at higher and lower shear rates. This may be unwanted due to poor cuttings suspension.

For the high $\mathrm{pH}$ system, results show that only $0.3 \%$ wt. of nanoaluminum causes enhancement for the effective viscosity compared with the effective viscosity of the basic mud. Concentrations greater than $0.3 \%$ wt. may result in very low effective viscosity.

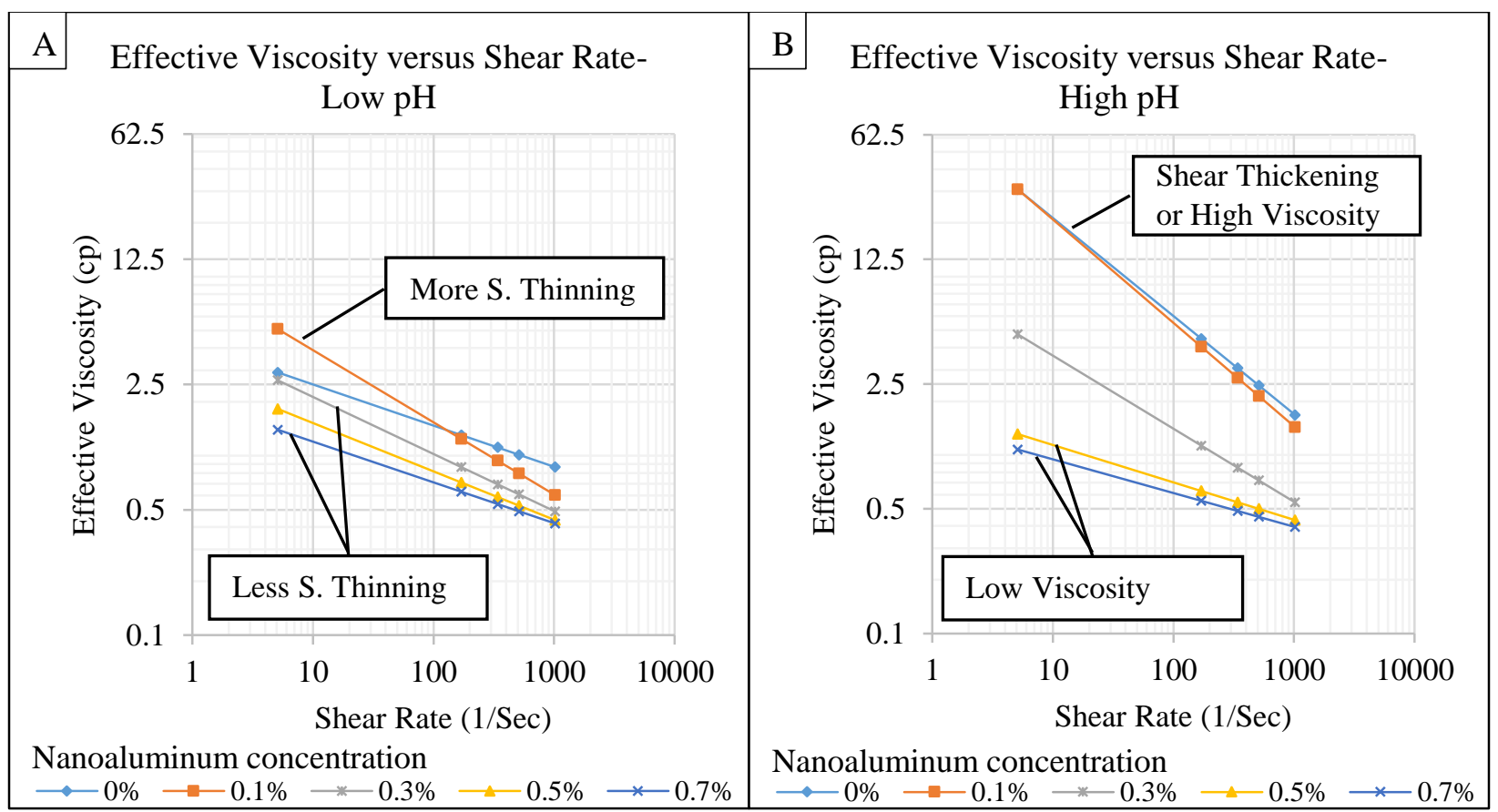

Figure 44: The impact of the nanoaluminum on effective viscosity

Figure 45 (A-D) shows the impact of the nanoaluminum on the gel strength. Based on the observations, the basic muds exhibit progressive gels. In addition, no positive impact of nanoaluminum was recorded on the gel strength of the low $\mathrm{pH}$ muds, except for the $0.1 \%$ wt. This concentration leads to a lower and more fragile gel than the basic muds, which is desirable. Other concentrations lead to almost flat gels, which is not acceptable due to poor cuttings 
suspension. In this case, using nanoaluminum with only the smallest amounts was enough to enhance the gel property.

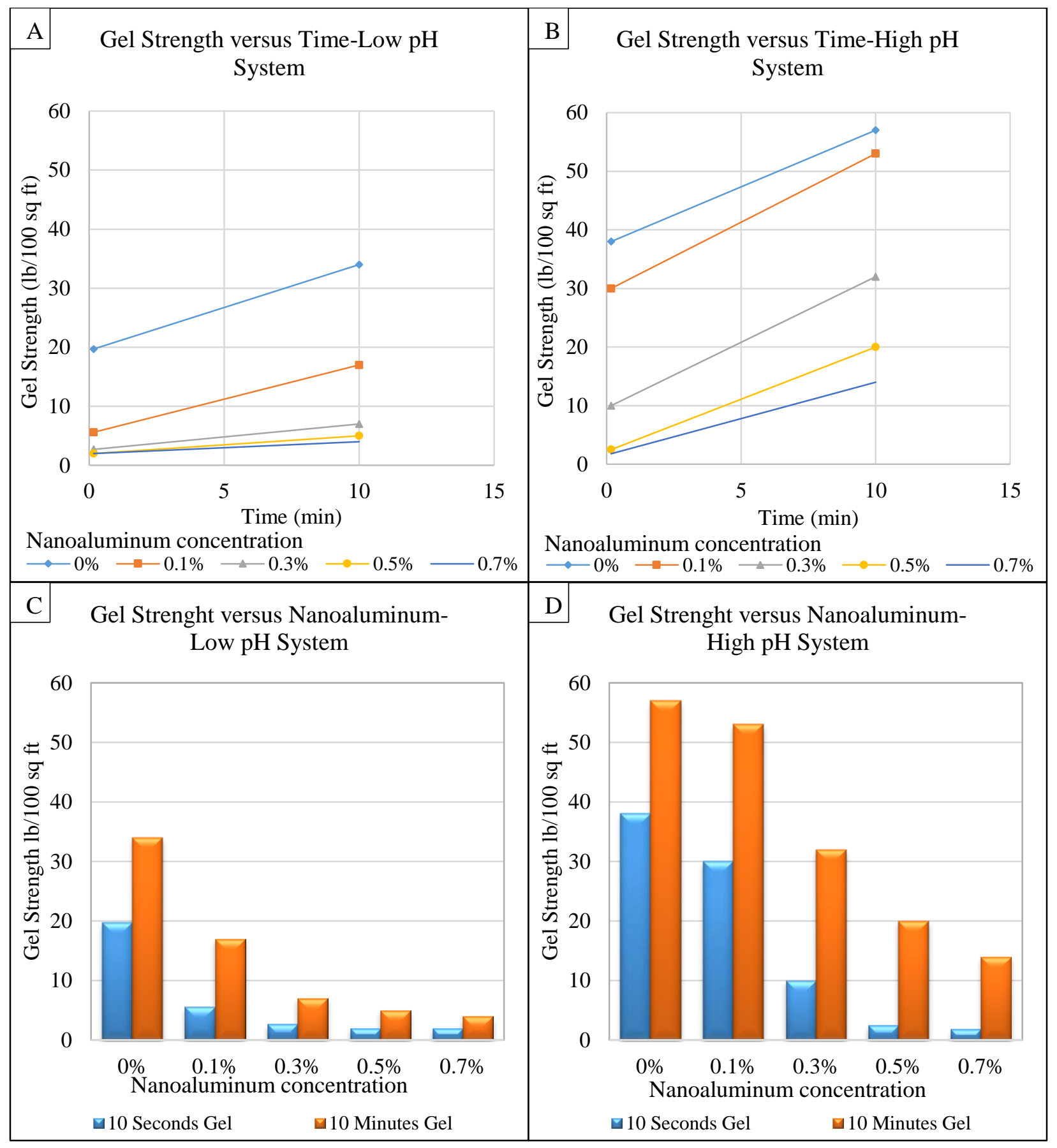

Figure 45: The impact of the nanoaluminum on the gel strength

For the high $\mathrm{pH}$ muds, high and low progressive type of gels can be observed in most of the muds. In general, very low 10 seconds and very high 10 minutes' gels result in cutting settling 
and high circulation pressure requirement, respectively. Practically, the big deference between 10 seconds and 10 minutes gel is not favorable, however; $0.3 \%$ wt. concentration results in more acceptable gel than the other concentrations and it reflects enhancement in comparison to the flocculated basic mud's gel.

Figure $45(\mathrm{C} \& \mathrm{D})$ show a gradual reduction in the gel as nanoaluminum concentration increases, which is desirable. This is due to the same repulsive force occurring between the nanoparticles themselves and between mud's solids and nanoparticles. Hence, nanoaluminum works as a deflocculant agent. Unlike other nanomaterials, nanoaluminum reflects a poor performance in terms of gel enhancement.

\subsubsection{API Filtration Properties of Water-Based Nanoaluminum Muds}

The API filtration profiles of the water-based nanoaluminum muds and the basic muds are shown in Figure $46(\mathrm{~A} \& \mathrm{~B})$. Unlike the nanosilica and nanotitanium particles, nanoaluminum particles with the current geometry do not improve or diminish the filtration as the concentration increases gradually. Only $0.5 \mathrm{cc}$ of the filtration reduction was recorded by using nanoaluminum particles with the low $\mathrm{pH}$ muds. It is believed that $100-200 \mathrm{~nm}$ particles are not large enough to seal the spaces and make narrower pathways within the developed mudcake causing the water to pass easily.

However, the spurt loss completely stops with nanoaluminum though only a small loss was recorded for the basic samples. Thus, the nanoaluminum with the current design can be used to reduce the formation damage, thereby increasing the oil and gas production. No increase in the filtration for both mud systems makes the nanoaluminum an acceptable modifier agent only, though it enhances the rheology with a limited range of concentrations. 


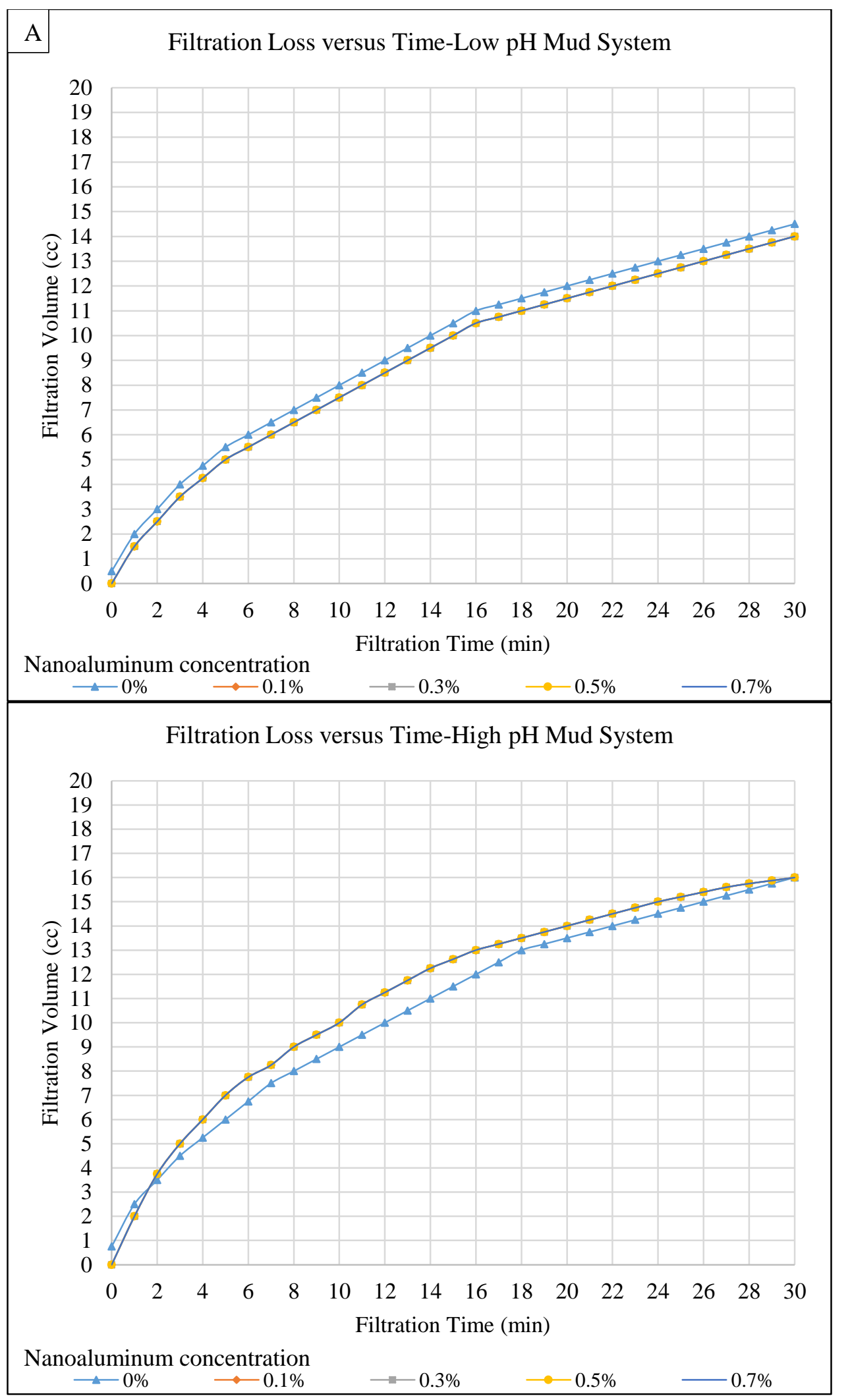

Figure 46: The filtration profiles for muds with and without nanoaluminum 
Figure $47(\mathrm{~A} \& \mathrm{~B})$ illustrate the volumes of the filtration loss and the filtration reduction percentages based on different concentrations of nanoaluminum for both mud systems. Unlike the nanosilica and nanotitanium, the filtration loss does not decrease significantly as the concentrations increase for both systems.

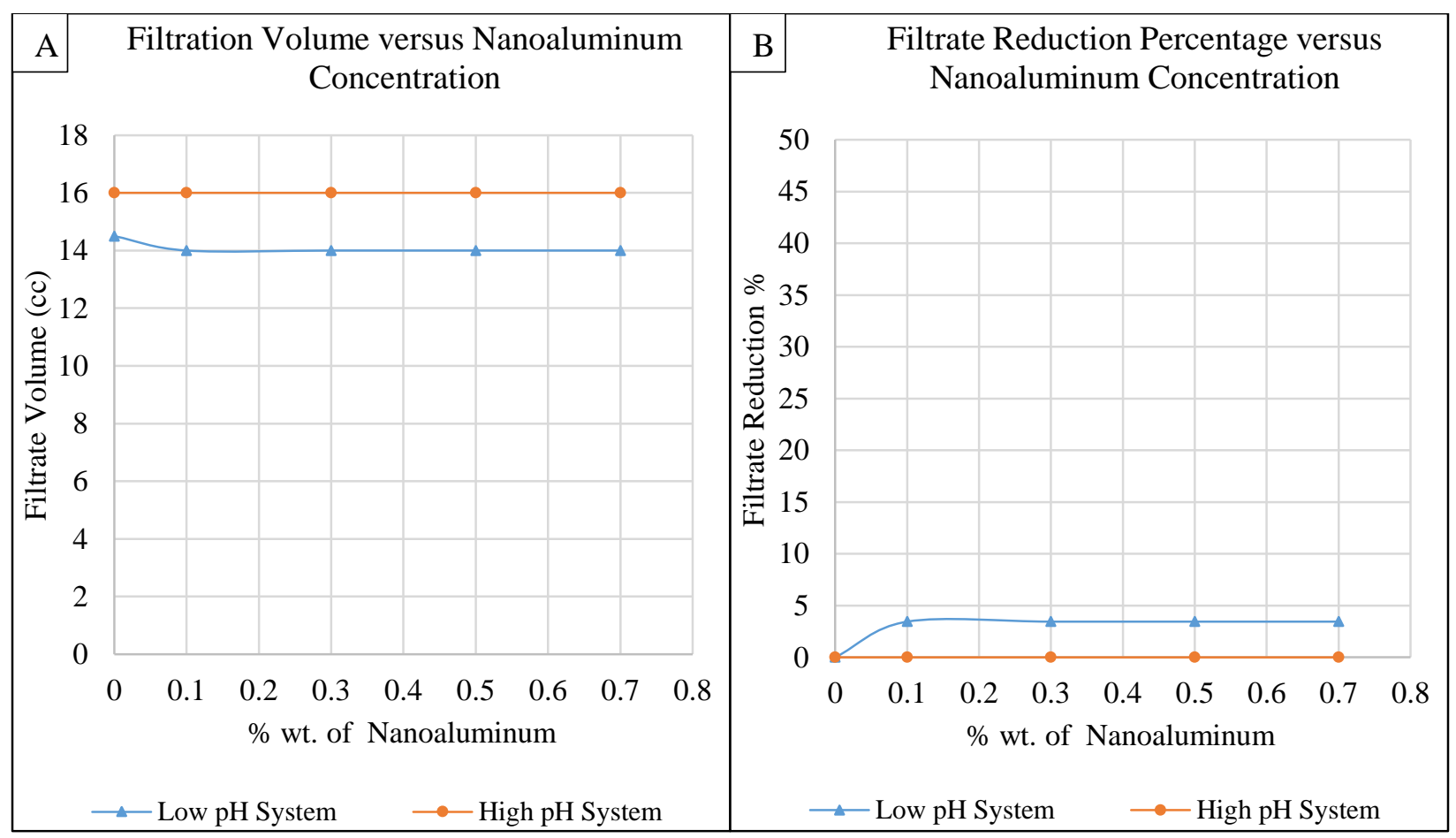

Figure 47: The impact of the nanoaluminum on the filtration volume

Due to its nano-size, however, nanoaluminum enhances the structure of the mudcake since it helps in solids arrangement, thereby resulting in slightly more compacted or thinner cakes. Figure 48(A\&B) demonstrate the impact of nanoaluminum on the mudcake structure for both mud systems. The results show that the nanoaluminum in the high $\mathrm{pH}$ mud system plays a less significant role than the low $\mathrm{pH}$ mud in reducing the cake thickness.

Unlike the mudcake obtained by nanosilica and nanotitanium muds, the thinner mudcakes ( 2.3$3.25 \mathrm{~mm}$ ) were obtained by using nanoaluminum. This means $18 \%$ and $3 \%$ of thickness reductions can be achieved for low and high pH muds, respectively. The biggest nanoaluminum particles trap the space between the mudcake solids, but they do not narrow the water pathways. Therefore, they are not promising in this function. 


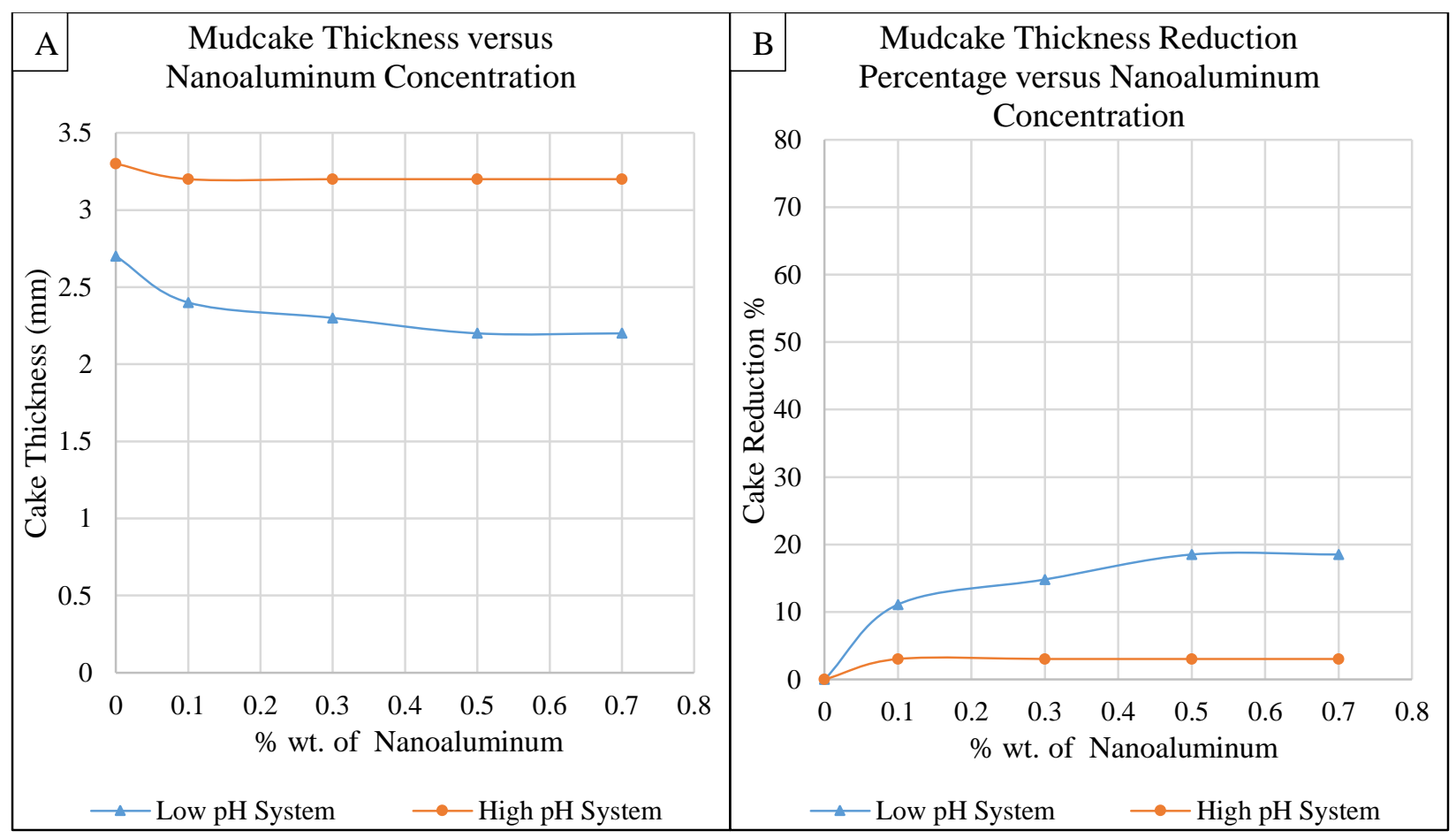

Figure 48: The impact of the nanoaluminum on the mudcake thickness

However, nanoaluminum helps in smoothing and baking the surface of the mudcake when they fill the tiny holes located on the surface of the mudcake as shown in Table 9.

Very smooth mudcake helps in reducing the stuck pipe in terms of increasing the lubricity. As solid additives, the nanoparticles trapped within the space between the Bentonite platelets and other mud's solids do not increase the mudcake thickness. In addition, nanoaluminum muds with weakly linked mudcake components and without spurt loss result in an external mudcake that can be removed easily prior to the cement job by the washer liquids, thereby enhancing the bond between cement and formations. 


\begin{tabular}{|c|c|c|}
\hline Description & Low pH Mud System & High pH Mud System \\
\hline Basic Muds & & \\
\hline $\begin{array}{l}\text { Water-Based Mud with } \\
0.1 \% \text { wt of Nanoaluminum }\end{array}$ & & \\
\hline $\begin{array}{l}\text { Water-Based Mud with } \\
0.3 \% \text { wt of Nanoaluminum }\end{array}$ & & \\
\hline $\begin{array}{l}\text { Water-Based Mud with } \\
0.5 \% \text { wt of Nanoaluminum }\end{array}$ & & \\
\hline $\begin{array}{l}\text { Water-Based Mud with } \\
0.7 \% \text { wt of Nanoaluminum }\end{array}$ & & \\
\hline
\end{tabular}

Table 9: Mudcake development for muds with and without nanoaluminum

\subsubsection{Mud Hydraulics-ECD \& Circulating Pressure based on Nanoaluminum muds}

As a rheological modifier, nanoaluminum with limited amounts reflects significant desirable impact on the hydraulics of the mud for both high and low $\mathrm{pH}$ mud systems with reduction in the ECD and drillpipe pressure. Figures $49 \& 50$ show the impact of the nanoaluminum on the Equivalent Circulating Density in the $9000 \mathrm{ft}$ long 12 1/4" diameter wellbore. 


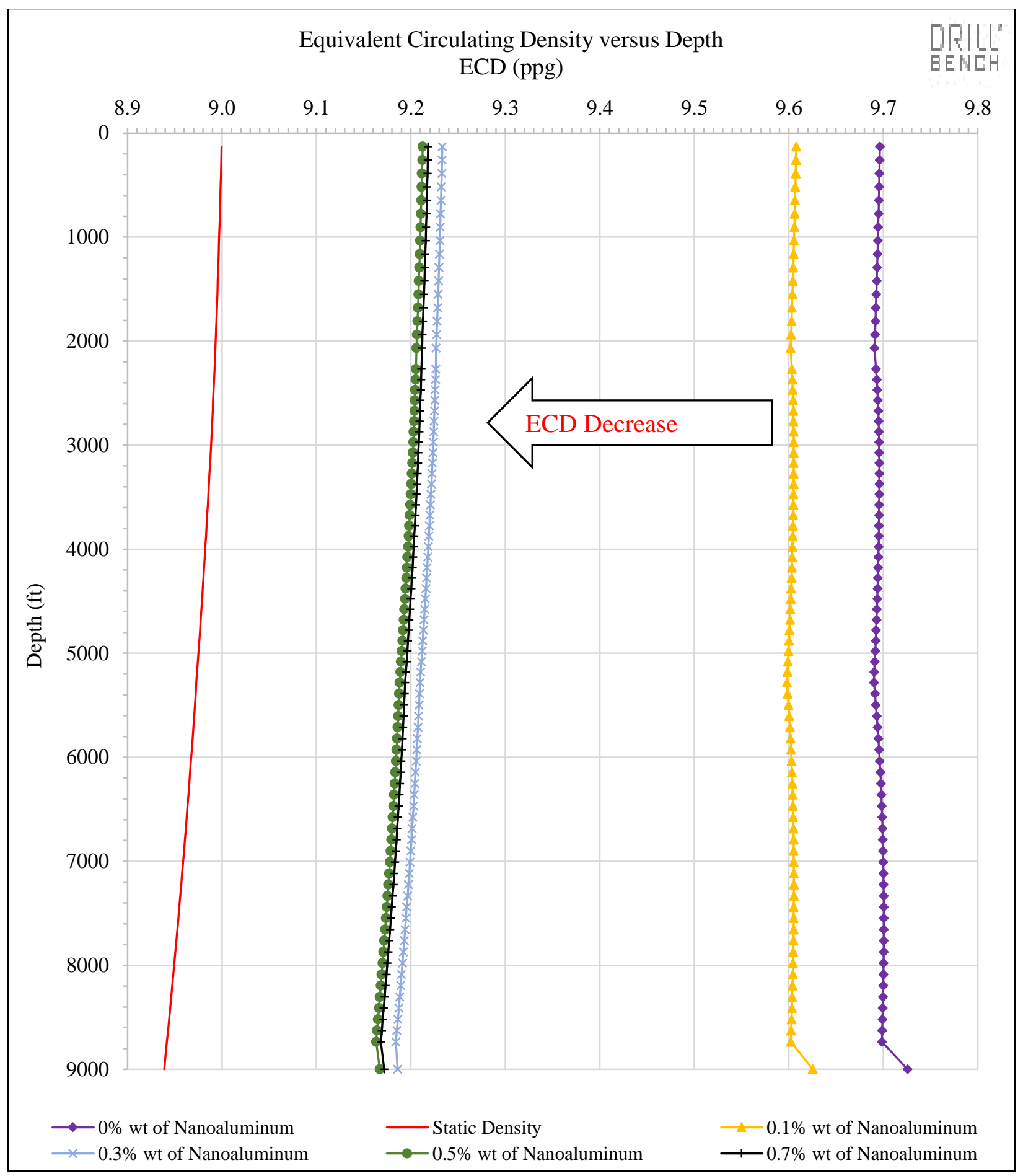

Figure 49: The impact of nanoaluminum on the equivalent circulating density-high pH mud system

The bigger enhancements are obtained after adding $0.3 \%$ wt. and $0.1 \%$ wt. of the nanoaluminum to the high and low $\mathrm{pH}$ muds, respectively. This supports the previous observation that implies the use of nanoaluminum with the same concentrations is sufficient to improve the drilling 
fluid's rheological properties. In this study, the nanoaluminum particles reduced the ECD from $9.7 \mathrm{lb} / \mathrm{gal}$ to $9.2 \mathrm{lb} / \mathrm{gal}$ for the high $\mathrm{pH}$ mud system and from $9.45 \mathrm{lb} / \mathrm{gal}$ to $9.2 \mathrm{lb} / \mathrm{gal}$ for the low pH mud system.

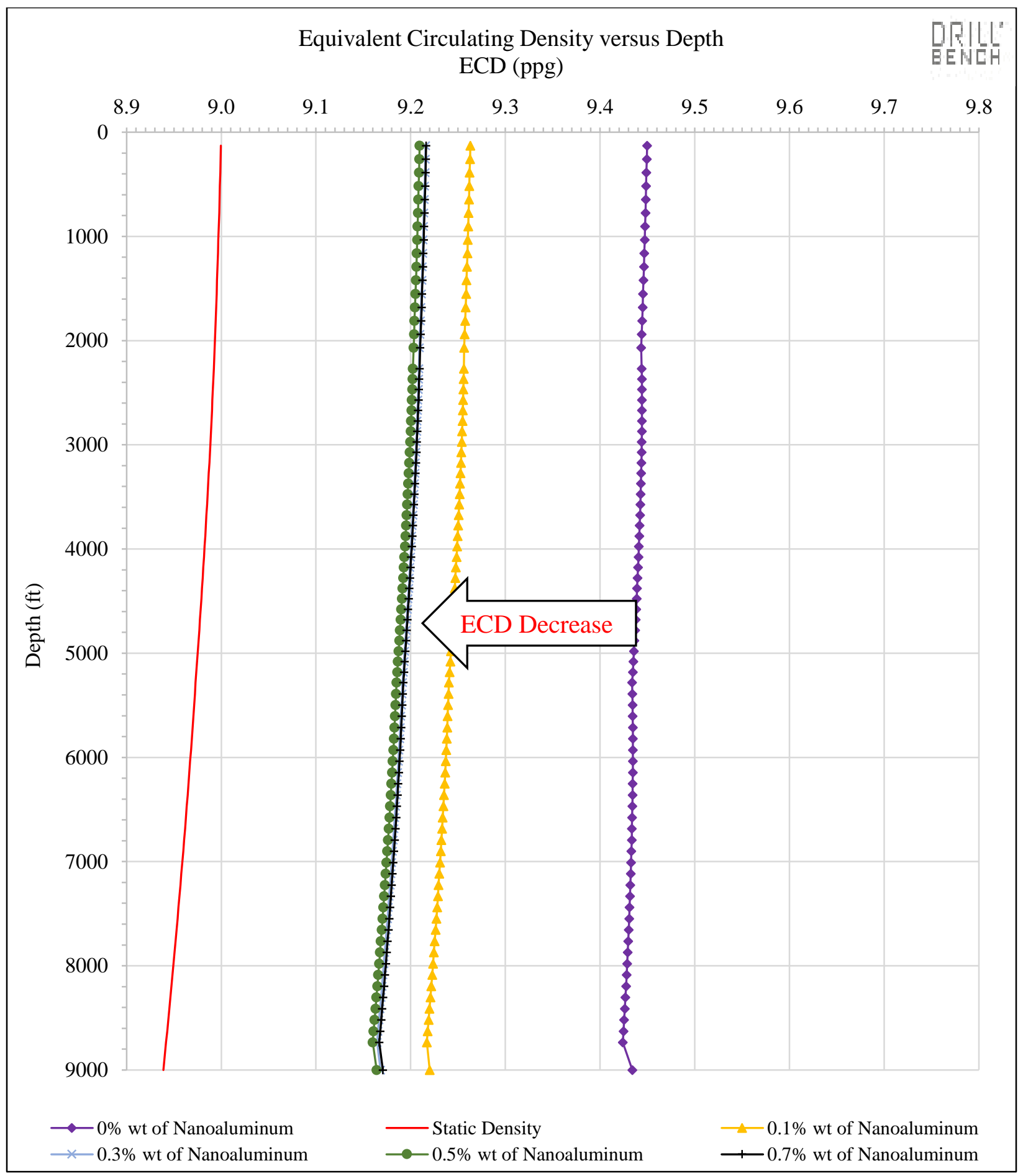

Figure 50: The impact of nanoaluminum on the equivalent circulating density-low pH mud system 
A low ECD will help in reducing loss circulation, formation fracture, and their associated blowouts in the fragile and pressurized formations. In this case, nanoaluminum can also be considered as lubricant in the water-based mud. Thus, enhancing the drilling fluid rheological properties by means of nanoaluminum is one of the main factors that help in optimizing the hydraulics and then reducing drilling costs.

However, the negatively impacted rheological property by using $0.7 \%$ wt. of the nanoaluminum reflects no impact or negative impact on the hydraulics. The ECD starts to increase based on using $0.7 \%$ wt. as shown in Figure 49 . This means the cuttings or formation solids start to deposit, causing this increase and this is not desired.

Subsequently, the results show reductions in the drillpipe circulation pressure for the concentrations below $0.3 \%$ wt. Figures $51 \& 52$ show the impact of nanoaluminum on the pressure for both high and low $\mathrm{pH}$ mud systems. As seen in Figure 51, the nanoaluminum reduces the surface drillpipe pressure by 360 psi.

Minimizing pump pressure is required in minimizing the energy exerted by mud pumps and increasing the operational life of the drilling equipment. Thus, $0.3 \%$ wt. of nanoaluminum was sufficient enough to make a significant reduction in the pump pressure loss throughout the 9000 $\mathrm{ft}$ directional well while the greater amounts lead to an increase in the pump pressure due to cutting settling that narrows the annular space. 


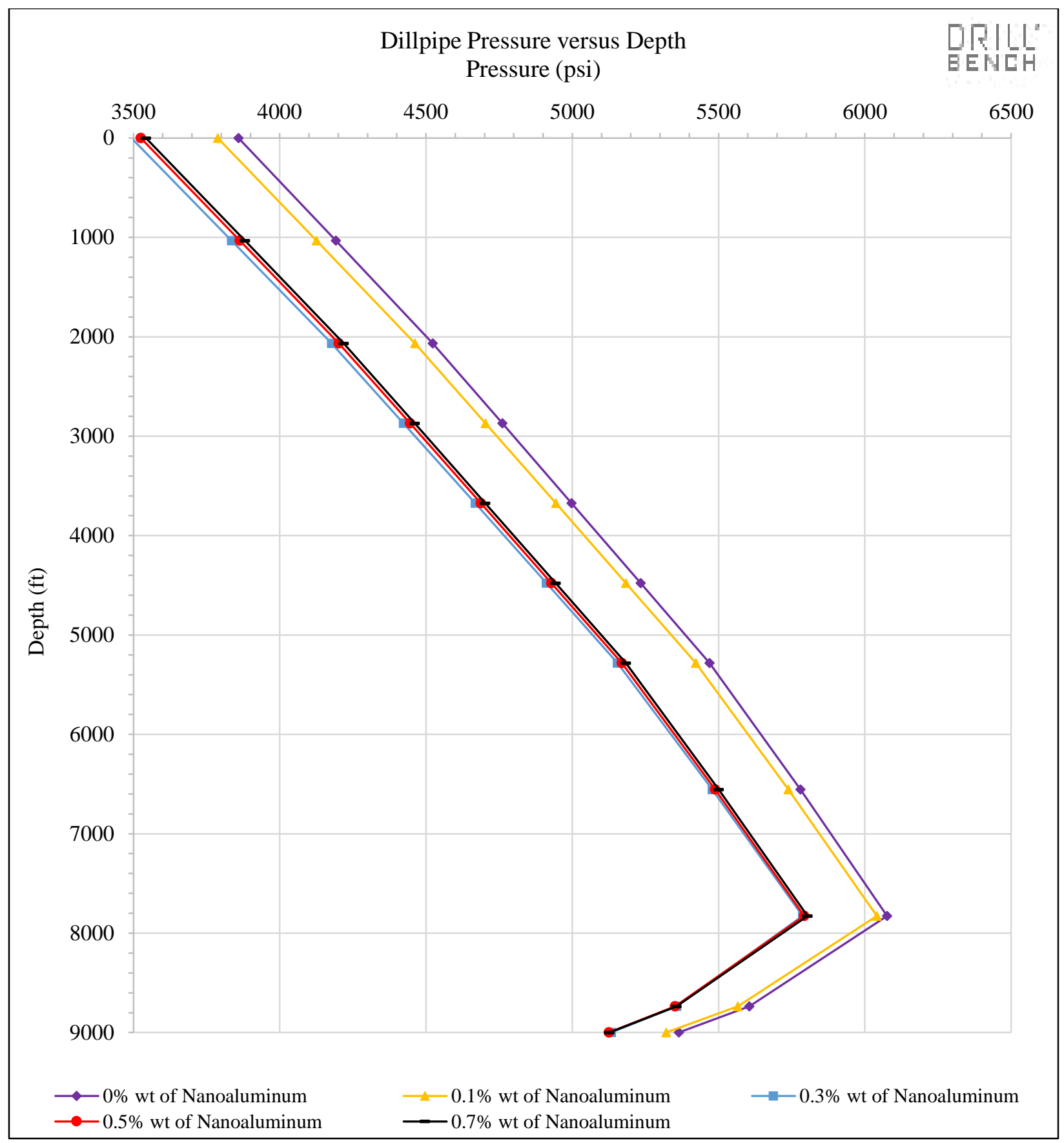

Figure 51: The impact of nanoaluminum on the drillpipe pressure-high $\mathrm{pH}$ mud system 


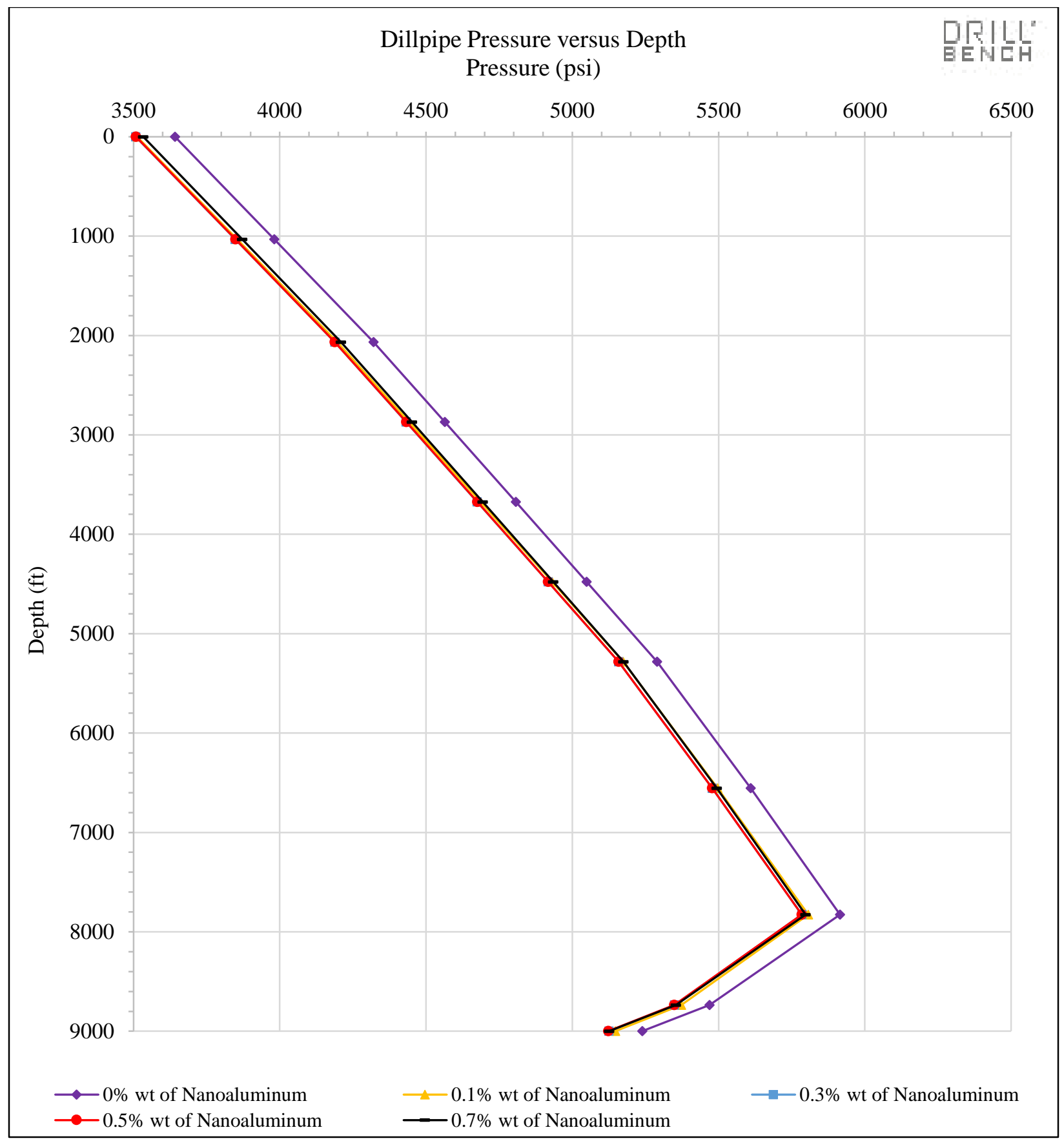

Figure 52: The impact of the nanoaluminum on the drillpipe pressure-low pH mud system

\subsection{The Impact of Cationic Nanoparticles on the Mud Properties}

The previous results are presented for anionic nanoparticles. Generally, the nanoparticles behave based on their chemical and physical properties and this section discusses the impact of cationic (positive surface charging) nanoparticles on the rheological and filtration properties. 
The positive ions are adsorbed within the Bentonite particles leading to an attraction, distance increasing, and lubrication between the particles. Only nanoaluminum was used to represent and provide a general behavior of the cationic nanoparticles. Figure 53 (A, B, C, and D) show clear differences between the anionic and cationic nanoaluminum behaviors.

The plastic viscosities in Figure 53 (A) show decrease as the concentration increases for both charges. The plastic viscosity is mostly a frictional force-dependent property and the nanoparticles distributed between the Bentonite particles work as lubricating balls easing the bigger solids movement. For both types, $0.3 \%$ wt. nanoaluminum resulted in the highest impact.

The results show a reduction in the yield points (Figure $53(\mathrm{~B} \& \mathrm{C})$ ) at concentrations less than $0.3 \%$ wt. and an increase at concentrations greater than $0.3 \%$. The yield point mainly depends on electro-chemical attractive forces and also on frictional forces. Both of these factors depend on the distance between the clay particles and the geometry of the nanoparticles. Regardless to the charging type, all the nanoparticles increase the distance and reduce the friction between the Bentonite particles.

For the smaller concentrations, it is believed that the cationic nanoaluminum particles significantly reduce the friction and increase the distance between the Bentonite and Barite particles - they work like ball bearings. This reduction overcomes the attractive forces between the mud solids. At the larger amounts, the attraction between Bentonite particles overcomes these influences. For the anionic nanoparticles, the repulsive forces work hand in hand with the lubrication influence of the nanoparticles. This leads to a continuous decrease in the yield point.

For the apparent viscosity (Figure 53 (D)), this behavior is a combination of plastic and yield point property. 


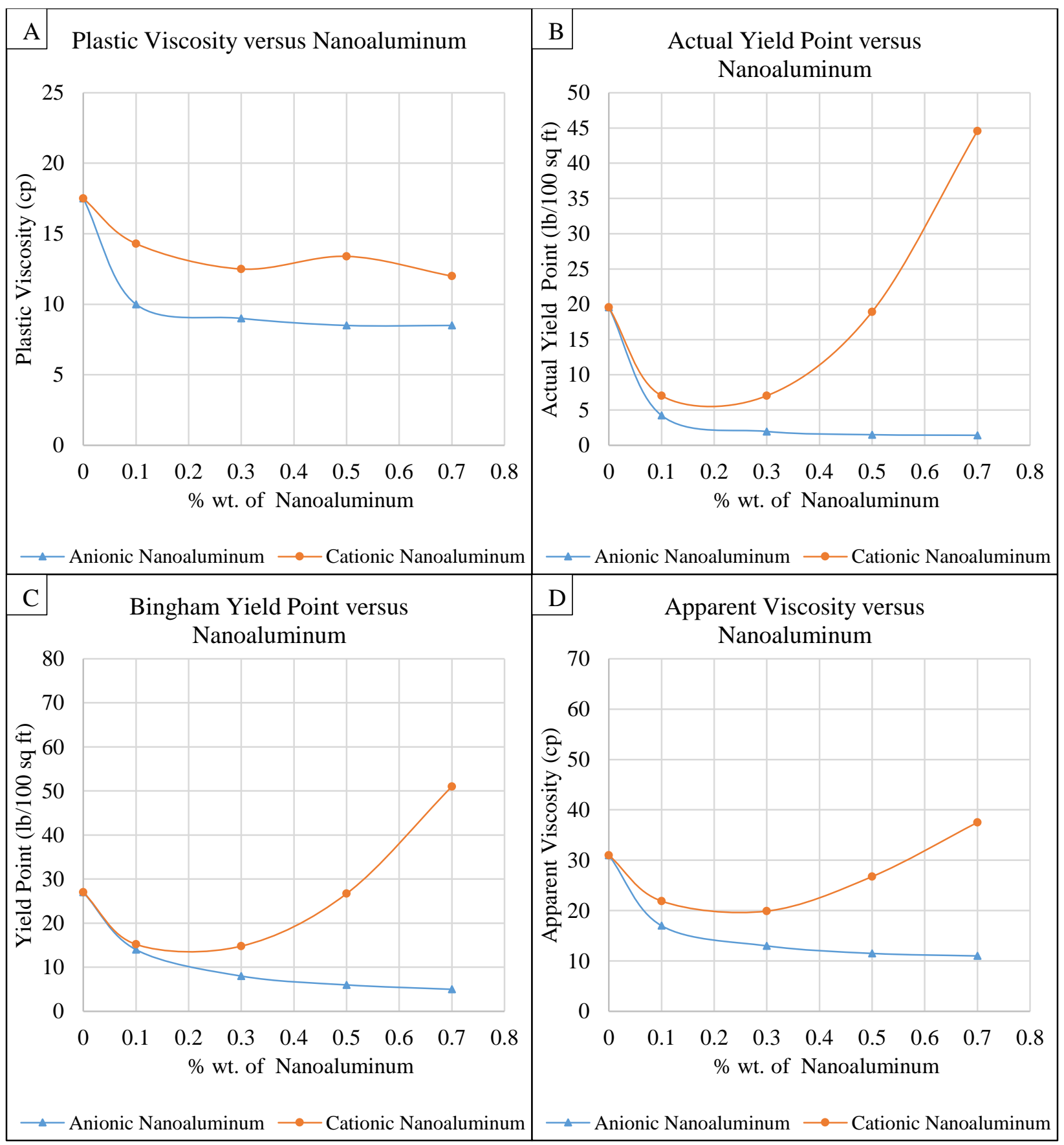

Figure 53: The impact of cationic \& anionic nanoaluminum on the rheological properties-low pH mud system

Figure 54 shows the gel strength profiles. Gel strength is controlled by the same forces governing the yield point. Hence, it is seen that the addition of anionic nanoaluminum particles results in lower values of 10 seconds and 10 minutes gels. As seen in Figure 54, different gel strengths are 
obtained by using both anionic and cationic nanoaluminum. The wide ranges of gel strength based on small amounts of nanoparticles are economically and operationally desirable.

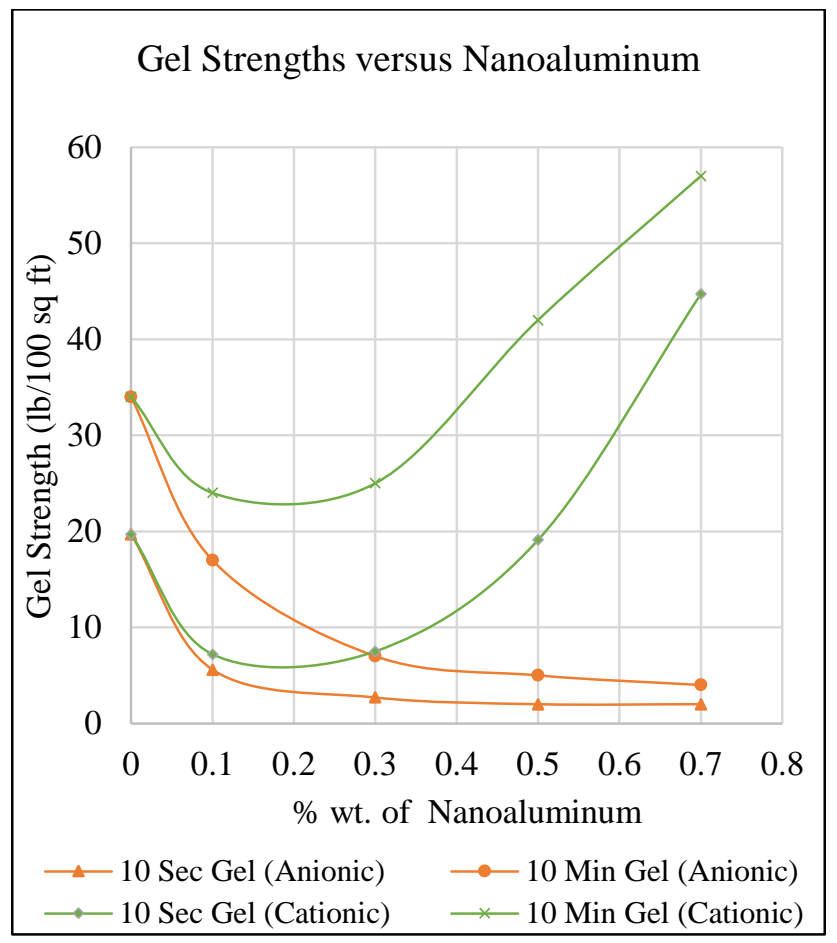

Figure 54: The impact of cationic \& anionic nanoaluminum on the gel strength-low pH mud system

Figure $55(\mathrm{~A} \& \mathrm{~B})$ illustrate the impact of the nanoaluminum types on the filtration volume and its associated mudcake. The cationic nanoaluminum particles do not enhance the filtration. Instead, they slightly increase the filtration and its associated mudcake thickness at the concentration greater than $0.3 \%$ wt. This is due to the poor particle distributions and arrangements after increasing the viscosity, attractive force, and due to the current large size of nanoparticles. Large amounts of cationic nanoparticles with larger dimensions may diminish the filtration properties of the water-based muds.

It is believed that using very small particle sizes of the cationic nanoparticles will enhance the filtration and give various rheological properties. These nanoparticles will provide low and high yield points and gel strengths. This means different drilling mud conditionings can be fulfilled by using different concentration of this kind of nanoparticles. 


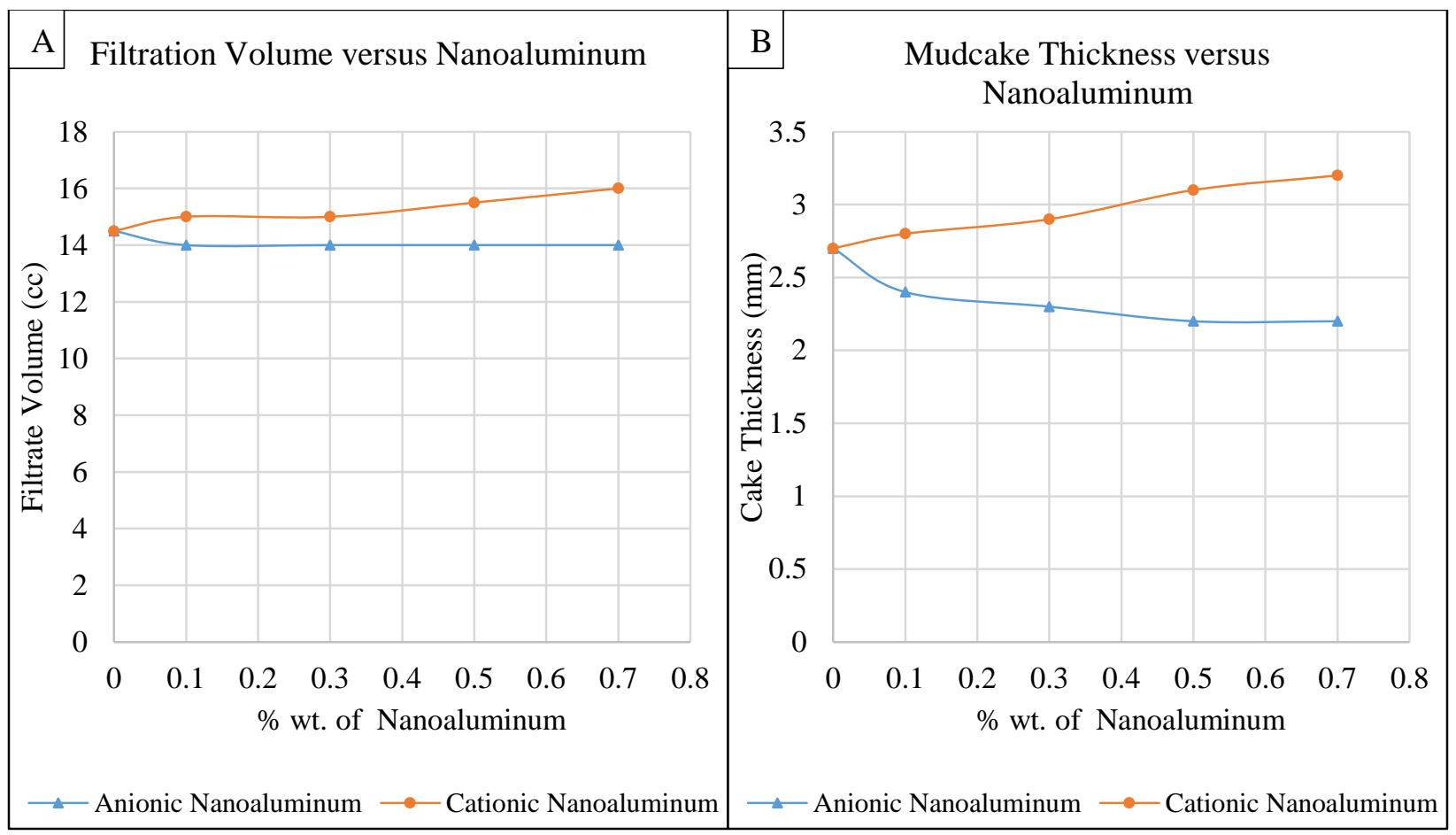

Figure 55: The impact of cationic \& anionic nanoaluminum on the filtration and mudcake thickness-low pH mud system

The impact of the cationic nanoaluminum on the high $\mathrm{pH}$ muds was not tested since the cationic nanoparticles increase the viscosity of the low $\mathrm{pH}$ muds and high $\mathrm{pH}$ muds already have higher viscosities. Figure 56 illustrates the difference between the cationic nanoaluminum mud before and after increasing the $\mathrm{pH}$. Therefore, it was not possible to perform the rheological and filtration tests with high $\mathrm{pH}$ mud due to losing the mud liquidity. 


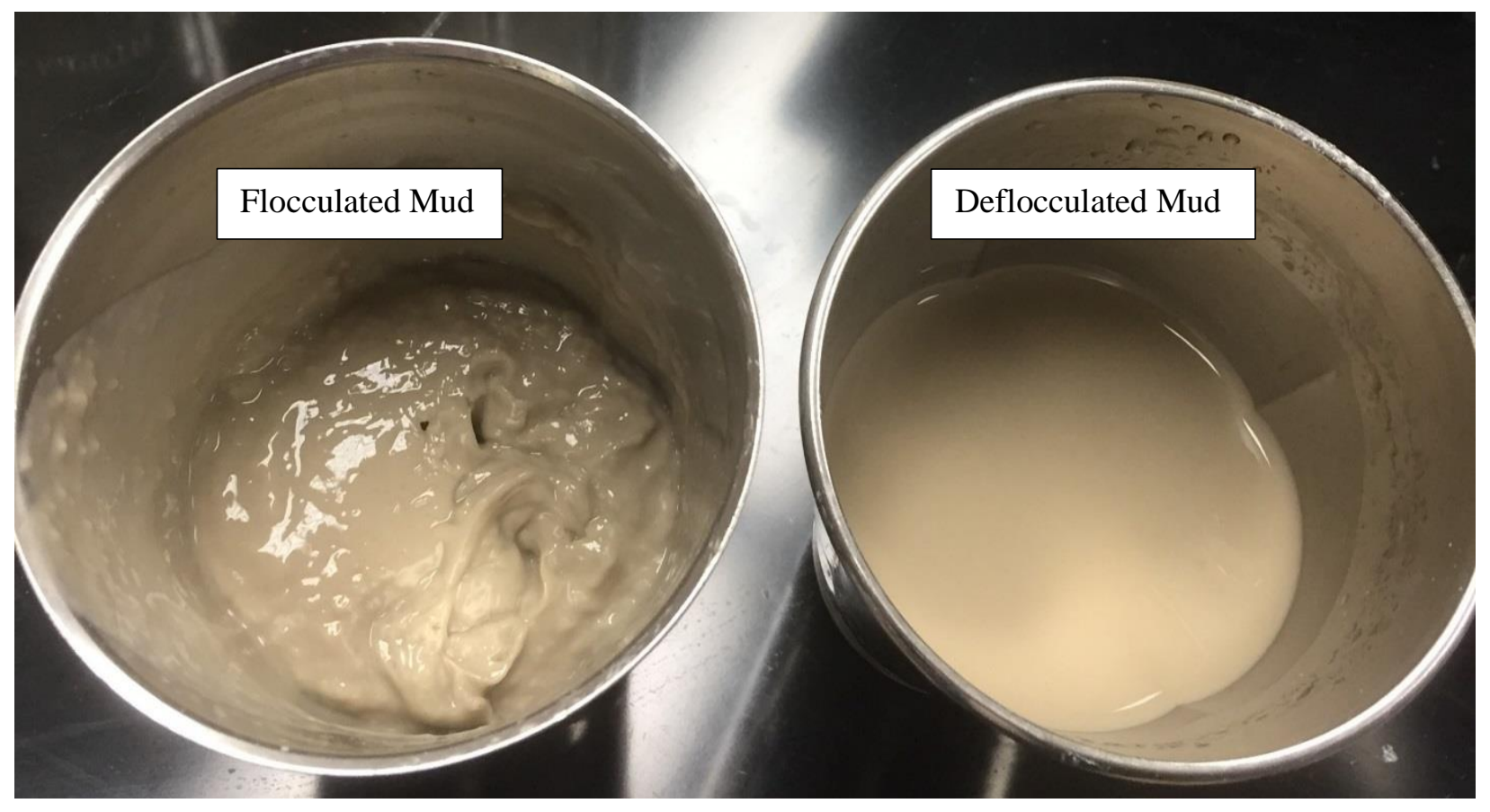

Figure 56: The cationic nanoaluminum muds before and after increasing the pH

\subsection{Impact of the Current Nanoparticles on the Mud density}

Interestingly, the four nanoparticle types with the current concentrations do not affect the mud density for all samples due to the small amounts that are used. This provides an advantage in the selection of nanoparticles as a rheological modifiers and/or filtration reducing agents without increasing solid concentration in the fluids. This will eliminate the large amounts of the microchemicals used to condition the drilling muds such as lignite, lignosulphonate, CMC, etc. that are desirable in the drilling operations, especially for horizontal and directional wells. 


\section{Chapter 6: The Final Comparison of the Main Results}

The difference in the nanoparticles' performances are highlighted in this chapter based on the comparisons between each other. Various rheological and filtration designs can be developed considering the difference in the physical and chemical properties and the amounts of the nanoparticles that were incorporated. The proper nanomaterial can be selected to condition the mud based on certain drilling situations. As anionic nanoparticles, the current nanomaterials reflect the same general trend of mudflow behaviors.

However, the filtration properties do not follow the same trend since the sizes of the particles are different. The smaller particle size results in a significant filtration reduction. The best way to compare the performances is to divide them into two sections - low $\mathrm{pH}$ and high $\mathrm{pH}$ sections.

\subsection{Impact of Different Nanoparticles on the Low pH Mud Properties}

In terms of rheological properties, Figure 57 (A, B, C, and D) show that the nanoaluminum reduces mud viscosities more than nanotitanium and nanosilica for all the concentrations. Considering the economic and sufficient mud designs, using $0.1 \%-0.3 \%$ wt. of the nanosilica and nanotitanium and $0.1 \%$ wt. of nanoaluminum are observed as the best concentrations for the low $\mathrm{pH}$ muds. Greater concentrations may not serve as perfect modifiers.

For example, $0.3 \%$ wt. and greater concentrations of nanoaluminum result in very low yield points. Low yield point may be useful for some drilling operations when the drilling gets deeper and the cuttings get smaller. However, it may cause cutting to sag. It is a serious problem especially in the surface holes where the larger drilled cuttings are generated. 


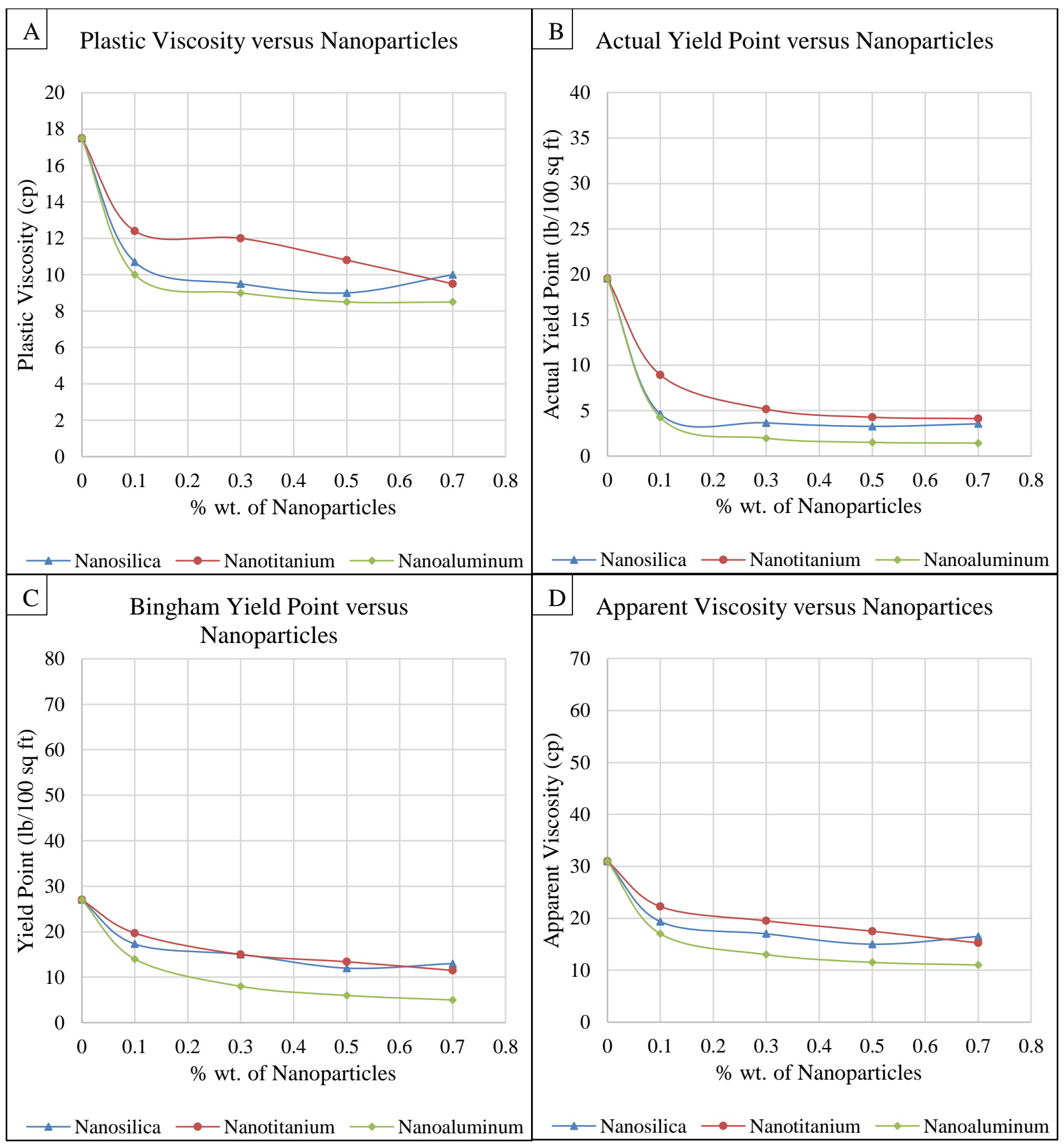

Figure 57: The impact of different nanoparticles on the rheological properties-low pH mud system

Figure $58(\mathrm{~A} \& \mathrm{~B})$ show that nanotitanium develops quicker gel strength than the others since the difference between 10 second and 10 minute gels for the corresponding concentrations is greater. This feature makes the nanotitanium suitable to treat the water-based drilling muds used to drill surface holes (large diameter) by using different concentrations. Nanotitanium provides more suspension capacity range than what the others do. Similarly, only $0.1 \%$ wt. or less of 
nanoaluminum and nanosilica provides acceptable gels in terms of solids suspension capacity. This makes nanosilica and nanoaluminum more suitable to drill deeper formations where the smaller cuttings are generated. In general, small amounts of these nanoparticles can be used to design the water-based mud's gels that may fulfill different drilling conditions.

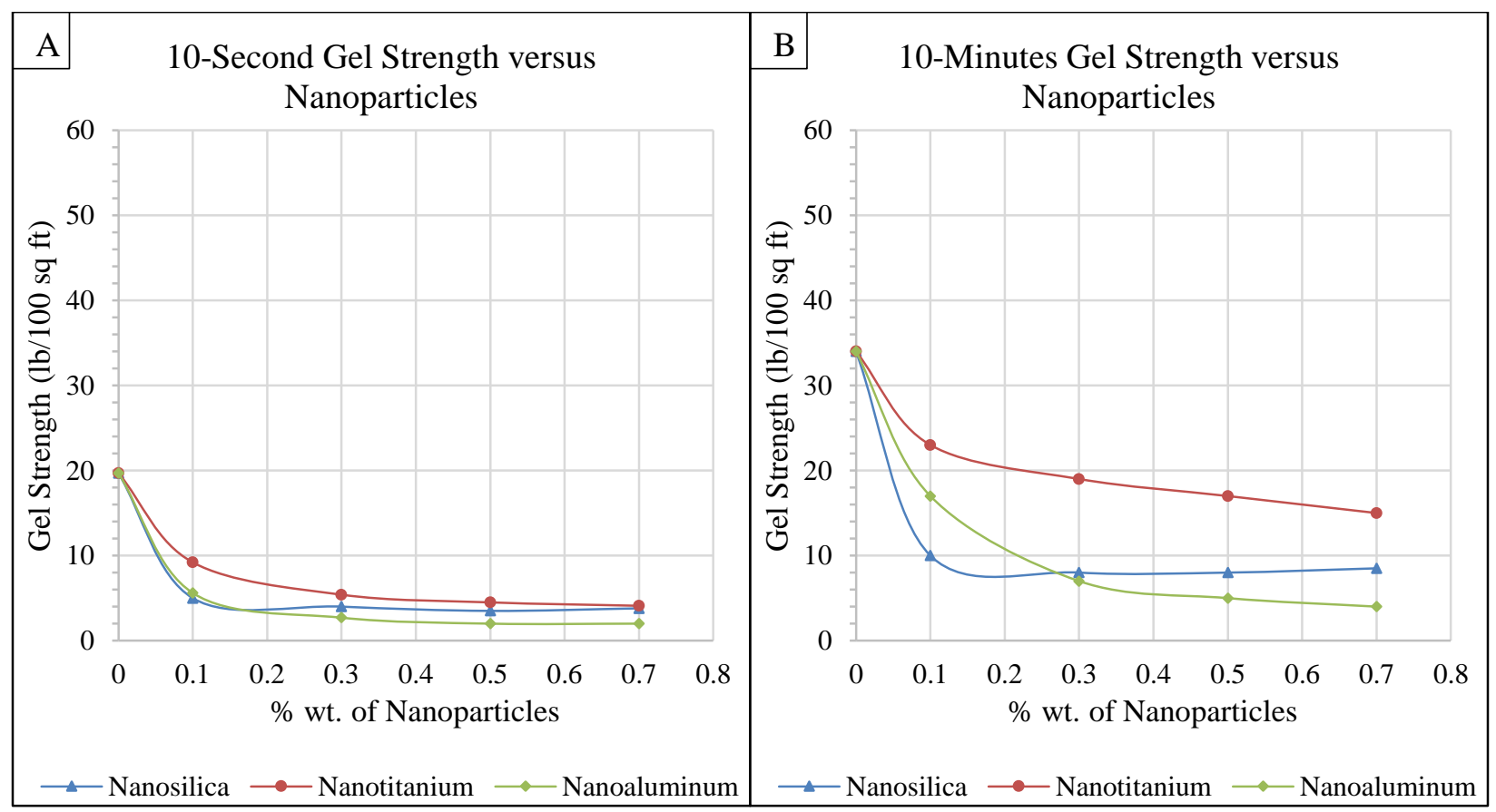

Figure 58: The impact of different nanoparticles on the gel strengths-low pH mud system

The smaller nanoparticle sizes resulted in more filtration reduction. Results shown in Figure 59 $(A \& B)$ support this finding. It can be seen that the $5 \mathrm{~nm}$ silica performs better in reducing the filtration than the other nanoparticles. Considering the economics and efficiency, no more than $0.5 \%$ wt. of nanosilica is needed to enhance the filtration. Nanotitanium slightly reduces the filtration while nanoaluminum does not influence the filtration. Both of them reflect poor performance in comparison to nanosilica due to their bigger particle sizes. 


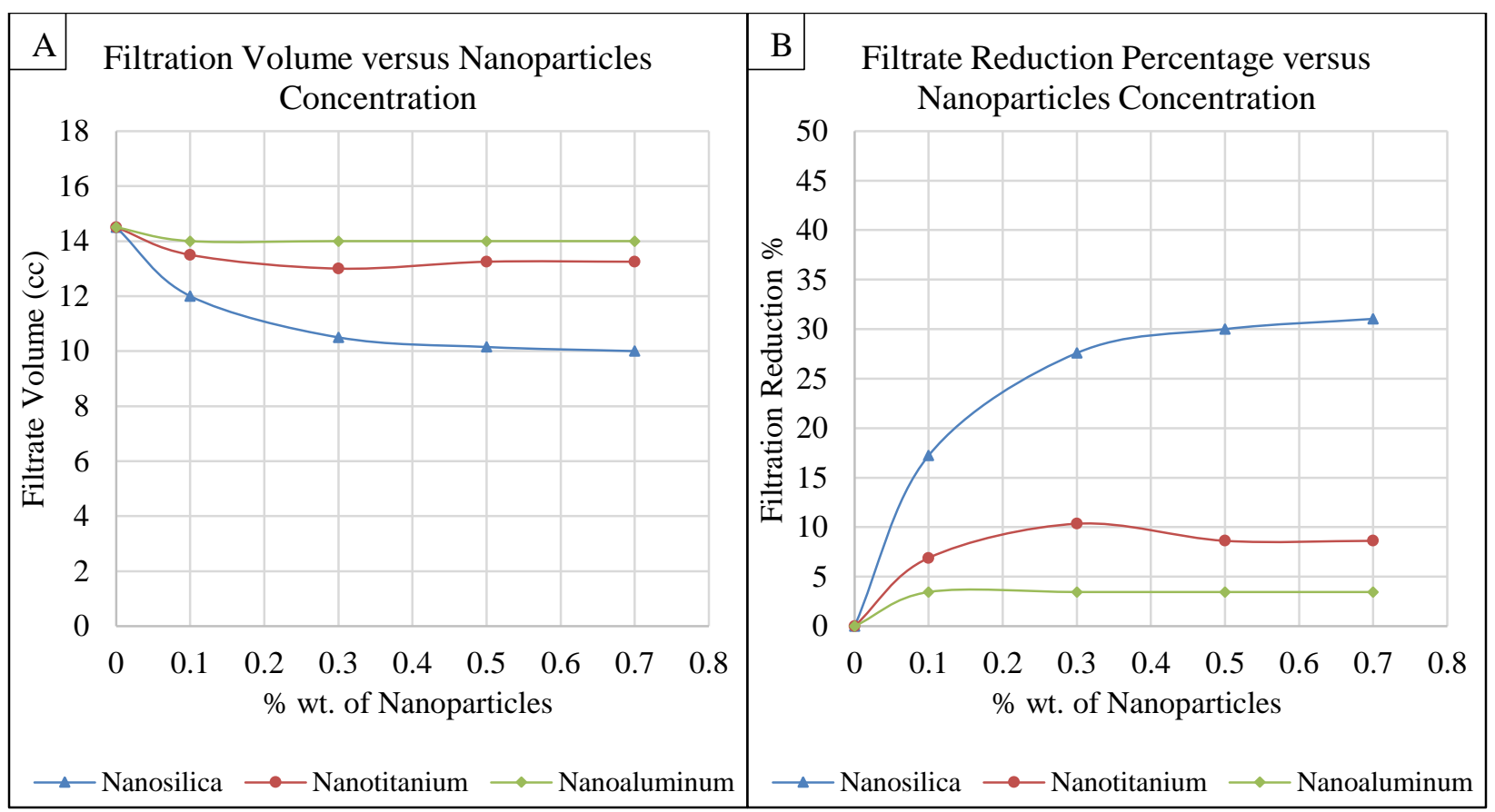

Figure 59: The impact of different nanoparticles on the filtration-low pH mud system

Figure $60(\mathrm{~A} \& \mathrm{~B})$ show the filtration-related mudcake thickness reduction. It was seen that nanosilica resulted in the thinnest mudcake. A $0.3 \%$ wt. of the nanoparticles or less was sufficient to cause the biggest improvement in the mudcake.

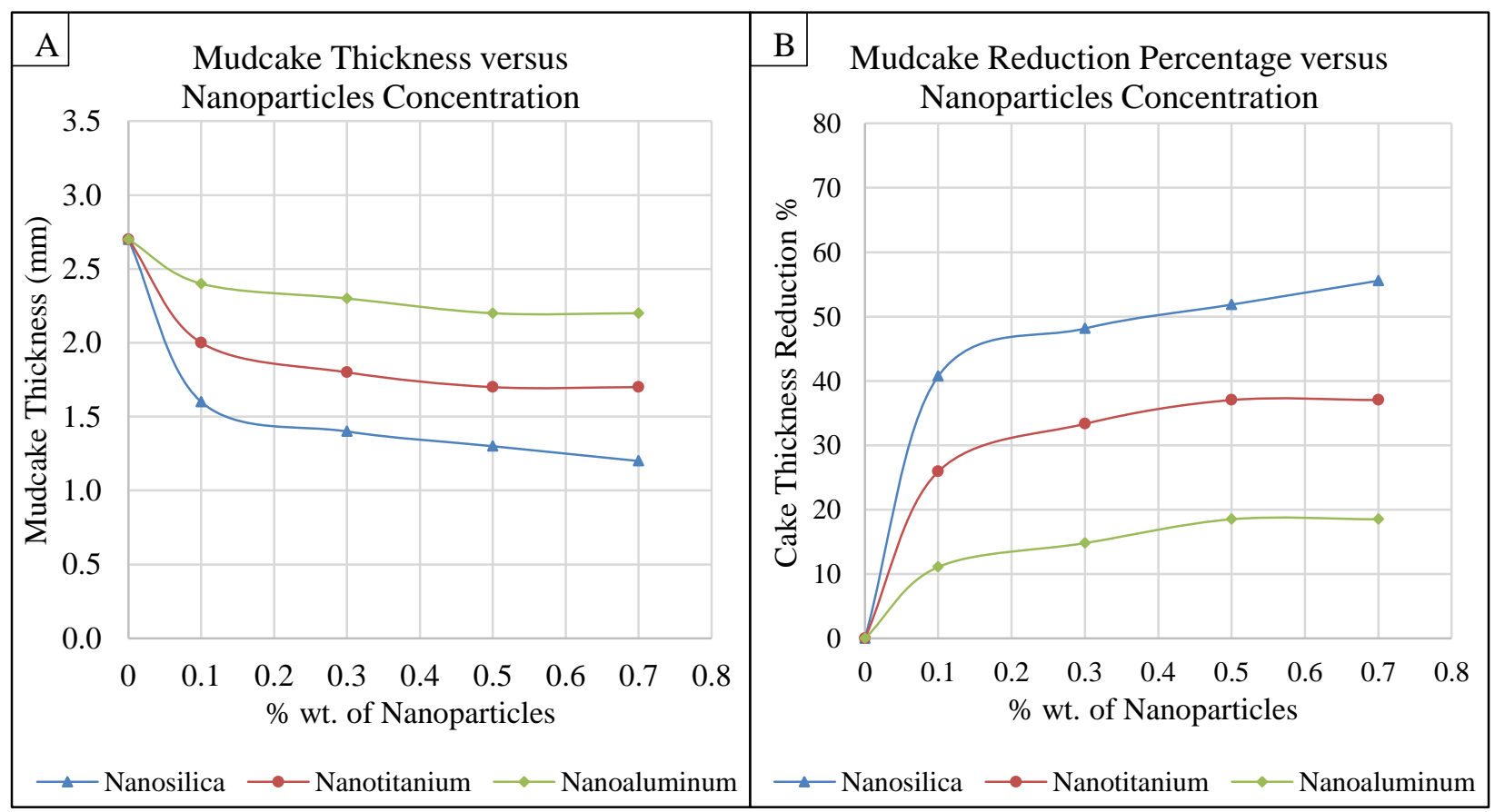

Figure 60: The impact of different nanoparticles on mudcake thickness-low pH mud system 


\subsection{Impact of Different Nanoparticles on the High pH Mud Properties}

Figure 61 (A, B, C, \& D) show the impact of the three nanoparticle types on the rheological properties when the $\mathrm{pH}$ of the water-based mud is increased from 9 to 12 .

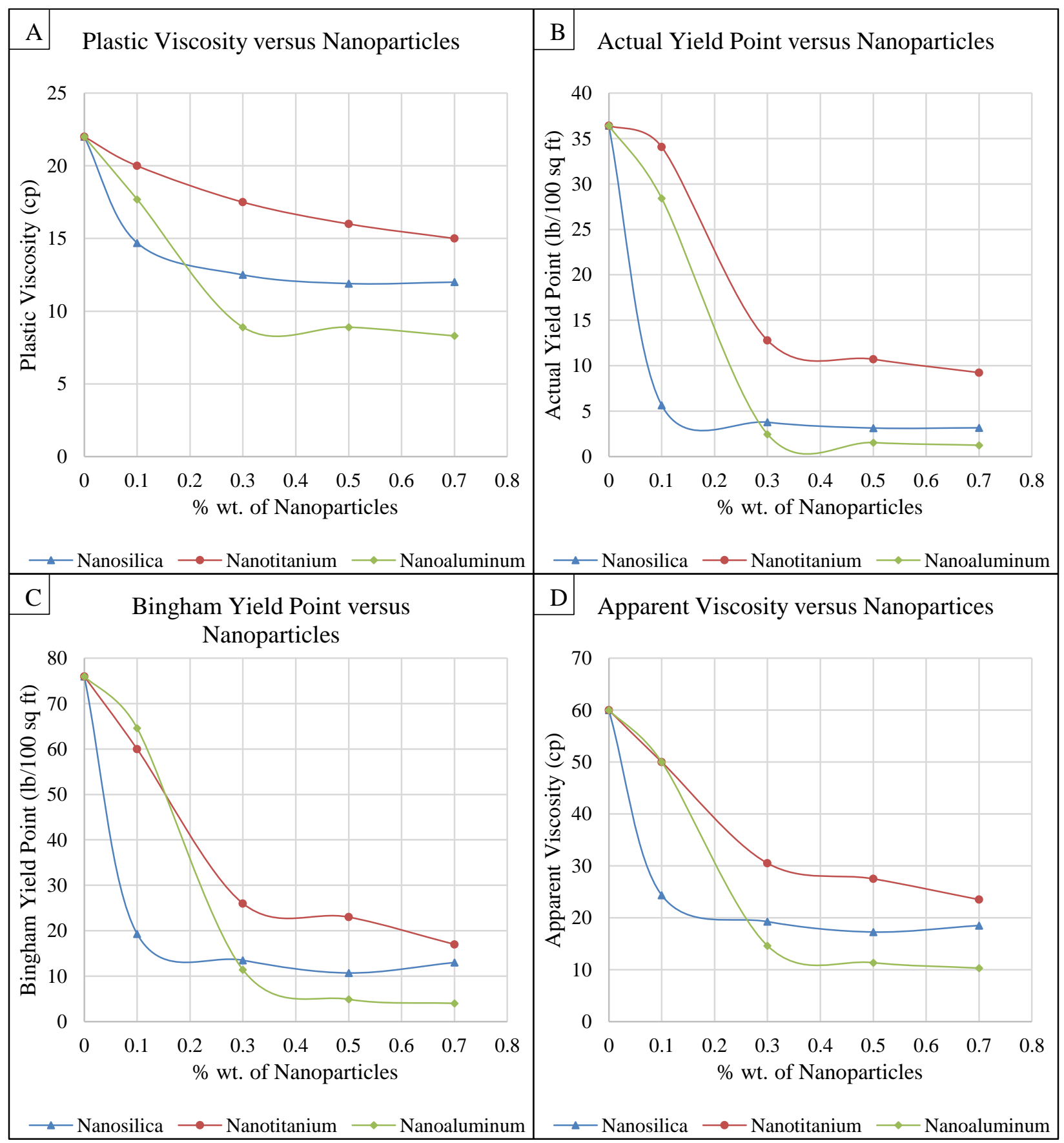

Figure 61: The impact of different nanoparticles on the rheological properties-high pH mud system 
The results for other properties follow the same trend of the low $\mathrm{pH}$ mud's results, but at a different level. The $\mathrm{pH}$ level influences the solubility of chemicals, such as Bentonite and nanoparticles. It was noticed that $0.3 \%$ wt. of each of the nanoparticles makes the biggest reduction in the viscosities. In addition, nanoaluminum reduces the mud viscosities more than nanotitanium and nanosilica for concentrations greater than $0.3 \% \mathrm{wt}$.

All of the nanoparticle types overcome the flocculation with less amounts and they can be used as deflocculants. For example, they can be used to condition the drilling muds after the cement jobs or during drilling formations containing magnesium hydroxide, potassium hydroxide, anhydrite, etc.

Figure 62 (A) shows that all the nanoparticles decrease the 10 second gel to the lowest values based on amounts less than or equal to $0.3 \%$ wt. of the nanoparticles. Further, nanoaluminum decreases the gel more than others for the concentrations greater than $0.5 \% \mathrm{wt}$. This severe reduction may cause poor cuttings suspension, especially for large size cuttings ( $>1$ inches). Thus, fewer amounts should be used.

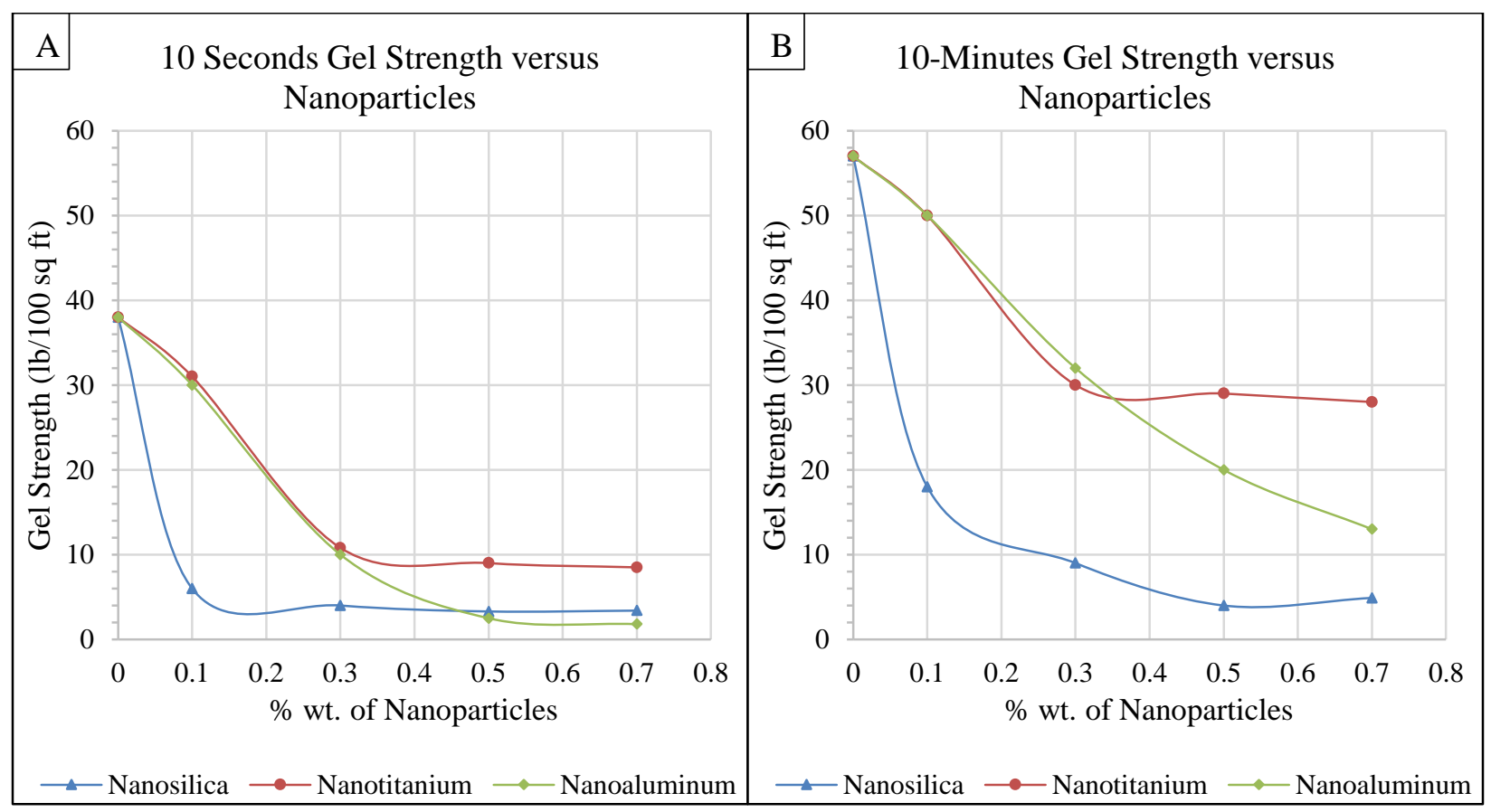

Figure 62: The impact of different nanoparticles on the gel strengths-high pH mud system 
Figure 62 (B), shows that nanoaluminum reduces the 10 minutes' gel linearly while the others do not. Also, $0.3 \%$ wt. of nanotitanium and nanosilica is enough to make the largest reduction. It appears that nanosilica with $0.5 \%-0.7 \%$ wt. yield the lowest gel strength.

Figure 62 (A\&B) show that nanotitanium and nanoaluminum reduced gel strengths less than nanosilica based on the differences between 10 second and 10 minute gels of the corresponding concentrations. Considering the drilled cuttings suspension requirements, this feature makes them suitable chemicals to treat the high $\mathrm{pH}$ water-based muds used to drill surface holes. However, they may not be desirable to break the mud circulation if they are used in the deeper holes. Only concentrations less than $0.3 \%$ wt. of nanoparticles are recommended.

More so, Figure $62(\mathrm{~A} \& \mathrm{~B})$ shows gel strength differences for these nanoparticles at all concentrations except the nanosilica at higher concentrations of 0.5 and $0.7 \%$ wt. In other words, more fragile gel can be obtained by using nanosilica. This makes nanosilica a suitable material to be added to the high $\mathrm{pH}$ muds used to drill deeper formations where the smaller cuttings exist and the fragile gel is needed. Finally, the wide range of gels provides flexibility to design the water-based mud according to different drilling requirements.

Figure 63 (A\&B) show that nanosilica yields the highest reduction in filtration volumes as its concentration increase gradually. This behavior is attributed to its smaller particle sizes. Nanotitanium slightly reduces the filtration loss while nanoaluminum does not impact the filtration. They reflect poor performance due to their bigger particle sizes. 


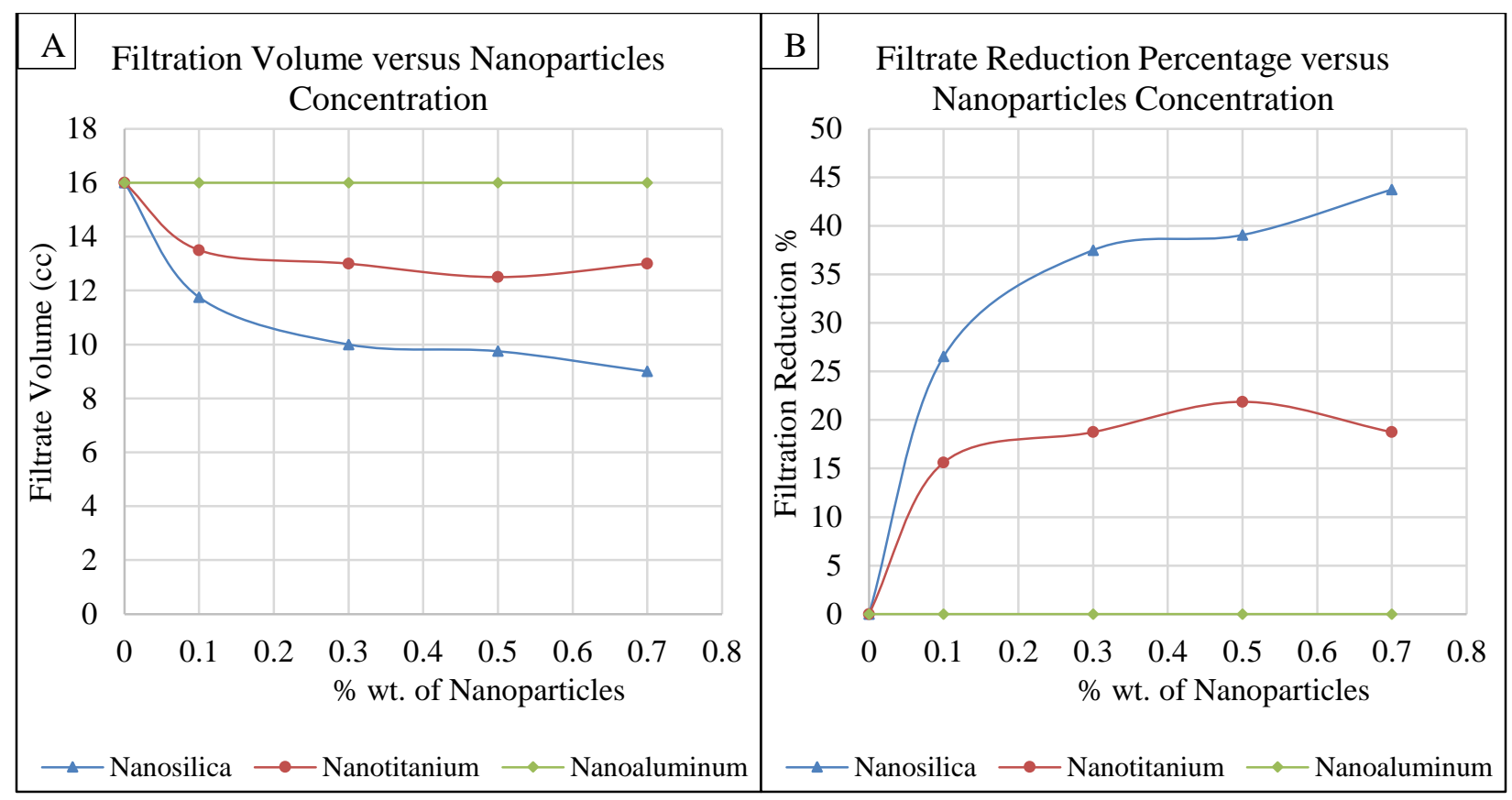

Figure 63: The impact of different nanoparticles on the filtration-high $\mathrm{pH}$ mud system

Figure 64 shows the filtration-associated mudcake thickness reduction. It is seen that nanosilica addition results in reduced mudcake thickness. For this particular purpose, $0.1 \% \mathrm{wt}$. of the nanoparticles is recommended to enhance the mudcake greatly. Nanotitanium also enhances the mudcake, but in lower efficiency than nanosilica.

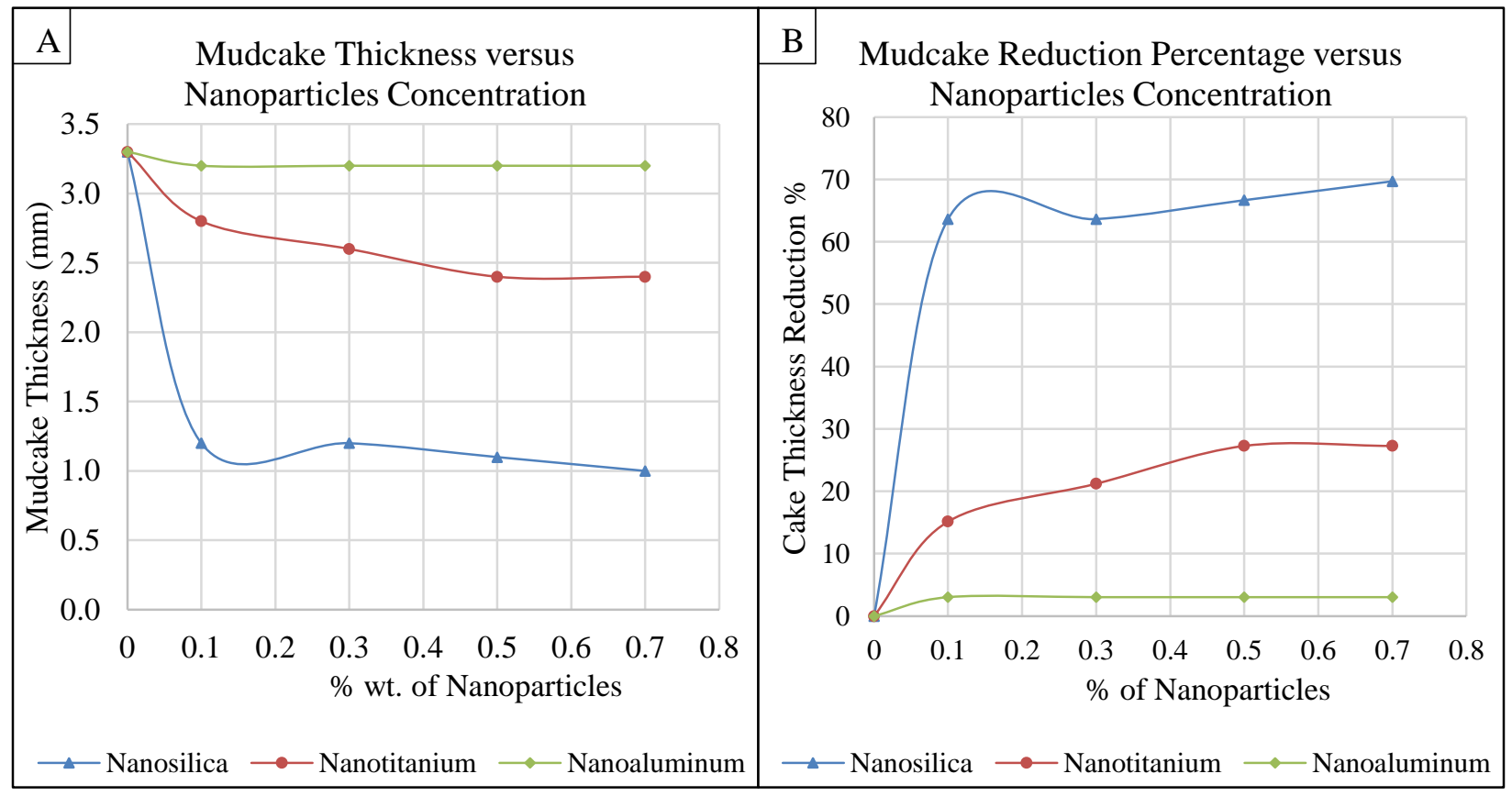

Figure 64: The impact of different nanoparticles on mudcake thickness-high pH mud system 


\section{Chapter 7: Conclusions}

Based on the results and observations, the following conclusions are presented:

1. Nanoparticles used in this study reduce the filtration losses but they cannot completely stop the water filtration into the exposed formations. However, they can be used to enhance the rheological properties and to reduce the filtration to acceptable levels if they are carefully formulated to reach the optimum performance.

2. Nanoparticles performance completely depends on their physical and chemical properties and the mud's components properties. This means the existence of other chemicals will lead to a different performance due to their sensitivity to them. For example, all of the nanoparticles used in this study are very sensitive to the caustic soda used to increase the $\mathrm{pH}$ with their current physical and chemical properties. They play significant roles in enhancing the flocculated mud properties due to high $\mathrm{pH}$. Hence, they work as deflocculant agents in the water-based muds.

3. The main chemical properties of the nanoparticles that influence the performance are the particle surface charges and $\mathrm{pH}$. Anionic nanoparticles, with negative ions, cause reductions in rheological properties due to the generated electro-chemical repulsive forces. These nanoparticles reduce the viscosity by weakening the attraction forces at the edges of the Bentonite platelets without impacting the viscosity due to hydration. This was the main experimental observation.

4. Positively charged cationic nanoparticles cause increase in the rheological properties due to the generated electro-chemical attractive force. These nanoparticles increase the viscosity by linking the wider surface of the Bentonite platelets. This is demonstrated by the results obtained from the cationic nanoaluminum. Therefore, knowing the surface charging property and the optimum concentration are sufficient to determine the required trend of the mud rheological behaviors.

5. The smaller nanoparticles caused more enhancements in the filtration and its associated mudcake properties than the bigger ones. This makes the smaller size nanoparticles work as 
multi-function agents. Thus, nanosilica and nanotitanium work as multifunction agents while nanoaluminum works as a single function agent as a rheological modifier. Therefore, the results can follow different trends when the chemical and physical properties of the nanoparticles change.

6. The nanosilica is superior among the other nanoparticles. It is chemically more sensitive than nanotitanium and nanoaluminum to the mud contents. As an effective and multifunction additive, $5 \mathrm{~nm}$ nanosilica can be used to design and enhance the rheological and filtration properties of water-based muds with very small concentrations. Less than $0.1 \%$ wt. of nanoparticles has the most significant impact on the high and low $\mathrm{pH}$ muds properties than other concentrations. Hence, the water-based muds with nanosilica can replace oil-based muds in horizontal, directional, and shale drilling operations due to their ability to reduce filtration loss and enhance rheology, thereby reducing drilling and production problems. Therefore, using nanosilica with water-based muds can result in the most efficient drilling operations.

7. The anionic nanotitanium with bigger particle sizes can also be used to enhance the rheological and hydraulic properties of the water-based muds with very small concentrations. However, they slightly enhance the filtration and its associated mudcake. The water-based muds with nanotitanium can also replace the oil-based mud, especially when the smaller particles are used. Nanotitanium in the range of $0.1-0.3 \% \mathrm{wt}$. concentrations has the most significant impact on the yield point and apparent viscosity of low and high $\mathrm{pH}$ muds than at other concentrations. However, the plastic viscosity decrease linearly with concentration.

8. The anionic nanoaluminum can be used to enhance only the rheological and hydraulic properties of the water-based muds with very small concentrations. Interestingly, nanoaluminum particles do not negatively impact the filtration property, however; they do not enhance it. As such, the nanoaluminum water-based muds cannot replace the oil-based mud in horizontal, directional, and shale drilling operations due to its poor ability to reduce the filtration, thereby reducing the drilling and production problems. Currently, $0.1 \%$ wt. or less and $0.3 \% \mathrm{wt}$. or less of the nanoaluminum are recommended to enhance the rheological properties for the low and high $\mathrm{pH}$ muds, respectively. The larger concentrations may cause 
solids to settle which is not preferable in terms of drilled cuttings suspension. However, it is preferable to use as a sagging agent that is usually used to remove contamination in the drilling muds, such as drilled solids and cement solids after a cement job.

9. Rheological modifiers may be added to avoid the negative impact of the nanoparticles with high concentrations $(\geq 0.5 \%)$ to adjust rheological properties, such as yield point, gel strength, and cutting suspension problems that may occur due to these concentrations. Unlike nanosilica and nanoaluminum, the severe impact of the nanotitanium with high concentrations $(\geq 0.5 \%)$ was not observed. Therefore, the rheological modifiers are not needed to adjust properties, such as yield point and gel strength.

10. The cationic nanoparticles can be used to enhance the rheological and hydraulics properties of the water-based mud. Small amounts are recommended to increase the viscosity, thereby switching the flow from turbulent to laminar and then reducing the erosion in some unconsolidated formations. Also, it can be used to enhance the carrying capacity of the mud used to drill the surface holes featured by very big cuttings.

11. It is observed that using very small size of cationic nanoparticles, around 1-5 nm, will cause high flexibility to design the water-based muds. Cationic nanoparticles show decrease in the mud viscosities at smaller amounts at or below $0.3 \% \mathrm{wt}$. and increase in the viscosities at larger amounts beyond $0.3 \%$ wt. In addition, they can reduce the filtration as shown in nanosilica performance. That means different behavior trends can be obtained by using the cationic nanoparticles.

12. No impact on the mud density is observed due to the small amounts of different nanoparticles needed to treat the drilling muds. This will eliminate the use of other micro material with large quantities to treat the muds. Also, no spurt loss is obtained when different types of nanoparticles are used. This makes them vital agents in this particular function. Some of the nanoparticles do not reduce the mudcake thickness, they enhance cake structure. They result in smoother and more compacted mudcake than the one developed by the basic muds. Also, as deflocculant agents, they deposit a fragile mudcake that can be removed easily before the cement job because they weaken the attractive force between the cake solids. 
13. The results of this experiment are valid for the tested conditions. Changing the mud's raw materials concentrations and types, temperature, and pressure will give different results.

14. The nanoparticles are sensitive materials and selection of the proper type, size, and concentration is the most challenging job before testing them with the water-based muds. 


\section{Chapter 8: Recommendations for Future Works Using Nanoparticles}

Various studies can be conducted using nanoparticles with the water-based muds since they are new to the drilling industry. Hundreds of nanoparticle types with different chemical and physical properties can be tested by using different methodologies and tools. However, not all the nanoparticles and methods lead to valuable results since many challenges are merged. Therefore, dealing with nanoparticles is time and effort consuming if they are not properly selected and formulated. The current study exposed the potential use of nanosilica, nanotitanium, and nanoaluminum in the drilling fluids. However, further work is recommended to explore the performance of these nanoparticles under various conditions and save time.

It is suggested to run the Transmission Electron Microscopy (TEM) test to figure out the geometry of the nanoparticles before using them and to make sure they do not agglomerate. Also it is suggested to make the drilling mud more complicated by incorporating more chemicals and then study and understand how the nanoparticles interact with the complexity of the mud. Also, testing the nanoparticles with different types of mud is recommended.

The nanoparticles should be tested under HPHT that closely simulate the downhole conditions. Performing Permeability Plug Test to measure how the nanoparticles plug the pore throats of the formation is highly recommended. It is important to measure the friction factor after treating the mud with the nanoparticles to simulate the ability of nanoparticles to release the stuck pipes. For shale swelling, it is recommended to test the nanoparticles as shale swelling inhibitors by means of the Shale Swell Meter.

Performing the aforementioned tests for the combination of more than one type of nanoparticles simultaneously is highly recommended. Similarly, it is important to investigate the cationic nanoparticles with 1-5 nm sizes. Use of in-house prepared nanoparticles instead of the commercial ones is better for the accuracy of results. 


\section{References}

Amoco Production Company, (1994). Drilling fluids manual. Tulsa, Oklahoma: Fluid Mechanics and Chemistry. Print.

Azar, J.J.(2006). Drilling Problems and Solutions. In R. F. Mitchell (Ed). Petroleum Engineering Handbook: Drilling Engineering (pp. 433-454). TX, USA: Society of Petroleum Engineers.

Amanullah, M., AlArfaj, M. K., \& Al-abdullatif Ziad Abdullrahman. (2011, January 1). Preliminary Test Results of Nano-based Drilling Fluids for Oil and Gas Field Application. Society of Petroleum Engineers. doi:10.2118/139534-MS.

Cai, J., Chenevert, M. E., Sharma, M. M., \& Friedheim, J. (2011, January 1). Decreasing Water Invasion into Atoka Shale Using Non-modified Silica Nanoparticles. Society of Petroleum Engineers. doi:10.2118/146979-MS.

Contreras, O., Hareland, G., Husein, M., Nygaard, R., \& Al-Saba, M. (2014, February 26). Application of In-House Prepared Nanoparticles as Filtration Control Additive to Reduce Formation Damage. Society of Petroleum Engineers. doi:10.2118/168116-MS.

Drilling Formulas.Com. (October 14, 2014). What You Need to Know about Drilling Bit Balling Up and How to Troubleshooting It. Drilling Formulas.Com.

El-Diasty, A. I., \& Ragab, A. M. S. (2013, April 15). Applications of Nanotechnology in the Oil \& Gas Industry: Latest Trends Worldwide \& Future Challenges in Egypt. Society of Petroleum Engineers. doi:10.2118/164716-MS.

Hughes, B. (2006). Drilling Fluids Reference Manual. Houston, Texas.

Hoelscher, K. P., De Stefano, G., Riley, M., \& Young, S. (2012, January 1). Application of Nanotechnology in Drilling Fluids. Society of Petroleum Engineers. doi:10.2118/157031-MS

Javeri, S. M., Haindade, Z. M. W., \& Jere, C. B. (2011, January 1). Mitigating Loss Circulation And Differential Sticking Problems Using Silicon Nanoparticles. Society of Petroleum Engineers. doi:10.2118/145840-MS.

Jung, Y., Barry, M., Lee, J. K., Tran, P., Soong, Y., Martello, D., \& Chyu, M. (2011, April). Effect of Nanoparticle-Additives on the Rheological Properties of Clay-Based Fluids at High Temperature and High Pressure. In AADE National Technical Conference and Exhibition, Houston, Texas (pp. 12-14).

Jung, C. M., Zhang, R., Chenevert, M., \& Sharma, M. (2013, August 12). High-Performance WaterBased Mud Using Nanoparticles for Shale Reservoirs. Society of Petroleum Engineers. doi:10.1190/URTEC2013-106.

Justin Pearson. 2015. 1 Fundamentals of Drilling Fishing - Stuck Pipe Problems Presentation No. 4 Fundamentals of Onshore Drilling References: Bernt S. Aadnoy, Iain Cooper. Slideplayer.Com.

Ismail, A. R., Rashid, N. M., Jaafar, M. Z., Sulaiman, W. R. W., \& Buang, N. A. (2014). Effect of Nanomaterial on the Rheology of Drilling Fluids. Journal of Applied Sciences, 14(11), 1192. 
Li, L., Xu, X., Sun, J., Yuan, X., \& Li, Y. (2012, January 1). Vital Role of Nanomaterials in Drilling Fluid and Reservoir Protection Applications. Society of Petroleum Engineers. doi:10.2118/160940-MS.

Napierska, D., Thomassen, L. C., Lison, D., Martens, J. A., \& Hoet, P. H. (2010). The nanosilica hazard: another variable entity. Particle and fibre toxicology, 7(1), 1.

Nasser, J., Jesil, A., Mohiuddin, T., Al Ruqeshi, M., Devi, G., \& Mohataram, S. (2013). Experimental Investigation of Drilling Fluid Performance as Nanoparticles. World Journal of Nano Science and Engineering, 2013.

Rabia, H. (2002). Well engineering \& construction. Entrac Consulting Limited.

Riley, M., Stamatakis, E., Young, S., Price-Hoelscher, K., \& De Stefano, G. (2012). Drilling Unconventional Shales with Innovative Water-Based Mud-Part II: Mud Formulations and Performance. AADE-12-FTCE-52, AADE Fluids Technical Conference, Houston 10-11 April.

Swaco, M. I. (2001). Drilling Fluids Engineering Manual. USA, MI LLC, 205-207.

Sharma, M. M., Chenevert, M. E., Guo, Q., Ji, L., Friedheim, J., \& Zhang, R. (2012, January 1). A New Family of Nanoparticle Based Drilling Fluids. Society of Petroleum Engineers. doi:10.2118/160045-MS.

Sensoy, T., Chenevert, M. E., \& Sharma, M. M. (2009, January 1). Minimizing Water Invasion in Shales Using Nanoparticles. Society of Petroleum Engineers. doi:10.2118/124429-MS.

Srivatsa, J. T., \& Ziaja, M. B. (2011, January 1). An Experimental Investigation on Use of Nanoparticles as Fluid Loss Additives in a Surfactant - Polymer Based Drilling Fluids. International Petroleum Technology Conference. doi:10.2523/IPTC-14952-MS.

Salih, A. H., Elshehabi, T. A., \& Bilgesu, H. I. (2016, September 13). Impact of Nanomaterials on the Rheological and Filtration Properties of Water-Based Drilling Fluids. Society of Petroleum Engineers. doi:10.2118/184067-MS

www.smithbits.com

Zakaria, M., Husein, M. M., \& Harland, G. (2012, January 1). Novel Nanoparticle-Based Drilling Fluid with Improved Characteristics. Society of Petroleum Engineers. doi:10.2118/156992-MS. 


\section{Appendix A: Mud Viscometer Dial Readings}

The measurements conducted with viscometer are given in Tables A-1 through A-6 for waterbased low and high $\mathrm{pH}$ mud systems using three different nanoparticles at selected concentrations of $0.0,0.1,0.3,0.5$, and 0.7 weight percent.

\begin{tabular}{|c|c|c|c|c|c|}
\hline $\begin{array}{c}\text { Rotation } \\
\text { Speed (rpm) }\end{array}$ & $\begin{array}{c}\text { Dial Readings } \\
\text { at 0\% wt. }\end{array}$ & $\begin{array}{c}\text { Dial Readings } \\
\text { at } 0.1 \% \text { wt. }\end{array}$ & $\begin{array}{c}\text { Dial Readings } \\
\text { at } 0.3 \% \text { wt. }\end{array}$ & $\begin{array}{c}\text { Dial Readings } \\
\text { at 0.5\% wt. }\end{array}$ & $\begin{array}{c}\text { Dial Readings } \\
\text { at 0.7\% wt. }\end{array}$ \\
\hline 600 & 62 & 38.7 & 33 & 30 & 33 \\
\hline 300 & 44.5 & 26 & 22 & 20 & 21 \\
\hline 200 & 38.7 & 20.5 & 17 & 15 & 16 \\
\hline 100 & 30.7 & 13.7 & 11.4 & 10 & 10.5 \\
\hline 3 & 19.7 & 4 & 3 & 2.5 & 2.8 \\
\hline
\end{tabular}

Table A-1: Viscometer readings for WBM with nanosilica-low pH

\begin{tabular}{|c|c|c|c|c|c|}
\hline $\begin{array}{c}\text { Rotation } \\
\text { Speed (rpm) }\end{array}$ & $\begin{array}{c}\text { Dial Readings } \\
\text { at 0\% wt. }\end{array}$ & $\begin{array}{c}\text { Dial Readings } \\
\text { at } 0.1 \% \text { wt. }\end{array}$ & $\begin{array}{c}\text { Dial Readings } \\
\text { at } 0.3 \% \text { wt. }\end{array}$ & $\begin{array}{c}\text { Dial Readings } \\
\text { at } 0.5 \% \text { wt. }\end{array}$ & $\begin{array}{c}\text { Dial Readings } \\
\text { at 0.7\% wt. }\end{array}$ \\
\hline 600 & 120 & 48.7 & 38.5 & 34.5 & 37 \\
\hline 300 & 98 & 31 & 24.6 & 21.6 & 23 \\
\hline 200 & 86 & 23.9 & 19 & 16.4 & 17.4 \\
\hline 100 & 70 & 15.7 & 12.4 & 10.3 & 10.9 \\
\hline 3 & 38 & 5 & 3 & 2.3 & 2.4 \\
\hline
\end{tabular}

Table A-2: Viscometer readings for WBM with nanosilica-high pH

\begin{tabular}{|c|c|c|c|c|c|}
\hline $\begin{array}{c}\text { Rotation } \\
\text { Speed (rpm) }\end{array}$ & $\begin{array}{c}\text { Dial Readings } \\
\text { at 0\% wt. }\end{array}$ & $\begin{array}{c}\text { Dial Readings } \\
\text { at } 0.1 \% \text { wt. }\end{array}$ & $\begin{array}{c}\text { Dial Readings } \\
\text { at } 0.3 \% \text { wt. }\end{array}$ & $\begin{array}{c}\text { Dial Readings } \\
\text { at 0.5\% wt. }\end{array}$ & $\begin{array}{c}\text { Dial Readings } \\
\text { at 0.7\% wt. }\end{array}$ \\
\hline 600 & 62 & 44.5 & 39 & 35 & 30.5 \\
\hline 300 & 44.5 & 32.1 & 27 & 24.2 & 21 \\
\hline 200 & 38.7 & 26.1 & 21.7 & 19 & 16.3 \\
\hline 100 & 30.7 & 18.9 & 14.7 & 12.8 & 10.9 \\
\hline 3 & 19.7 & 9.2 & 5.4 & 4.5 & 4.3 \\
\hline
\end{tabular}

Table A-3: Viscometer readings for WBM with nanotitanium-low pH 


\begin{tabular}{|c|c|c|c|c|c|}
\hline $\begin{array}{c}\text { Rotation } \\
\text { Speed (rpm) }\end{array}$ & $\begin{array}{c}\text { Dial Readings } \\
\text { at } 0 \% \mathrm{wt} .\end{array}$ & $\begin{array}{c}\text { Dial Readings } \\
\text { at } 0.1 \% \mathrm{wt} .\end{array}$ & $\begin{array}{c}\text { Dial Readings } \\
\text { at } 0.3 \% \mathrm{wt} .\end{array}$ & $\begin{array}{c}\text { Dial Readings } \\
\text { at } 0.5 \% \mathrm{wt} .\end{array}$ & $\begin{array}{c}\text { Dial Readings } \\
\text { at } 0.7 \% \mathrm{wt} .\end{array}$ \\
\hline 600 & 120 & 100 & 61 & 55 & 47 \\
\hline 300 & 98 & 80 & 43.5 & 39 & 32 \\
\hline 200 & 86 & 71.1 & 36.3 & 31 & 25.8 \\
\hline 100 & 70 & 58.8 & 27.8 & 22 & 18.7 \\
\hline 3 & 38 & 34.9 & 13.1 & 11 & 9.4 \\
\hline
\end{tabular}

Table A-4: Viscometer readings for WBM with nanotitanium-high pH

\begin{tabular}{|c|c|c|c|c|c|}
\hline $\begin{array}{c}\text { Rotation } \\
\text { Speed (rpm) }\end{array}$ & $\begin{array}{c}\text { Dial Readings } \\
\text { at 0\% wt. }\end{array}$ & $\begin{array}{c}\text { Dial Readings } \\
\text { at } 0.1 \% \text { wt. }\end{array}$ & $\begin{array}{c}\text { Dial Readings } \\
\text { at } 0.3 \% \text { wt. }\end{array}$ & $\begin{array}{c}\text { Dial Readings } \\
\text { at } 0.5 \% \text { wt. }\end{array}$ & $\begin{array}{c}\text { Dial Readings } \\
\text { at 0.7\% wt. }\end{array}$ \\
\hline 600 & 62 & 34 & 26 & 23 & 22 \\
\hline 300 & 44.5 & 24 & 17 & 14.5 & 13.5 \\
\hline 200 & 38.7 & 19.6 & 12.9 & 10.9 & 9.7 \\
\hline 100 & 30.7 & 13.7 & 8.3 & 6.8 & 6 \\
\hline 3 & 19.7 & 4.5 & 2.1 & 1.6 & 1.5 \\
\hline
\end{tabular}

Table A-5: Viscometer readings for WBM with nanoaluminum-low pH

\begin{tabular}{|c|c|c|c|c|c|}
\hline $\begin{array}{c}\text { Rotation } \\
\text { Speed (rpm) }\end{array}$ & $\begin{array}{c}\text { Dial Readings } \\
\text { at 0\% wt. }\end{array}$ & $\begin{array}{c}\text { Dial Readings } \\
\text { at } 0.1 \% \text { wt. }\end{array}$ & $\begin{array}{c}\text { Dial Readings } \\
\text { at } 0.3 \% \text { wt. }\end{array}$ & $\begin{array}{c}\text { Dial Readings } \\
\text { at } 0.5 \% \text { wt. }\end{array}$ & $\begin{array}{c}\text { Dial Readings } \\
\text { at 0.7\% wt. }\end{array}$ \\
\hline 600 & 120 & 100 & 29.2 & 22.7 & 20.6 \\
\hline 300 & 98 & 82.3 & 20.3 & 13.8 & 12.3 \\
\hline 200 & 86 & 75 & 16.1 & 10.2 & 8.7 \\
\hline 100 & 70 & 60 & 10.9 & 6.5 & 5.3 \\
\hline 3 & 38 & 30 & 2.7 & 1.6 & 1.3 \\
\hline
\end{tabular}

Table A-6: Viscometer readings for WBM with nanoaluminum-low pH 